$9-1-2019$

\title{
Guidelines for costing of social and behavior change health interventions
}

James Rosen

Willyanne DeCormier Plosky

Lori Bollinger

Follow this and additional works at: https://knowledgecommons.popcouncil.org/departments_sbsr-pgy

Part of the Health Communication Commons, and the Public Health Commons How does access to this work benefit you? Let us know!

\section{Recommended Citation}

Rosen, James, Willyanne DeCormier Plosky, and Lori Bollinger. 2019. "Guidelines for costing of social and behavior change health interventions." Breakthrough RESEARCH. Washington, DC: Population Council. 


\section{Guidelines for Costing of Social and Behavior Change Health Interventions}

SEPTEMBER 2019

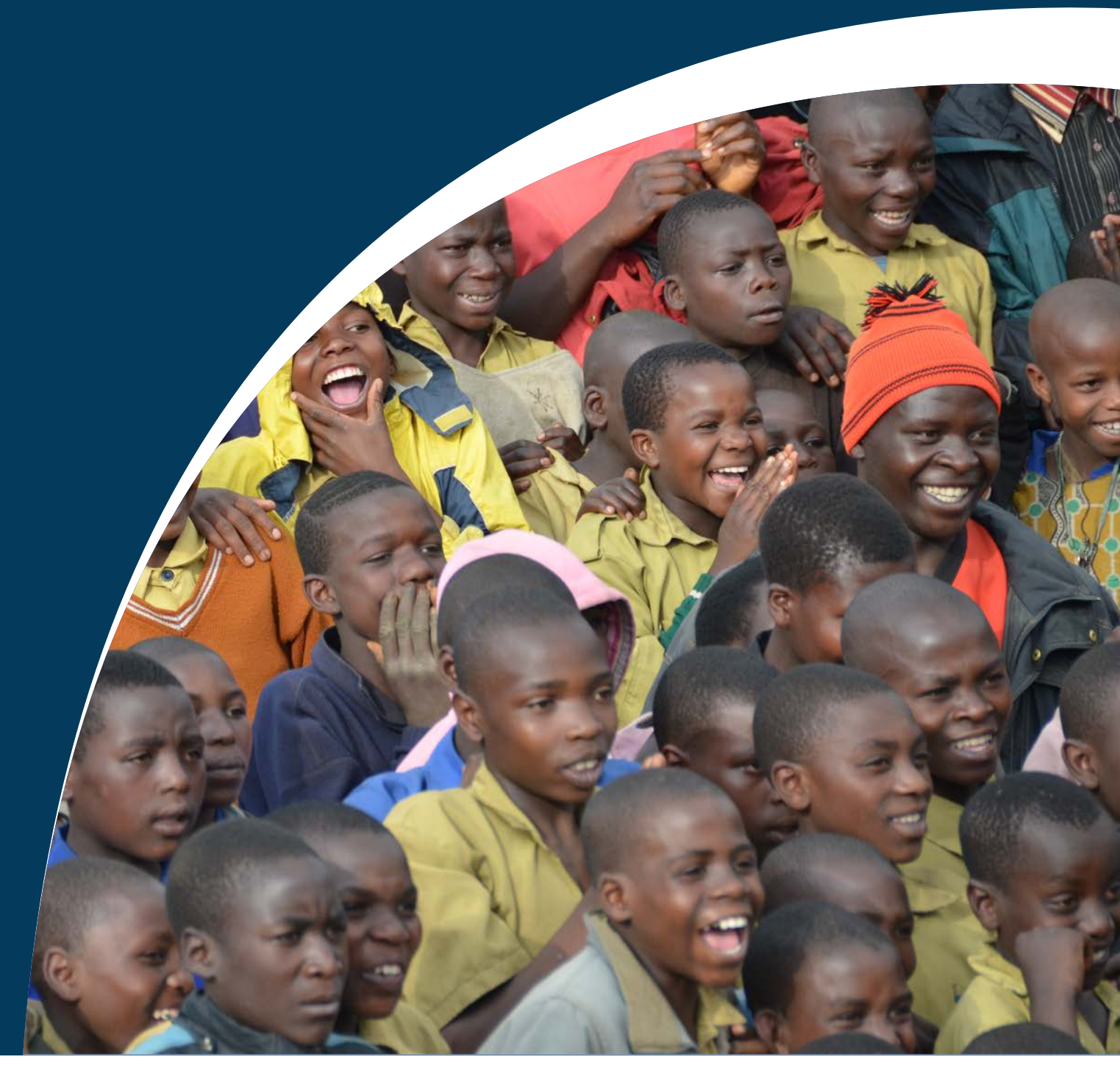

(E) USAID

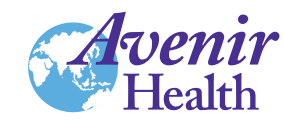




\section{Acknowledgments}

The authors are grateful to the many people who contributed to these guidelines. We thank our Breakthrough RESEARCH and Breakthrough ACTION colleagues who provided insights and encouragement along the way. Thanks also to our Breakthrough RESEARCH USAID management team for their suggestions and guidance. We also thank the reviewers who saw this document in its various incarnations and gave constructive advice on how to make it better.

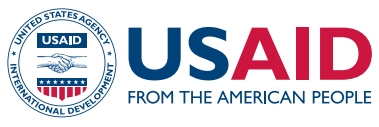

Breakthrough RESEARCH is made possible by the generous support of the American people through the United States Agency for International Development (USAID) under the terms of cooperative agreement no. AID-OAA-A-17-00018. The contents of this document are the sole responsibility of the Breakthrough RESEARCH and Population Council and do not necessarily reflect the views of USAID or the United States Government.

\section{Avenir}

Avenir Health was founded in 2006 as a global health organization that works to enhance social and economic development by providing tools and technical assistance in policy, planning, resource allocation and evaluation. Its focus is on developing and implementing demographic, epidemiological and costing models for long-range planning to assist with setting goals, strategies, and objectives. Avenir Health assists in both developing and implementing programs in HIV/AIDS, reproductive health, maternal health and other programming areas. Avenir Health works with government agencies, foundations, corporations, and nongovernmental organizations around the world.

\section{POPULATION \\ COUNCIL \\ Ideas. Evidence. Impact.}

The Population Council confronts critical health and development issuesfrom stopping the spread of HIV to improving reproductive health and ensuring that young people lead full and productive lives. Through biomedical, social science and public health research in about 50 countries, the Council works with our partners to deliver solutions that lead to more effective policies, programs, and technologies to improve lives worldwide. Established in 1952 and headquartered in New York, the Council is a nongovernmental, nonprofit organization with an international board of trustees.

\section{Breakthrough RESEARCH FOR SOCIAL \& BEHAVIOR CHANGE}

Breakthrough RESEARCH catalyzes social and behavior change (SBC) by conducting state-of-the-art research and evaluation and promoting evidence-based solutions to improve health and development programs around the world. Breakthrough RESEARCH is a consortium led by the Population Council in partnership with Avenir Health, ideas42, Institute for Reproductive Health at Georgetown University, Population Reference Bureau, and Tulane University.
(C)2019 The Population Council. All rights reserved.

Cover photo by (C2012 Kim Burns Case/JHUCCP, Courtesy of Photoshare

\section{Suggested Citation}

Rosen, James E., Willyanne DeCormier Plosky, and Lori Bollinger. 2019. Guidelines for Costing of Social and Behavior Change Health Interventions. Breakthrough RESEARCH. Washington DC: Population Council.

\section{Contact}

4301 Connecticut Avenue NW, Suite 280 | Washington, DC 20008 +12022379400 | BreakthroughResearch@popcouncil.org breakthroughactionandresearch.org 
Guidelines for Costing of Social and Behavior Change Health Interventions

James E. Rosen Willyanne DeCormier Plosky Lori Bollinger Avenir Health 


\section{Contents}

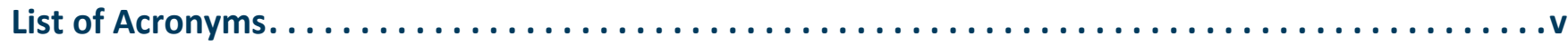

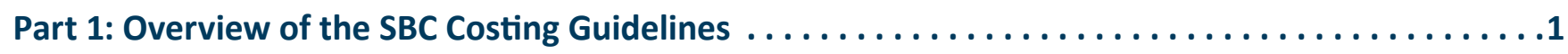

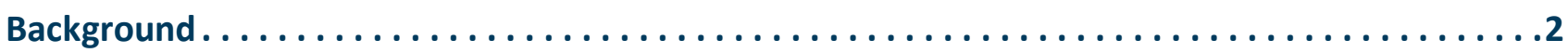

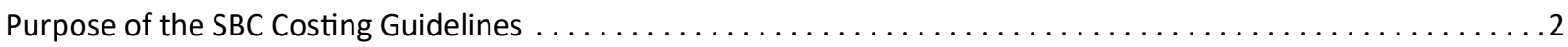

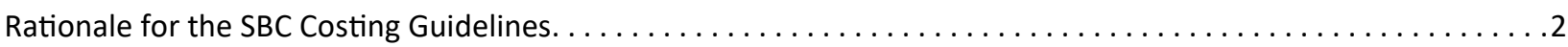

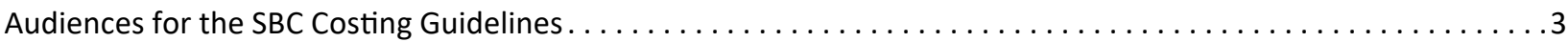

How do the SBC Costing Guidelines align with other costing guidance? $\ldots \ldots \ldots \ldots \ldots \ldots \ldots \ldots \ldots \ldots \ldots$

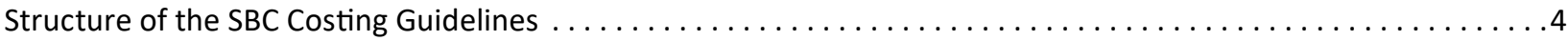

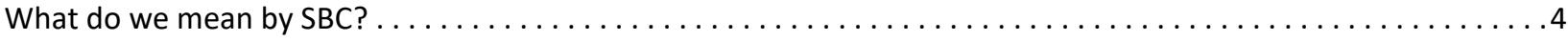

What are some unique challenges associated with costing $\mathrm{SBC}$ interventions? $\ldots \ldots \ldots \ldots \ldots \ldots \ldots \ldots \ldots$

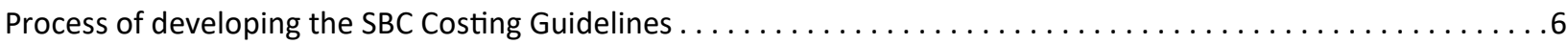

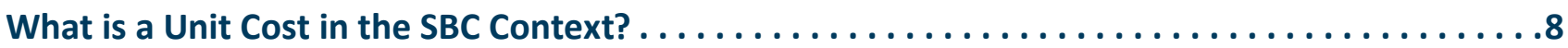

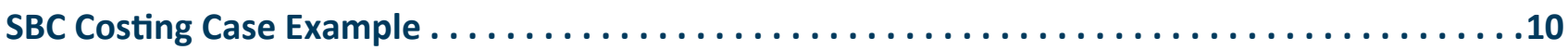

Part 2: Methodological Principles of SBC Costing .......................

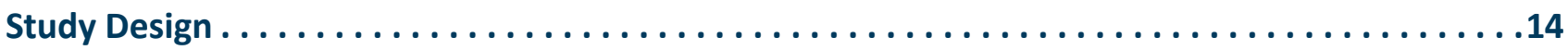

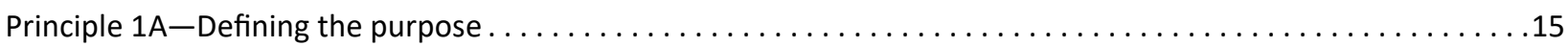

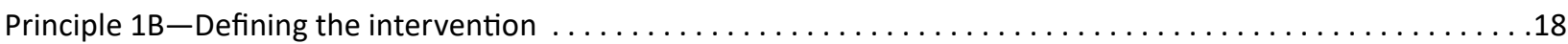

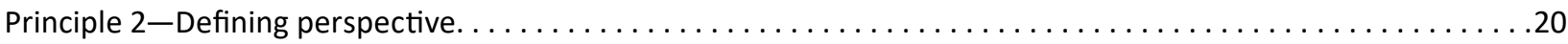

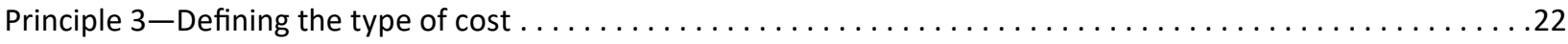

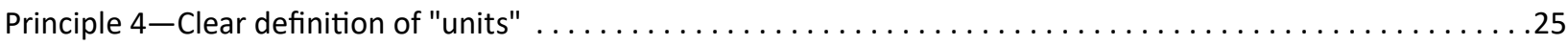

Principle 5-Determining the appropriate timeframe of cost data collection and disaggregated periods

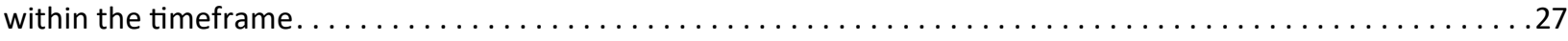

Resource Use Measurement . . . . . . . . . . . . . . . . . . . . . . . . . . . 29

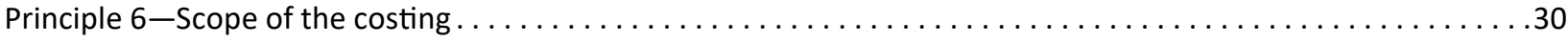

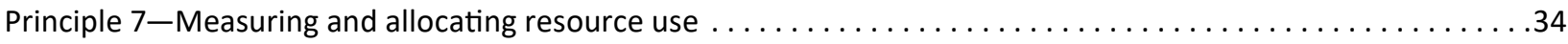

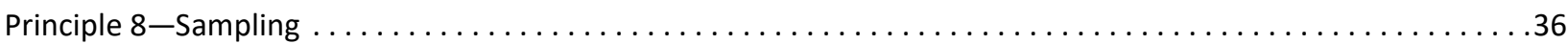

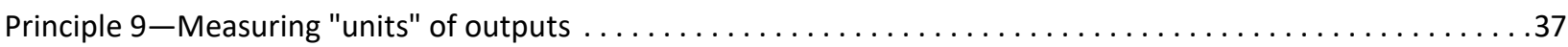

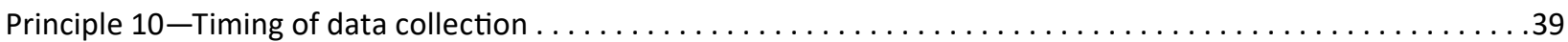

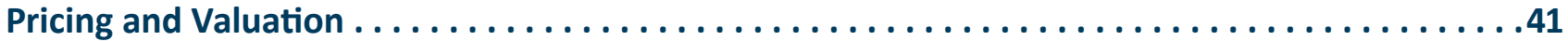

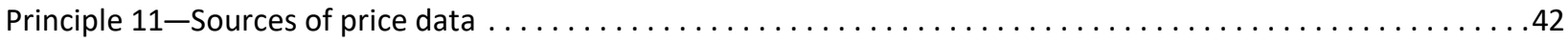

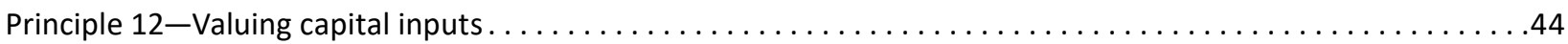

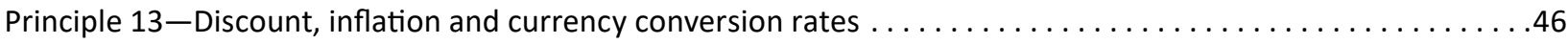

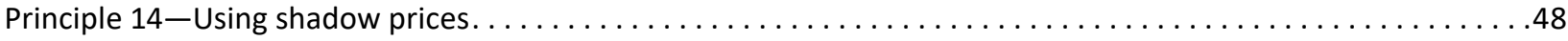

Analyzing and Presenting Results . . . . . . . . . . . . . . . . . . . . . . .

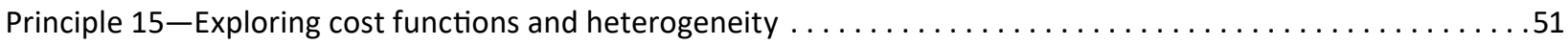




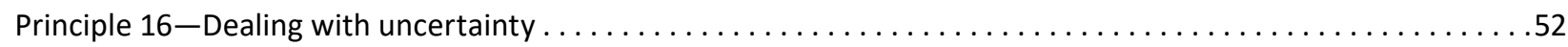

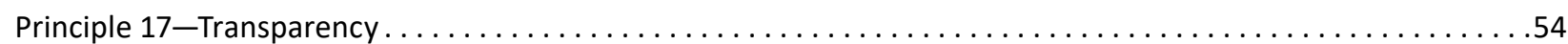

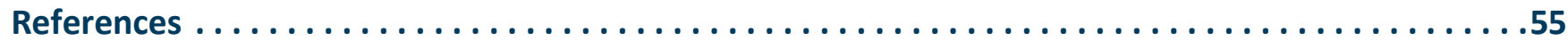

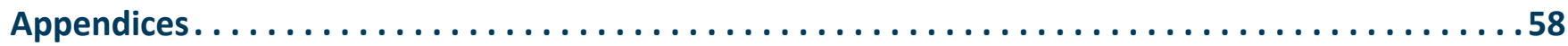

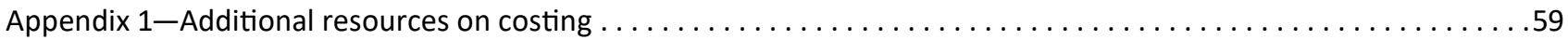

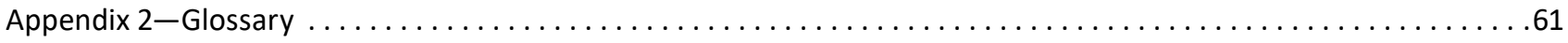

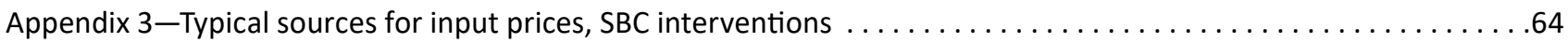

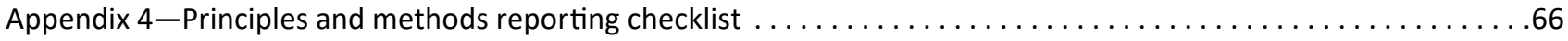

Tables

Table 1 Similarities and differences between the SBC Costing Guidelines, the GHCC Reference Case, and the

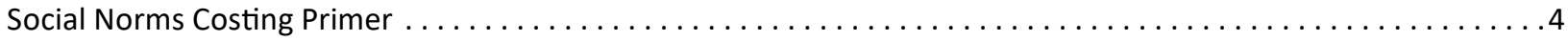

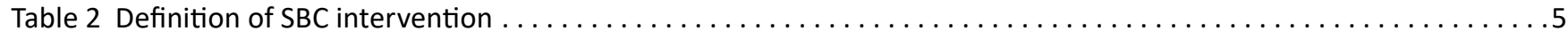

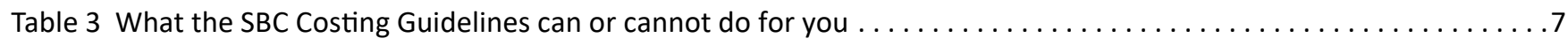

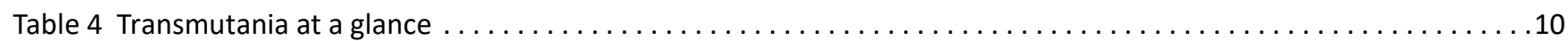

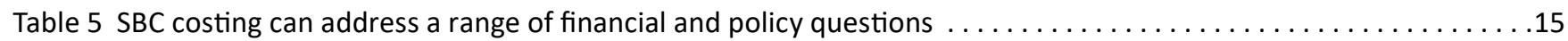

Table 6 Illustration of how costs included vary according to a costing study of a community mobilization

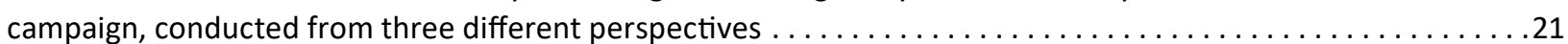

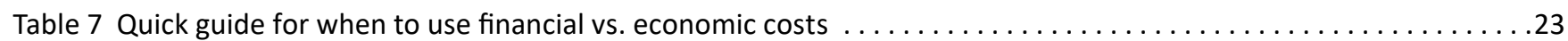

Table 8 Proposed standardized intervention unit associated with specific SBC intervention categories . . . . . . . . . .25

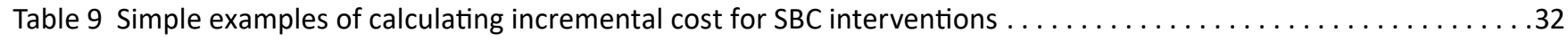

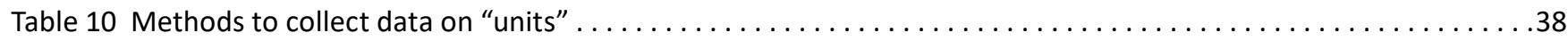

Table 11 Typical classification of SBC intervention inputs as tradable or non-tradable. . . . . . . . . . . . 43

Table 12 Adjusting prices using different methods for tradeable and non-tradeable inputs . . . . . . . . ...46

Table 13 Cost results reported in local currency, US, and international dollars . . . . . . . . . . . . . . .

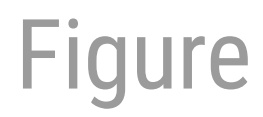

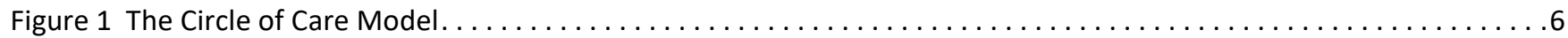

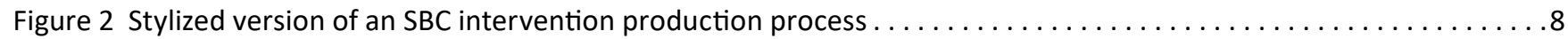

Figure 3 How the definition of "unit cost" varies according to where you focus in the production process ............9

Figure 4 Site-level and above-site level activities of the illustrative community mobilization intervention in

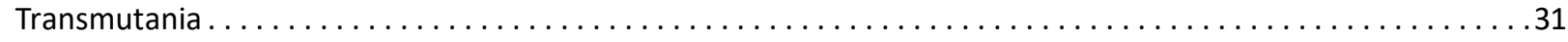

Figure 5 Site-level and above-site level activities of the illustrative digital media intervention in Transmutania .........31 


\section{List of Acronyms}

\begin{tabular}{|c|c|}
\hline$B-A$ & Breakthrough ACTION \\
\hline$B-R$ & Breakthrough RESEARCH \\
\hline CIP & Costed implementation plan \\
\hline $\mathrm{CPI}$ & Consumer price index \\
\hline GDP & Gross domestic product \\
\hline GHCC & Global Health Cost Consortium \\
\hline PPP & Purchasing power parity \\
\hline HPV & Human papilloma virus \\
\hline IPC & Interpersonal communication \\
\hline IUD & Intrauterine device \\
\hline $\mathrm{MNCH}$ & Maternal, newborn, and child health \\
\hline NGO & Nongovernmental organization \\
\hline PMNCH & Partnership for maternal, newborn, and child health \\
\hline PrEP & Pre-exposure prophylaxis \\
\hline SBC & Social and behavior change \\
\hline USAID & United States Agency for International Development \\
\hline WASH & Water, sanitation, and hygiene \\
\hline WHO & World Health Organization \\
\hline
\end{tabular}




\section{Part 1}

\section{Overview of the SBC Costing Guidelines}

These Guidelines for Costing of Social and Behavior Change Health Interventions (SBC Costing Guidelines) provide a framework for estimating the cost of interventions for social and behavior change (SBC), which seek to change health behaviors by addressing factors such as knowledge, attitudes, and norms.
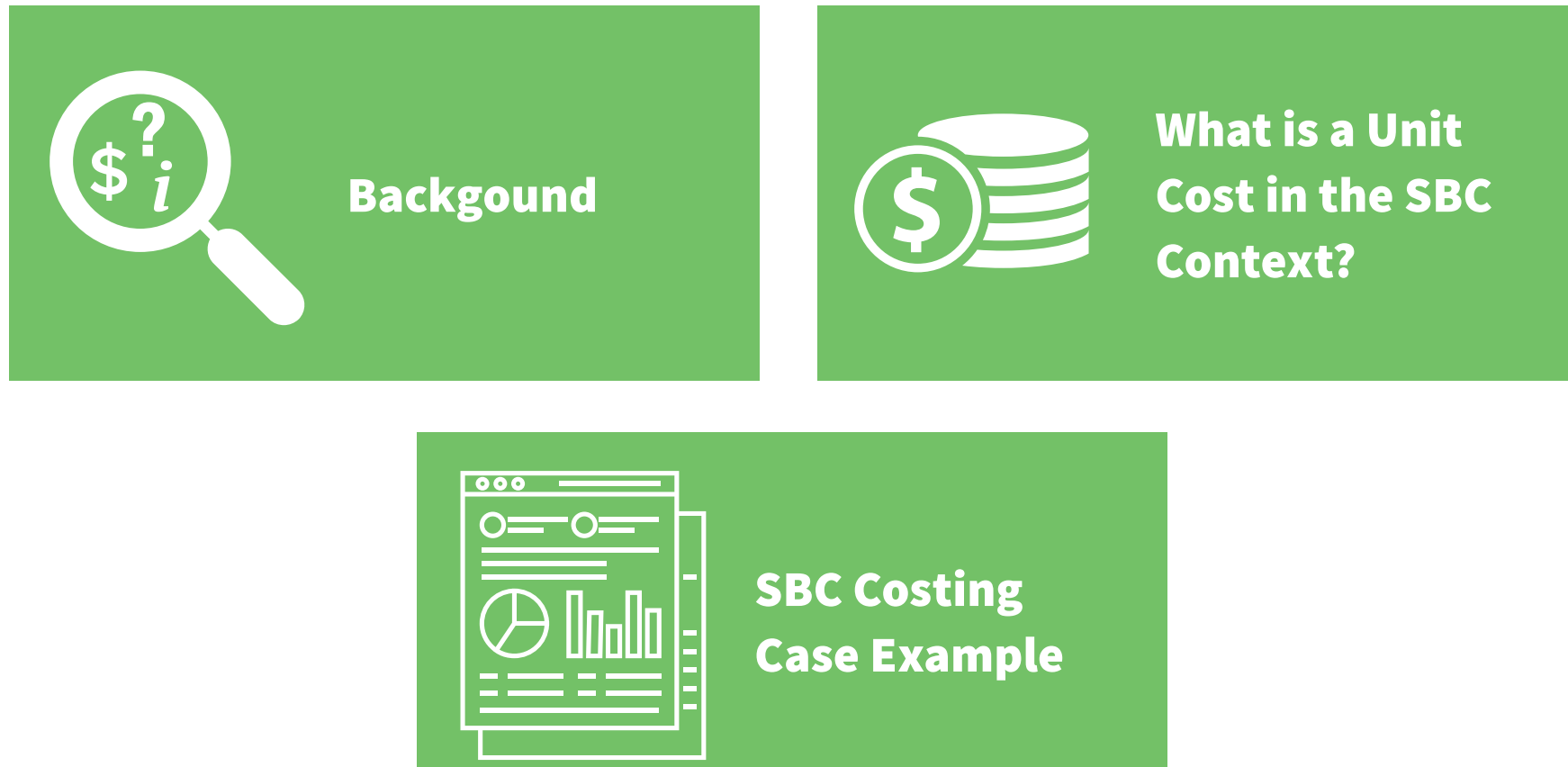

SBC Costing

Case Example 


\section{Background}

\section{Purpose of the SBC Costing Guidelines}

Costing is the process of data collection and analysis for estimating the cost of a health intervention. High-quality cost data on SBC are critical not only for developing budgets, planning, and assessing program proposals, but can also feed into advocacy, program prioritization, and agenda setting. To better serve these data needs, these guidelines aim to increase the quantity and quality of SBC costing information. By encouraging cost analysts to use a standardized approach based on widely accepted methodological principles, we expect the SBC Costing Guidelines to result in well-designed studies that measure cost at the outset, to allow assessment of cost-effectiveness and benefit-cost ratios ${ }^{1}$ for SBC programming. Such analyses could also potentially help advocates for SBC to better make the case for greater investment in SBC programming. ${ }^{2}$ These guidelines lay out a consistent set of methodological principles that reflect best practice and that can underpin any SBC costing effort.

\section{Rationale for the SBC Costing Guidelines}

Why are SBC-specific guidelines needed? Although many guidelines for costing of health programs exist, none focuses on the broad range and unique character of SBC interventions. Moreover, recent literature reviews (Breakthrough RESEARCH 2018b) and expert consultations (Breakthrough RESEARCH 2018c) have exposed the wide gaps in measuring SBC cost. There is not sufficient quality and rigor in many of the cost studies to confidently make the case for SBC. More and higher-quality SBC costing studies would help to address this gap and support USAID's overall efforts to collect and analyze cost data (USAID 2016). The recent Global Health Cost Consortium (GHCC) "Reference Case for Estimating the Costs of Global Health Services and Interventions" (referred to hereafter as the GHCC Reference Case) also provides a framework for developing a rigorous set of SBC costing guidelines (Vassall et al. 2017). The GHCC Reference Case is an internationally agreed-on standard, and is a product of the GHCC, ${ }^{3}$ whose stakeholders represent a range of organizations, including the United States Agency for International Development (USAID).

${ }^{3}$ For more on the Global Health Cost Consortium, go to https://ghcosting. org/

\footnotetext{
${ }^{1}$ Formerly referred to as cost-benefit ratios

${ }^{2}$ For more discussion on this point, see Breakthrough RESEARCH (2018) A Framework for Business Case for Social and Behavior Change.
} 


\section{Audiences for the SBC Costing Guidelines}

Many actors could play a part in achieving more and better SBC costing information, including program managers who use cost data to plan and budget, donors assessing funding requests and allocating resources, and cost data producers who rely on guidelines to generate robust cost estimates and report their findings in a standardized manner. The SBC Costing Guidelines have as their primary audience the latter group-cost data producers and analysts. They aim to be useful for the diverse set of SBC interventions, which includes mass and digital media, interpersonal communication, and provider-focused approaches, across the range of health areas important to developing countries.

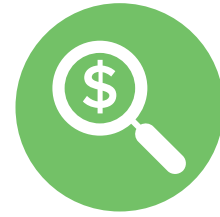

If you are a cost analyst, you may already be familiar with the general principles of costing but searching for SBC-specific guidance. Depending on your level of expertise, you might sample from one or more of the sections of the guide. If you are approaching costing not knowing much about SBC, you may want to look at definitions of SBC in "What do we mean by SBC?" (pg 5) and how the unit cost concept applies in the SBC world ("What is a unit cost in the SBC context?", pg 9).

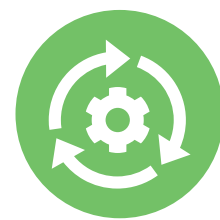

If you are implementing an SBC intervention, you may be commissioning your own cost study, be undergoing an external costing analysis, or want to add costing to your organizational skill set. You should find valuable information in all of the sections of the SBC Costing Guidelines to facilitate conversations with cost analysts and make informed decisions about costing. The glossary and list of additional costing documents may also be helpful as you look to elucidate specific costing concepts or approaches.

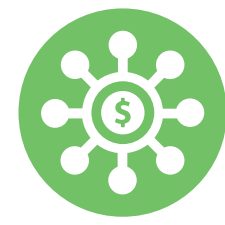

If you are a donor supporting, or considering supporting, costing studies, you are probably interested in setting the scope of work for SBC costing, want to understand what constitutes a high quality costing, and want to get a sense of methods and required resources. All of the sections are relevant and valuable to inform your decision making about the appropriate costing approach.

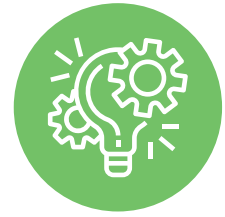

If you are an SBC program manager or funder using cost estimates generated from other settings, you likely want to know the extent to which the estimates are high quality and whether they are applicable in your setting. One important section for you is the principles and methods reporting checklist in Appendix 4. In particular, pay attention to the SBC intervention description (including platform, setting).

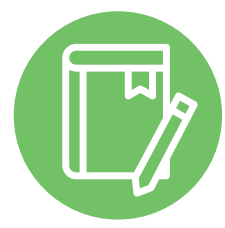

If you are a journal editor reviewing an SBC costing study, your main concern is the technical quality of the study and its programmatic relevance. You will want to review the principles and methods reporting checklist in Appendix 4 to help determine the extent to which the study adheres to good principles. The introductory sections that are specific to SBC and its definitions may also be useful to help familiarize yourself with SBC-specific concepts. 


\section{How do the SBC Costing Guidelines align with other costing guidance?}

These guidelines follow closely the intent and structure of the GHCC Reference Case. The SBC Costing Guidelines also align with the "Costing of social norm interventions: a primer from the Passages Project," also know as the Social Norms Costing Primer (Homan 2016) a product of the USAID-funded Passages Project. Although aimed primarily at an audience of program implementers, the Social Norms Costing Primer encompasses some SBC interventions (the " $\mathrm{S}$ " in SBC). Table 1 shows similarities and differences between the guidelines mentioned.

The analyst can also draw on many other costing guidelines. Appendix 1 has a list of other key documents and guidance that analysts can refer to as a supplement to the SBC Costing Guidelines.

\section{Structure of the SBC Costing Guidelines}

Like the GHCC Reference Case, the SBC Costing Guidelines are organized around 17 methodological principles, grouped into sections on study design, measuring use of resources, pricing and valuation, and presentation of results. Each principle begins with a link to the GHCC Reference Case and contains best practice recommendations, illustrating concepts with SBC-specific examples and referencing in text boxes how real-life costing exercises have applied these principles. Background sections and appendices provide readers with additional information. Although technical in nature, the SBC Costing Guidelines aim to be accessible to a non-economist audience.

\section{What do we mean by SBC?}

Before getting too far, it is useful to describe what SBC means for the purpose of these guidelines, particularly since the meaning and nomenclature around SBC has evolved over the years. USAID's High Impact Practices Initiative defines SBC as activities or interventions that seek to understand and facilitate change in behaviors and the social norms and environmental determinants that drive those behaviors (HIPs 2018). SBC interventions are grounded in behavioral theory and are informed by research and programmatic experience. SBC programs often consider social norms and dynamics in their design and implementation. SBC includes both communication

\section{TABLE 1 SIMILARITIES AND DIFFERENCES BETWEEN THE SBC COSTING GUIDELINES, THE GHCC REFERENCE CASE, AND THE SOCIAL NORMS COSTING PRIMER}

\begin{tabular}{|c|c|c|c|}
\hline PARAMETER & SBC COSTING GUIDELINES & GHCC REFERENCE CASE & $\begin{array}{l}\text { SOCIAL NORMS } \\
\text { COSTING PRIMER }\end{array}$ \\
\hline Health area focus & Generic & Generic & Generic \\
\hline Intervention type focus & SBC interventions & Generic health & $\begin{array}{l}\text { Social norms interventions, a } \\
\text { subset of SBC interventions }\end{array}$ \\
\hline Purpose & $\begin{array}{l}\text { Improve the quality of } \\
\text { SBC cost estimates }\end{array}$ & $\begin{array}{l}\text { Improve the quality of } \\
\text { health cost estimates }\end{array}$ & $\begin{array}{l}\text { Improve the quality of cost esti- } \\
\text { mates for interventions to change } \\
\text { social norms for better health }\end{array}$ \\
\hline Primary audience & Cost analysts & Cost analysts & Program implementers \\
\hline Format & Web document & PDF and Web document & Web document \\
\hline Content & Built around 17 principles & Built around 17 principles & Measuring and reporting costs \\
\hline Technical level & $\begin{array}{l}\text { Medium, economists and } \\
\text { non-economists }\end{array}$ & $\begin{array}{l}\text { Medium, economists and } \\
\text { non-economists }\end{array}$ & $\begin{array}{l}\text { Low, easy to understand for } \\
\text { non-economists }\end{array}$ \\
\hline $\begin{array}{l}\text { Extent to which living } \\
\text { document }\end{array}$ & $\begin{array}{l}\text { Projected to be a living } \\
\text { document, with additional } \\
\text { material added over time }\end{array}$ & $\begin{array}{l}\text { A living document, with } \\
\text { additional material added } \\
\text { over time }\end{array}$ & $\begin{array}{l}\text { A living document, with additional } \\
\text { material added over time }\end{array}$ \\
\hline Exists on the web & Yes & Yes & Yes \\
\hline
\end{tabular}


and non-communication approaches to address behavior change. The interventions draw on a variety of disciplines including marketing, advocacy, behavioral economics, human-centered design, and social psychology. They also encompass communication between health workers and their clients, and engagement with community leaders and other influencers. ${ }^{4}$

Table 2 shows how Breakthrough RESEARCH (B-R) operationalizes the interventions that make up SBC, using an

${ }^{4}$ For more, see USAID (2018) Social and behavior change. https:// www.usaid.gov/what-we-do/global-health/cross-cutting-areas/ social-and-behavior-change adapted version of the 3ie framework currently used by the Partnership for Maternal, Newborn, and Child Health (PMNCH) in its scoping work for its social, behavioral, and community engagement interventions business case (Portela et al. 2017). This framework encompasses four broad intervention categories plus a fifth that includes combination "packages" of one or more of the four broad categories. Within each of these five categories is a narrower set of intervention sub-categories.

These SBC interventions are coordinated with the system of health service delivery that is the path to behavior change and, ultimately, improved health outcomes. The Health Communication Capacity Collaborative (HC3)

\section{TABLE 2 DEFINITION OF SBC INTERVENTION}

\begin{tabular}{|c|c|c|}
\hline $\begin{array}{l}\text { BROAD INTERVENTION } \\
\text { CATEGORY }\end{array}$ & SUB-CATEGORY & DEFINITION \\
\hline \multirow[t]{2}{*}{$\begin{array}{l}\text { Interpersonal } \\
\text { communication (IPC) }\end{array}$} & $\begin{array}{l}\text { Individual/household IPC and } \\
\text { counseling }^{\dagger}\end{array}$ & $\begin{array}{l}\text { Provision of education, information, and counseling to indi- } \\
\text { viduals by a health professional or trained volunteer. }\end{array}$ \\
\hline & $\begin{array}{l}\text { Group IPC, including all peer and } \\
\text { popular opinion leader interventions }\end{array}$ & $\begin{array}{l}\text { Provision of education, information, and counseling to } \\
\text { groups by a health professional or trained volunteer. }\end{array}$ \\
\hline \multirow[t]{3}{*}{$\begin{array}{l}\text { Mass, digital, and social } \\
\text { media }\end{array}$} & $\begin{array}{l}\text { Mass media and entertainment } \\
\text { education }\end{array}$ & $\begin{array}{l}\text { Use of a diverse set of technologies capable of simultane- } \\
\text { ously reaching an audience, including the internet, televi- } \\
\text { sion, print materials, film, and radio. }\end{array}$ \\
\hline & $\begin{array}{l}\text { Social marketing of products or } \\
\text { behaviors }\end{array}$ & $\begin{array}{l}\text { Using marketing concepts-product design, appropriate } \\
\text { pricing, sales and distribution, and communication-to in- } \\
\text { fluence behaviors that benefit individuals and communities. }\end{array}$ \\
\hline & Social media and m-health & $\begin{array}{l}\text { Using a variety of web-based and mobile technologies } \\
\text { and software applications that enable users to engage in } \\
\text { dialogue and share information. }\end{array}$ \\
\hline \multirow[t]{2}{*}{$\begin{array}{l}\text { Community } \\
\text { mobilization }\end{array}$} & Community mobilization & $\begin{array}{l}\text { Interventions to encourage community individuals, groups } \\
\text { (including in schools), or organizations plan, carry out, and } \\
\text { evaluate activities on a participatory and sustained basis to } \\
\text { improve their health and other needs. }\end{array}$ \\
\hline & $\begin{array}{l}\text { Community participation (in health } \\
\text { service planning/programs); social } \\
\text { accountability }\end{array}$ & $\begin{array}{l}\text { Activities to create ongoing relationships between commu- } \\
\text { nity members and health service delivery providers/actors. } \\
\text { The objective is to institutionalize community participation } \\
\text { in decision-making within health services and programs. }\end{array}$ \\
\hline $\begin{array}{l}\text { SBC service and } \\
\text { program strengthening } \\
\text { activities }\end{array}$ & $\begin{array}{l}\text { Provider behavior change interventions, } \\
\text { including training and service delivery } \\
\text { adjustments }\end{array}$ & $\begin{array}{l}\text { Training of health providers and other service providers, } \\
\text { such as teachers and pharmacists, in skills and techniques } \\
\text { related to communication, health education, and commu- } \\
\text { nity engagement and any adjustments made to service } \\
\text { provision based on community perspective of quality (i.e., } \\
\text { hours for service delivery). }\end{array}$ \\
\hline Packages & $\begin{array}{l}\text { Various combinations of the } \\
\text { interventions above }\end{array}$ & \\
\hline
\end{tabular}

${ }^{\dagger} \mathrm{B}-\mathrm{R}$ excludes from SBC interventions individual counseling that is part of the standard of care for clinical services.

Source: Rosen et al. 2018, "Roadmap for an SBC Business Case" 
(2017) illustrated the connections between SBC and health service delivery using the Circle of Care Model (Figure 1).

\section{What are some unique challenges associated with costing SBC interventions?}

Part of the reason SBC interventions merit their own costing guidelines are the myriad unique challenges associated with costing them. At the costing design stage, the analyst must have a clear understanding of what constitutes an SBC intervention and how it is linked to delivery of health services. Moreover, SBC interventions span a diverse range of interventions, often consist of "packages," and can cross health areas, meaning that their structure (the "production process") can vary substantially, along with their aims. The reality that SBC interventions are often not stand-alone, but rather part of a broader service delivery package, complicates identifying and measuring SBC-specific inputs. The SBC Costing Guidelines try to address these and other challenges to help the analyst make appropriate decisions on which methods to use.

\section{Process of developing the SBC Costing Guidelines}

Any guideline is only useful to the extent that it meets the needs of its intended audiences. With that in mind, in developing the SBC Costing Guidelines, B-R consulted

\section{FIGURE 1 THE CIRCLE OF CARE MODEL}

\section{BEFORE}

Services:

SBC motivates clients to

access services

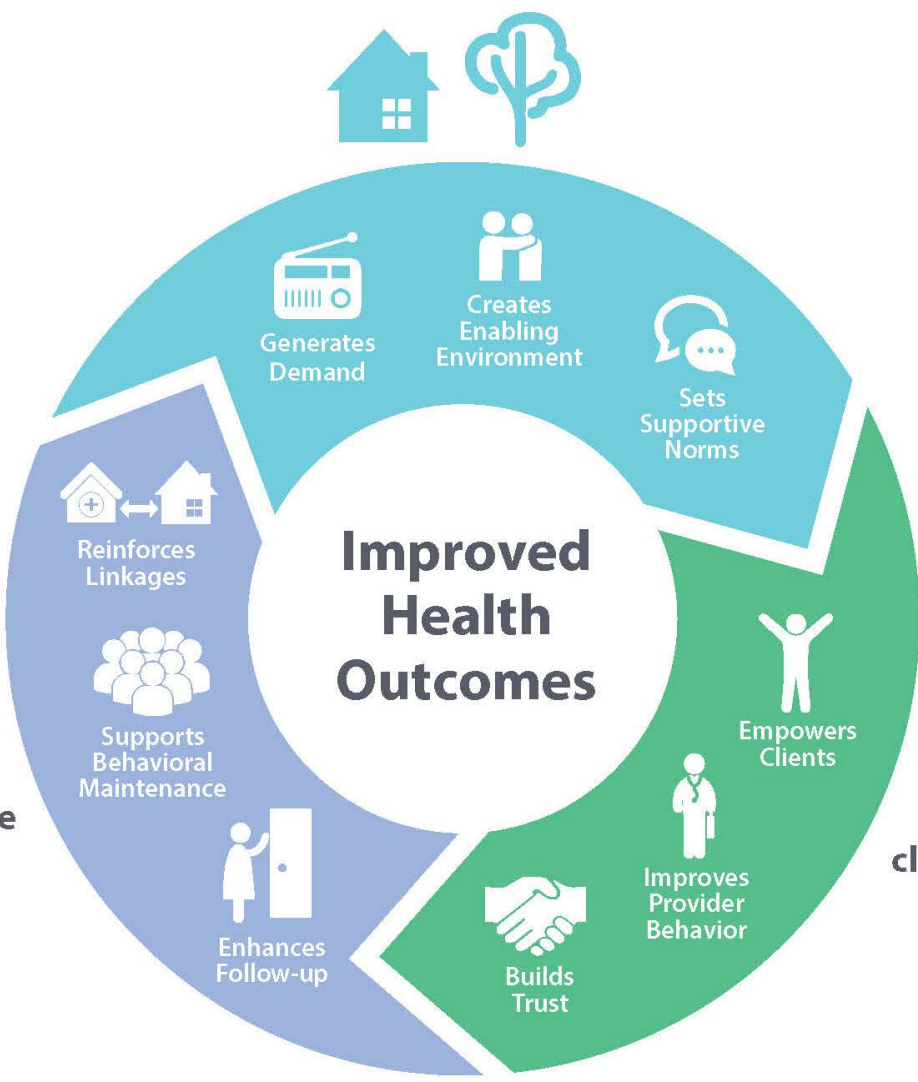

DURING

Services:

SBC improves the client-provider interaction

(4) 
with cost analysts and with Breakthrough ACTION (B-A) and other SBC implementers to understand their costing priorities, financial data systems, and on-the-ground realities that influence costing design, data collection, and reporting. We reviewed existing costing guidelines and solicited input from experts at the SBC Business Case consultation, including from B-A, the Passages Project, other SBC implementers, and SBC costing experts. We had multiple conversations with staff of the Passages Project vis-à-vis their Social Norms Costing Primer and other costing activities. We gained insight into B-A financial systems and the potential for routine collection of cost data. We drafted these guidelines and shared them with a broader group of SBC and costing experts for feedback. Depending on future funding availability, our vision is for the SBC Costing Guidelines to be a dynamic, living document, at the center of a web-based SBC costing community of practice.

\section{The scope of the SBC Costing Guidelines}

Since a single guideline cannot cover everything, it is important to be clear upfront about the scope of these
SBC Costing Guidelines (Table 3). These guidelines are relevant to costing of all SBC interventions and for all health areas, with specific applicability to developing countries. They focus on techniques for primary data collection, rather than reliance on routine finance tracking or accounting systems (which are typically deficient in most developing country settings). Cost analysts looking for guidance on developing investment cases or global price tags that might include SBC intervention costs can use these guidelines as a foundation. However, the SBC Costing Guidelines themselves will not tell you how to carry out those analyses. Similarly, although the SBC Costing Guidelines discuss how different costing approaches can feed into economic evaluation techniques such as cost-effectiveness and benefit-cost analysis, they do not detail how to perform such analyses. Finally, the SBC Costing Guidelines emphasize generally applicable principles and do not provide detailed forms or instructions on collecting and analyzing SBC cost data. Given the wide range of interventions under the $\mathrm{SBC}$ rubric, there is no one-size-fits all template; if an Excel template is used, the analyst would need to adapt it to purpose and context. Additional resources that include costing templates are in Appendix 1, especially Homan (2016) and Terris-Prestholt et al. (2011).

TABLE 3 WHAT THE SBC COSTING GUIDELINES CAN OR CANNOT DO FOR YOU

\begin{tabular}{l} 
WHAT YOU ARE LOOKING FOR \\
\hline Do you want to cost SBC interventions? \\
Do you want to cost in developing countries? \\
Do you want to cost health interventions? \\
Do you want to cost any health area? \\
Do you want to do primary cost data collection? \\
Do you want to know how to develop a global price tag that includes SBC interventions? \\
Do you want to know how to develop an investment case for SBC? \\
Do you want to know how to do economic evaluation of SBC interventions? \\
Do you want detailed forms/spreadsheets that will help you collect and analyze SBC cost \\
data?
\end{tabular}




\section{(5)刍 What is a Unit Cost in the SBC Context?}

Before moving on to the main part of the guide, it is useful to review the concept of "unit cost" and introduce some costing terminology used throughout these guidelines. The transparent calculation and reporting of unit costs enhances the ability to generalize the study findings. "Unit cost" is literally what it costs to produce one of something, but cost analysts use the term differently in different situations, often generating confusion.
One way to understand unit cost is through the analogy of the production process, the process that transforms inputs into outputs. Figure 2 depicts a typical production process for SBC interventions. At each phase of the process (design, start-up, implementation), activities take place that combine inputs (labor, capital, supplies, space). The implementation phase of an intervention will generally have multiple services (or components) that work through activities to generate an intervention product (or output).

FIGURE 2 STYLIZED VERSION OF AN SBC INTERVENTION PRODUCTION PROCESS
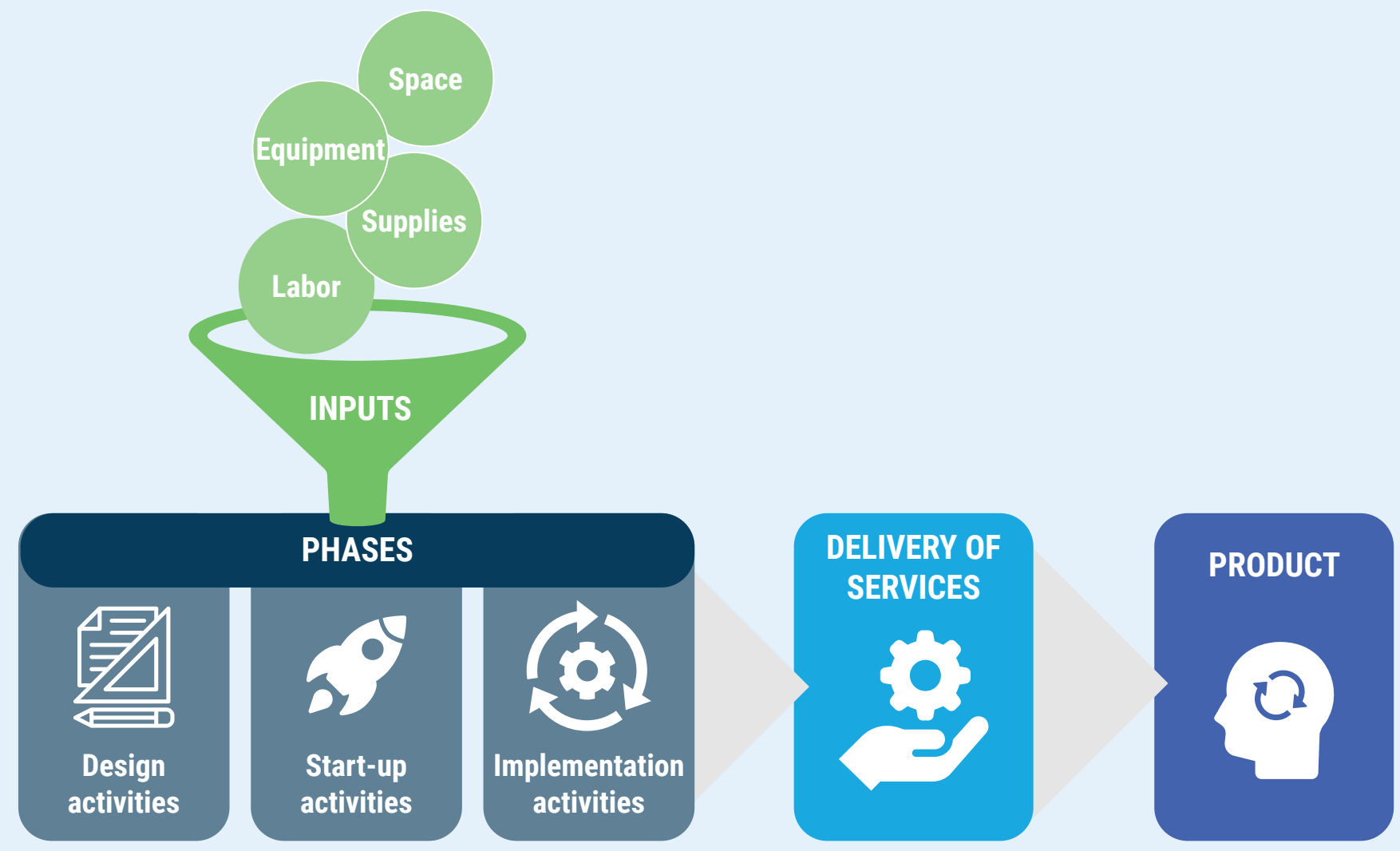
Depending on where in the production process the cost analyst focuses, the definition of unit cost will vary. Focusing on the implementation phase of an example SBC intervention with two services (community meetings and individual counseling) helps illustrate this (Figure 3). The community meetings service is composed of two activities: one activity is community volunteers generating demand for meetings by recruiting neighbors, and a second activity is holding the meetings, where trained field workers lead discussions on the importance of supporting young women in their contraceptive use. Holding the meetings requires several inputs, including the labor of the field workers, which has a unit cost per minute of their time. Field workers also pass out brochures during those meetings, and each brochure has a cost per brochure. The program also pays the bus fare for those attending the meetings, and there is a unit cost for a single bus fare. The "input unit cost" will be the cost of one of those inputs (what cost analysts typically refer to as the "price"). Using these inputs, the production process generates outputs at the activity, service, or intervention level. If the focus shifts to the activity level, the concept of unit cost now changes to include the cost (on average) of organizing and/or holding a meeting. Moving the focus to the level of "service," the unit cost becomes the average cost per meeting (including the costs of organizing and the cost of holding it). You can apply a similar process to arrive at a cost per counseling session, the other "service" that the intervention provides. Finally, moving to the level of intervention, a unit cost per individual reached (through community meetings and counseling) can be calculated, summing the costs of the services and dividing by the number of people the program reaches.

\section{FIGURE 3 HOW THE DEFINITION OF “UNIT COST" VARIES ACCORDING TO WHERE YOU FOCUS IN THE PRODUCTION PROCESS}

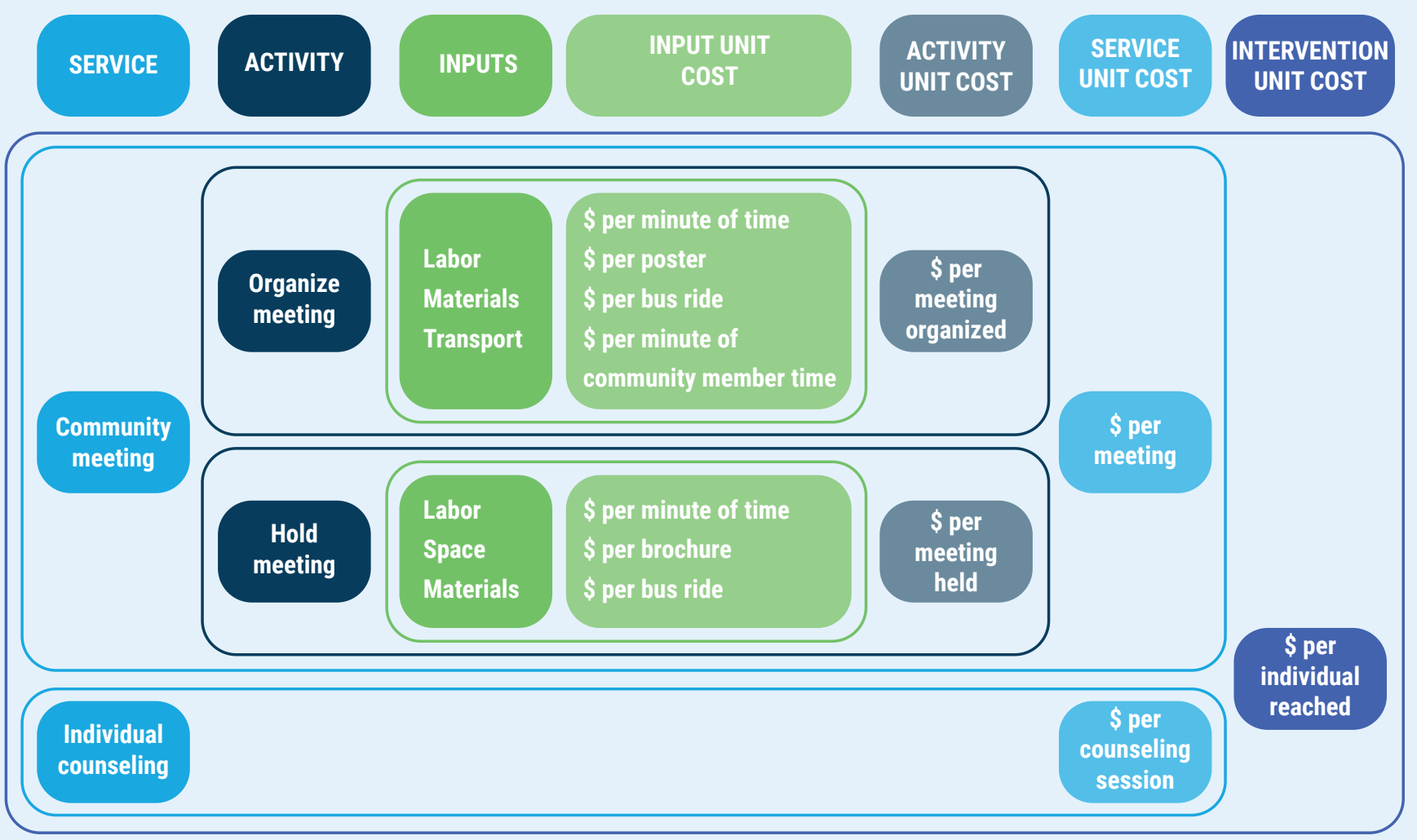




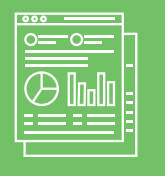 SBC Costing Case Example}

The principles in the following sections will refer often to this brief description of a fictional country's comprehensive SBC programming approach.

Transmutania ${ }^{5}$ is facing a broad array of health challenges. The government, with the help of international funders, is planning a major expansion of health services. However, numerous studies show that barriers exist to the actual practice of a range of health behaviors. The government hopes to continue and expand upon a broad SBC program, involving the coordinated use of a range of channels or approaches to achieve the result of increased practice of priority healthy behaviors by individuals, households, and communities. The government will focus its efforts on malaria; maternal, newborn, and child health (MNCH); family planning and reproductive health; HIV; and tuberculosis, with additional investments possible in the areas of nutrition and water, sanitation, and hygiene (WASH).

There is general agreement that investment in SBC programs on the part of the government is inadequate, and that the government could strengthen its capacity to design and carry out an SBC program. Thus, international funders and SBC technical assistance agencies

${ }^{5}$ The fictional country is named after "transmutation," the action of changing or the state of being changed into another form. will continue to play an important role. The government collaborates with a range of partners at national and subnational levels to design and implement SBC activities. Activities focus on addressing the priority behaviors, with concerted efforts to align SBC activities with government service delivery efforts. The health system operates at three administrative tiers: central, regional, and district (Table 4).

Research has identified a broad range of concerns that SBC programs could potentially address, including low demand for various services, an environment in which social norms continue to hinder the practice of healthy behaviors, weak interpersonal communication and counseling skills of health providers, provider discrimination and lack of respect toward clients, lack of knowledge of healthy behaviors among key population groups, lack of follow-up mechanisms to reinforce the practice of healthy behaviors, and missing links between services.

To address these concerns, the government of Transmutania operates a multi-channel approach with integrated interventions that simultaneously address different health areas, with both communication and non-communication-based interventions aimed at the behavioral determinants. The approach includes:

\section{TABLE 4 TRANSMUTANIA AT A GLANCE}

\begin{tabular}{lr} 
Population (mid-year 2018) & 35 million \\
Proportion of population under 15 years of age & $40 \%$ \\
Government administrative levels & Central, regional, district \\
Annual inflation rate (2018) & $6 \%$ \\
Exchange rate (1 July 2018) & 10 Transmutanian \\
Percent of adults who use internet or own a smartphone 1 SUS \\
Percent of households with television & $39 \%$ \\
Percent of households with radio & $47 \%$ \\
Percent of adults with mobile phone & $75 \%$ \\
\hline
\end{tabular}


- Provision of education, information, and counseling by both paid health workers and community volunteers.

- Radio and television campaigns to promote a range of healthy behaviors and to motivate clients to access services and use specific health products.

- Mixed media campaigns, including posters, brochures, and billboards that similarly motivate clients to take up health behaviors, access services, and use specific products.

- For the more digitally savvy in Transmutania, especially those in the large youth bulge of the population, SBC activities also encompass a range of new digital media approaches to provide information and counseling, motivate behavior change, and direct clients to services and products.

- Meanwhile, community mobilization campaigns tap into community structures and channels to aim to create a more enabling environment for uptake of key behaviors, and to promote client rights and empowerment.

- The SBC program also carries out a range of interventions to improve provider behaviors, addressing attitudes and norms that shape how providers perceive and interact with clients, and emphasizing principles of informed choice, respectful care, confidentiality, and equity.

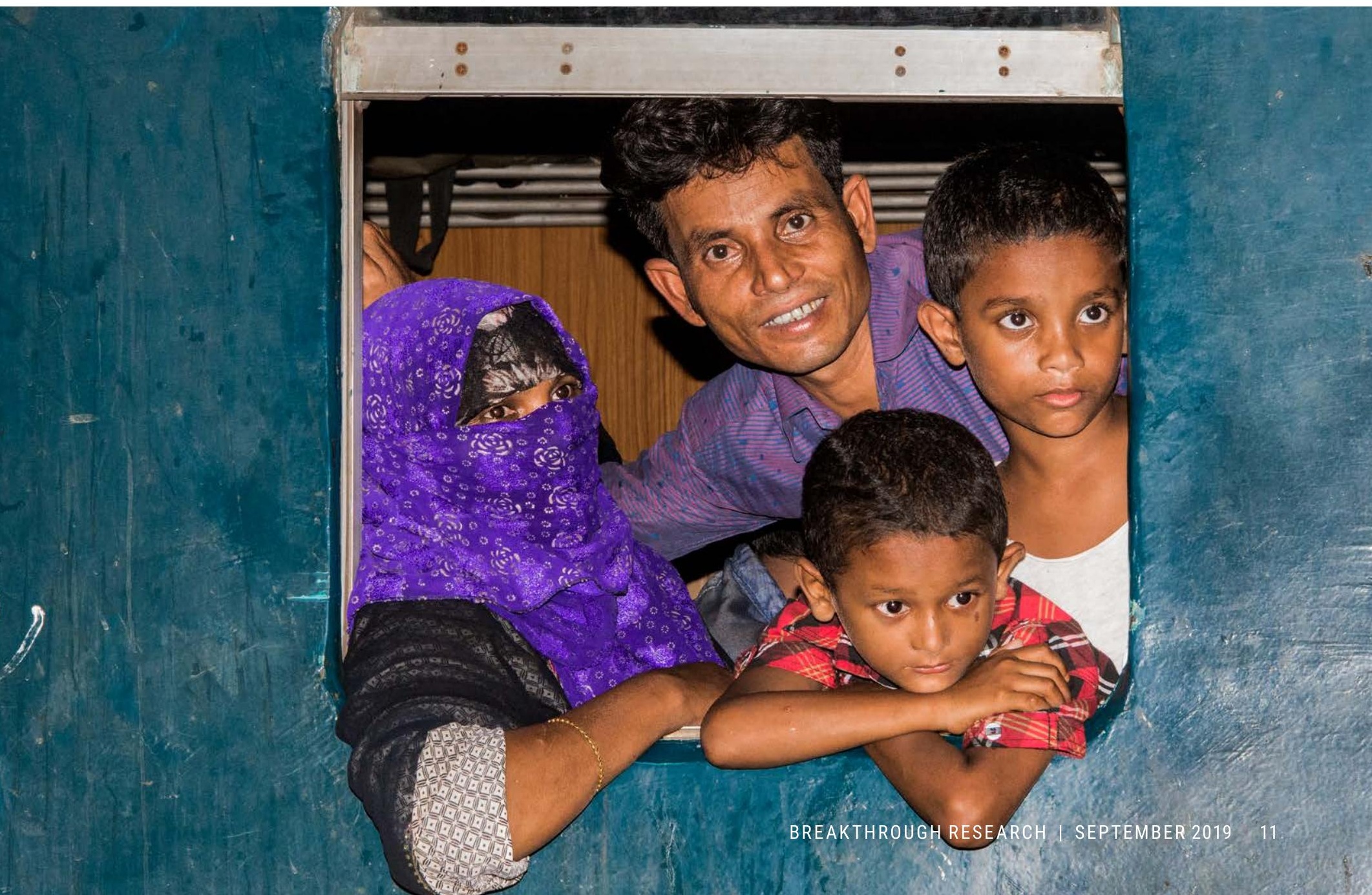




\section{Part}

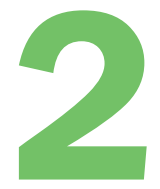

\section{Methodological Principles of \\ SBC Costing}

The guidelines include 17 principles that cover the full range of a costing exercise. These are grouped into four sections:
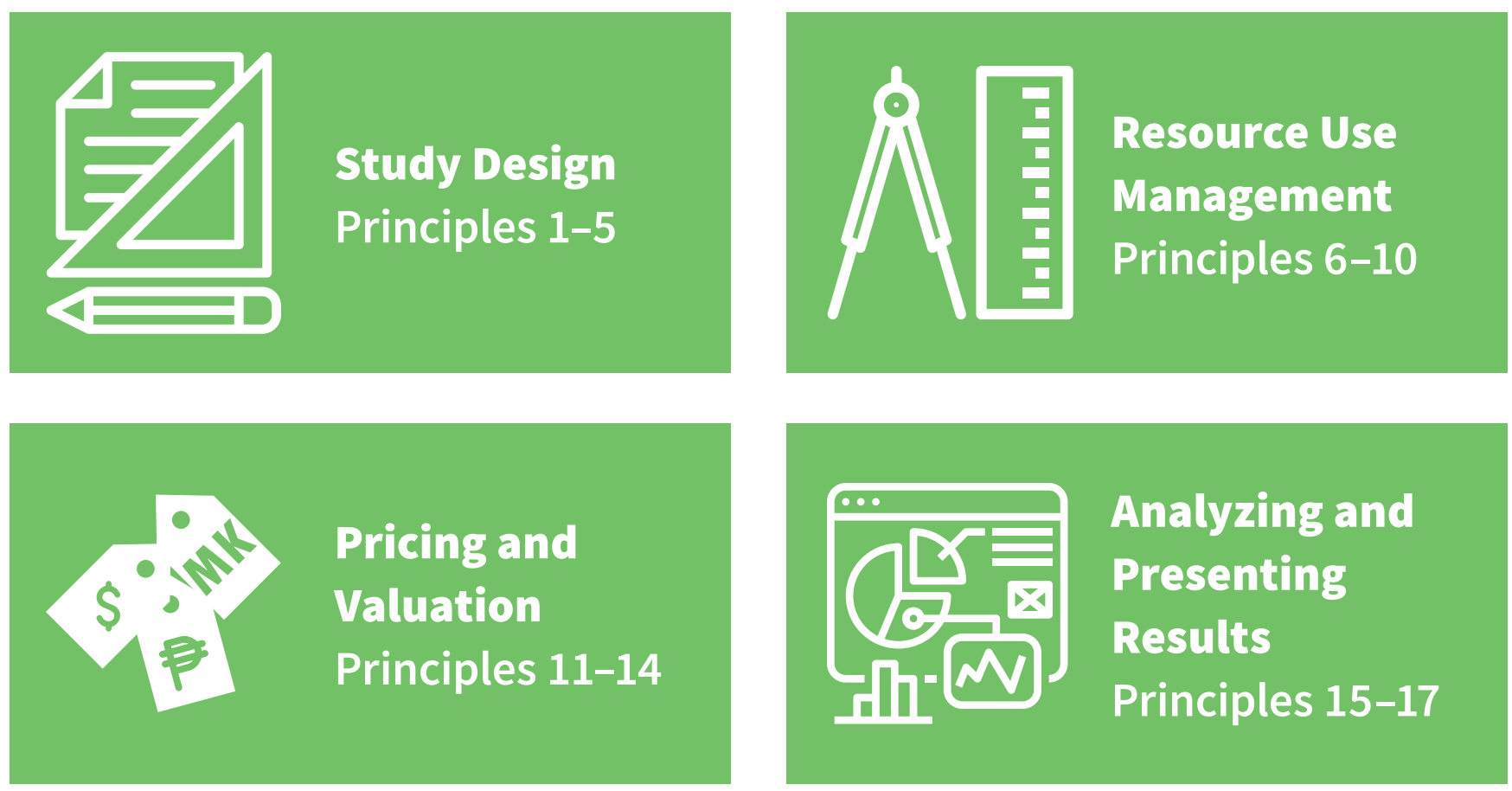

Each principle begins with a link to the GHCC Reference Case, which contains additional reference material for those interested in cost estimation.

Real world costing study examples are provided for most principles. 


\section{堅}

\section{Study Design}

Design is the starting point for any costing, and design choices will determine many of the later choices on data collection and presentation. Study design encompasses five principles:

\section{$1 \mathrm{~A}$ - Defining the purpose \\ $B$ - Defining the intervention}

\section{2 - Defining perspective}

3 - Defining the type of cost

4 - Clear definition of "units"

5 - Determining the appropriate timeframe of cost data collection and disaggregated periods within the timeframe

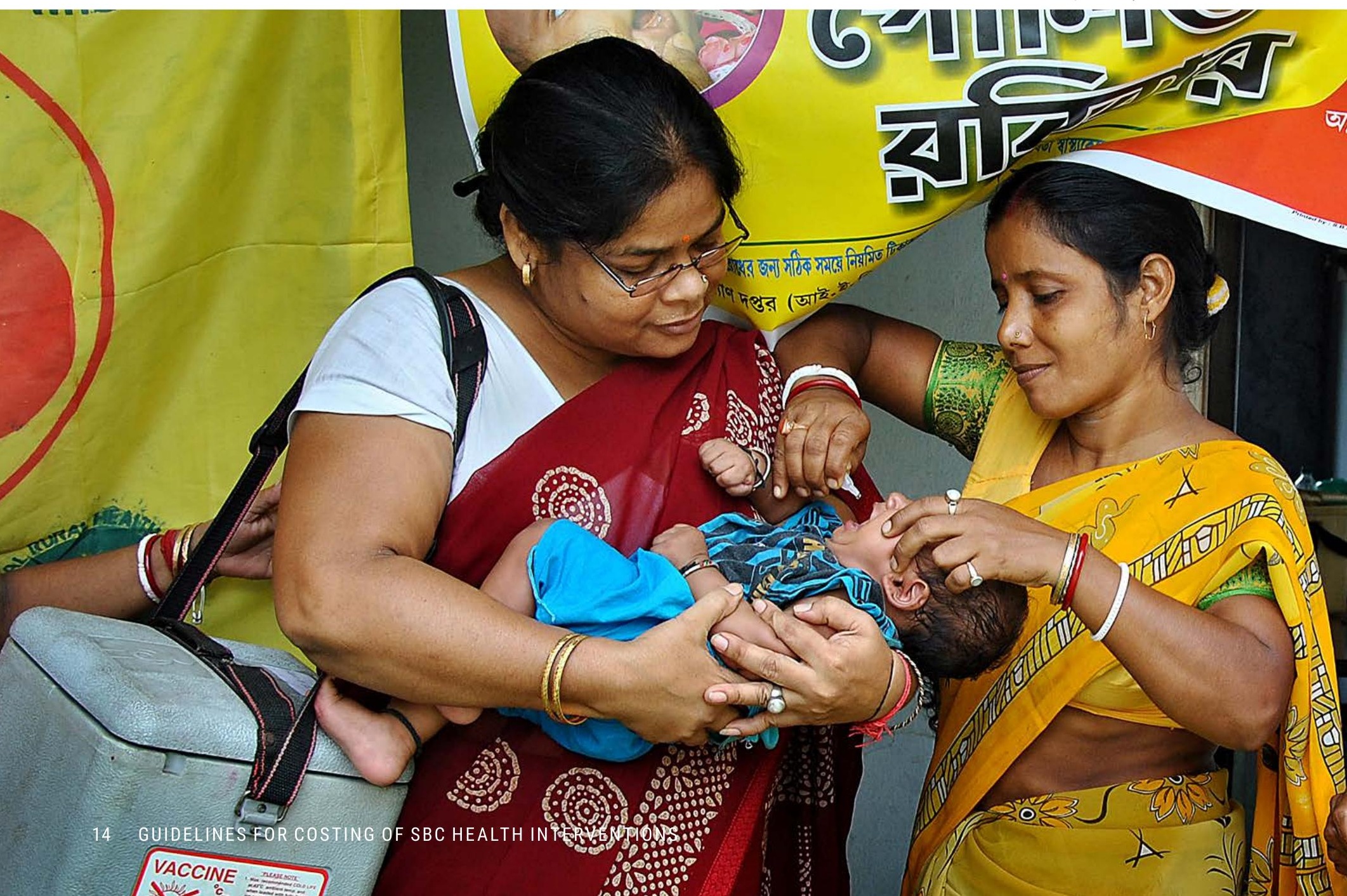




\section{Principle 1A \\ Defining the purpose}

https://ghcosting.org/pages/standards/

principles/defining_the_purpose

https://ghcosting.org/pages/standards/ principles/study_design

\section{The principle}

The purpose of the SBC cost estimation should be defined.

\section{Why it is important}

Asking the question, "Why are we doing this costing?" is the most important step in any costing. The purpose (the "why") will drive the choices about how to collect, analyze, and report the data.

\section{Define the purpose of the SBC cost estimation.}

The purpose of your SBC costing may fall into one or more of four categories, each addressing different financial or policy questions (Table 5).

\section{Costing for short-term budgeting. Knowing costs for} $S B C$ interventions can be extremely helpful in developing annual budgets, as a way for program managers to know what they will need to spend for specific SBC

activities. Moreover, costs are critical to allowing funders of SBC activities to appropriately assess the extent to which SBC intervention costs are consistent with generally accepted costs of such activities. There can be wide variation in the purpose for costing for budgeting based on who you are. In our fictional country of Transmutania ("SBC costing case example," pg 11), the SBC coordination office for the Ministry of Health works with each of the health program managers to develop annual budget estimates reflecting the expected SBC work. This helps ensure that there is adequate funding for $\mathrm{SBC}$ activities in next year's budget. For new interventions in the plan, the government may commission a special study to understand the additional cost to add that new intervention into its current SBC programming portfolio. At the same time, the main international funding organization that supports the government wants to know how much funding to consider for SBC activities for its next budget
TABLE 5 SBC COSTING CAN ADDRESS A RANGE OF FINANCIAL AND POLICY QUESTIONS

\begin{tabular}{|c|c|}
\hline COSTING PURPOSE & $\begin{array}{l}\text { QUESTION YOU ARE TRYING TO } \\
\text { ANSWER }\end{array}$ \\
\hline $\begin{array}{l}\text { Short-term budgeting } \\
\text { and price-setting }\end{array}$ & $\begin{array}{l}\text { How much will my SBC intervention } \\
\text { cost me this year? }\end{array}$ \\
\hline $\begin{array}{l}\text { Medium-term } \\
\text { planning }\end{array}$ & $\begin{array}{l}\text { How much will my SBC intervention } \\
\text { cost me over the next } 3-10 \text { years? }\end{array}$ \\
\hline \multirow[t]{3}{*}{ Economic evaluation } & $\begin{array}{l}\text { Is investing in SBC the best way for } \\
\text { me to reach my health goal? }\end{array}$ \\
\hline & $\begin{array}{l}\text { How does investing in SBC compare } \\
\text { to investing in some other health } \\
\text { intervention? }\end{array}$ \\
\hline & $\begin{array}{l}\text { Will I save any money through invest- } \\
\text { ing in } \mathrm{SBC} \text { ? }\end{array}$ \\
\hline Technical efficiency & $\begin{array}{l}\text { What is the lowest cost way to pro- } \\
\text { duce maximum output for a given } \\
\text { SBC intervention? }\end{array}$ \\
\hline
\end{tabular}

cycle. The funder might request the Ministry of Health to cost specific SBC interventions. Alternatively, the funder could draw on historical data on unit costs of SBC activities to benchmark the costs that implementing agencies propose.

\section{Costing for price-setting. Cost data can help to set a price for a particular SBC intervention or service. For} private or government agencies seeking to purchase SBC services, knowledge of costs is critical to setting or negotiating a fair price. Similarly, for an organization that sells SBC services, knowing costs and being able to present high-quality cost estimates to purchasers is helpful during negotiation and price setting with purchasers. The Transmutanian government, lacking the capacity to design a national mass media campaign, wants to contract out design and management services to private companies, and thus commissions a costing study to determine fair prices for mass media design services. At the same time, nongovernmental organization (NGOs) that specialize in community mobilization campaigns hear that the government may be interested in contracting out such efforts around malaria prevention and other health prevention activities. To convince the government that it might be worthwhile to contract out such campaigns, they commission a cost study to determine what it might cost to carry out such campaigns in target regions. 
Costing for medium- and long-term financial planning and resource requirements estimation. Costing of $S B C$ interventions is also critical to medium and long-term planning and resource requirements estimation. These types of estimates are typically required for either the health sector as a whole or for specific health areas. In Transmutania, the Ministry of Health develops a five-year health sector plan that requires cost estimates for the range of projected SBC activities. The SBC office of the Ministry of Health typically coordinates information from across the different Ministry of Health programs (e.g., $\mathrm{HIV}$, family planning, MNCH, malaria). Transmutania is also developing a country investment case for the Global Financing Facility, one that requires knowing SBC costs associated with priority interventions. The family planning division of the Ministry of Health is putting together a five-year cost estimate as part of development of the Costed Implementation Plan (CIP) that requires costing of SBC and other demand generation activities, and that will draw on a database of unit costs for specific SBC activities.

\section{Costing for economic evaluation and/or priority setting. Costing is a key input to economic evaluation,} a range of techniques that help decision makers choose between alternative courses of action; it encompasses cost-effectiveness analysis, cost-minimization analysis, benefit-cost analysis, and investment or business cases. ${ }^{6}$ Economic evaluation is a technique to inform allocative efficiency of interventions. Several different opportunities exist for using costing for economic evaluation around SBC interventions in Transmutania. For example:

- The USAID Mission is interested in helping the government test its new, integrated approaches to SBC across a range of health interventions, for which data on both cost and effectiveness is lacking.

- Cost-effectiveness analysis helps the government determine whether and how it is worthwhile to pursue the integrated approach.

- In addition, the government is deciding what services to include in its health care benefits package and thus commissions a cost-effectiveness analysis to determine the relative cost and impact of including specific SBC interventions.

\footnotetext{
${ }^{6}$ For more detail on the analyses that comprise economic evaluation, see Drummond, M. et al. 2015. Methods for the Economic Evaluation of Health Care Programmes, Fourth Edition. New York: Oxford University Press.
}

- The SBC community within Transmutania is advocating for greater spending on SBC interventions and wants to commission cost-effectiveness analyses to compare SBC with other health interventions, and to show the health impact of adding SBC.

- The Ministry of Health is trying to convince the finance ministry of the need to allocate more money for SBC interventions and uses benefit-cost analysis to illustrate the economic impacts of SBC interventions.

- An international funder is trying to decide how best to allocate its resources within its portfolio of activities and uses cost-effectiveness analysis to compare SBC interventions with other interventions in the health sector.

- HIV advocates in Transmutania are developing a country investment case for HIV interventions and want to understand better the costs and potential impact of a combination of different HIV interventions, including SBC activities.

Costing for technical efficiency analyses. While the allocative efficiency analysis taking place under the rubric of economic evaluation helps answer questions about the best ways to use limited resources among different potential interventions, technical efficiency analysis tries to answer the question of, for a specific intervention, how does an organization produce the maximum output for a given set of inputs (in other words, at lowest unit cost)? In Transmutania, several opportunities exist for $\mathrm{SBC}$ costing to inform technical efficiency analyses. For example, the government wants to know how technical efficiency varies among the hundreds of sites where it is carrying out its community mobilization activities, to know which sites are most efficient (i.e., have lowest cost per person reached via mobilization activities) and why certain sites are more efficient than others. ${ }^{7}$

${ }^{7}$ For more on allocative versus technical efficiency, see World Bank (2015) HIV Allocation Efficiency Analysis: Guidelines: Methods for improving the Efficiency of HIV Resource Allocation, Volume 1. Washigton, DC: World Bank. http://optimamodel.com/docs/AE-Guidelines-Vol-1.pdf; Hernandez, A. and M. San Sebastian (2014) "Assessing the technical efficiency of health posts in rural Guatemala: a data envelopment analysis," Global Health Action 7: 23190. doi: 10.3402/gha.v7.23190; Jehu-Appiah, C. et al. (2014) "Ownership and technical efficiency of hospitals: evidence from Ghana using data envelopment analysis," Cost Effectiveness and Resource Allocation 12: 9. doi: 10.1186/1478-7547-12-9; and RuizRodriguez, M., L.A. Rodriguez-Villamizar, and I. Heredia (2016) "Technical efficiency of women's health prevention programs in Bucaramanga, Colombia: a four-stage analysis," BMC Health Services Research 16: 576. 10.1186/s12913-016-1837-0. 
A cost analysis in Turkey compared the cost of couple's education on family planning versus wife-only education (Fisek and Sumbologlu 1978).

\section{COSTING OF DEMAND CREATION ACTIVITIES IN \\ FAMILY PLANNING COSTED IMPLEMENTATION PLANS}

Over 30 countries have prepared family planning costed implementation plans, and almost all of these have included a demand creation component in the plan. Templates exist to cost the demand creation activities using input unit costs (prices) specific to each country (FP2020 2018).

\section{COST-EFFECTIVENESS ANALYSIS OF A}

MULTICOMPONENT SBC INITIATIVE IN KENYA

In the evaluation of the Tupange program in Kenya, analysts used cost-effectiveness analysis to compare different elements of a multi-component SBC initiative that aimed to increase use of modern family planning methods in urban Kenya (Benson et al. 2018).

\section{COST-EFFECTIVENESS ANALYSIS OF AN \\ INTEGRATED FAMILY PLANNING AND \\ IMMUNIZATION PROGRAM IN RWANDA}

In Rwanda, analysts looked at the additional cost and effectiveness in terms of family planning use associated with applying the Health Belief Model during immunization visits in an intervention that integrated family planning with immunization visits (Dulli et al. 2016).

\section{COST-EFFECTIVENESS ANALYSIS OF A}

REFRESHER TRAINING IN GUATEMALA

Cost analysts in Guatemala compared the costs of three different approaches to refresher training for family planning providers, calculating a cost per provider trained (Naik et al. 2010). 
https://ghcosting.org/pages/standards/

principles/study_design\#purpose

\section{The principle}

The analyst should clearly define the intervention being costed.

\section{Why important}

After defining the purpose, the next step for the analyst is to clearly define the SBC intervention. The act of costing is to describe as best as possible the costs associated with a defined production process for a particular context. The more clearly you define the intervention, the better the cost estimate will be. Homan (2016) emphasizes this point by recommending as a first step that the cost analyst identify all phases and activities in the production process, then define the inputs for each activity. Given the varying definitions of SBC and the broad range of interventions that SBC encompasses, it is important to be very clear in your definition of the intervention. Clear specification is key to determining the appropriate measurement and to be able to fairly compare results of costings across countries, time periods, and populations. 
Principle 1B

\section{Defining the intervention}

\section{Clearly define the context, the population, and the intervention and/or service/output of the SBC cost estimation.}

You should clearly define the intervention and the context of the SBC intervention, including the following information:

Country and geography. The purpose of the study will determine the country or countries and whether the costing will examine a particular geographic setting (urban, rural, or specific areas of the country).

Epidemiological context (incidence/prevalence of health conditions of interest in the county and in the studied area or population). This will vary according to the particular health area being analyzed.

Other contextual issues that analysts feel are relevant to effective provision of SBC interventions (such as economic turbulence, conflict, environmental changes, and communication modality changes affecting social norms). For SBC, key contextual factors include social norms that underlay uptake of desired health behaviors and that may ultimately influence intervention cost and effectiveness.

Target population/s. Who is the SBC intervention aimed at? Be sure to specify age, gender, geographical location, members of particular risk groups, etc. This is important not only for generalizability, but also because it can cost more to reach certain target populations.

Ecological level. State which level the intervention is targeting for social or behavior change, per the SBC ecological framework:

- Individual (e.g., client)

- Household

- Community

- Organization (e.g., provider $^{8}$ )

- Policy (e.g., advocacy)

\section{ANALYSTS IN NIGERIA EXAMINED COSTS} FOR A RANGE OF SETTINGS

In describing the production process for an intervention to scale up the use of sulfadoxine-pyrimethamine for the preventive treatment of malaria in pregnancy in Nigeria, analysts examined costs for health facilities, local government authority technical administration, community-based health volunteers and supervisors, and ward development committees (Orobaton et al. 2016).

Delivery platform. SBC delivery platforms are wide-ranging and can include fixed facilities such as health posts, clinics, or hospitals; outreach modalities such as mobile vans or tents; community such as where the project is community-driven (even if supported by outside parties); or population-wide such as mass media or legal change.

Ownership. SBC activities can be initiated by public, private, or NGO actors who own the intervention site or SBC product.

Main SBC intervention activities and clear description of the production process. There is no single way of carrying out an SBC intervention; thus, it is important for the cost analyst to clearly describe the activities that comprise the intervention and the process of "producing" the expected outcome of the intervention. The analyst should also be sure to state whether the study excludes key parts of the production process (more on what to include in Principle 6-Scope of the costing).

Coverage level or project phase (pilot, implementation, post scale-up). This is important to state clearly, because the phase may have a strong bearing on costs. Pilot interventions may include elements that managers will discard after piloting (special design activities; intense monitoring and evaluation). Programs operating at large scale may have a different cost profile depending on the proportion of fixed to variable costs. Clearly stating the phase of the interventions will be very useful in allowing others to interpret and use the results.

${ }^{8}$ Even though individuals may benefit from provider behavior change, the initial target is the provider when provider is listed as the ecological level. 


\section{Principle 2 \\ Defining perspective}

https://ghcosting.org/pages/standards/

principles/study_design\#three

\section{The principle}

The perspective of the SBC cost estimation should be defined.

\section{Why important}

The perspective determines whose costs to include in the cost estimate. There is no "best" perspective to use in SBC costing. Rather, the purpose and audiences for the costing will determine the perspective to use.

\section{Clearly delineate the scope of the costs that are being included in the chosen perspective}

On one end of the spectrum, the "societal" perspective includes all costs, regardless of who pays. All other perspectives will exclude some costs, and it is the responsibility of the analyst to state clearly what costs are included or excluded, and why. For SBC, we can illustrate perspective by thinking about how different actors in Transmutania may approach a cost estimate of the same SBC interventions.

Provider perspective: Mrs. Smith, the director of a local Transmutanian NGO that carries out community mobilization campaigns for public health goals, received a request from the government SBC office potentially interested in contracting her organization to carry out an integrated prevention campaign for malaria, HIV, and diarrhea, focusing on meetings with village leaders and key community representatives, enlisting community volunteers as campaign promoters, and providing poster and leaflet advertising. Mrs. Smith asks her finance and program team to develop a budget for the proposed activity.

\section{Government perspective: Mr. Jones, head of} Transmutania's national SBC office, is concerned about the sustainability of the government's integrated efforts to prevent malaria, HIV, and diarrhea, and in particular about the ability of government offices to efficiently operate the community mobilization component of the campaign. Mr. Jones commissions an analysis of the community mobilization component of the program to understand better the extent to which the program is cost-effective and whether it might make sense to contract out the community mobilization component of the prevention efforts. Mr. Jones wants to know if contracting out will be more affordable than continuing to operate the community mobilization campaign as an arm of the Ministry.

Societal perspective: Dr. Allen, researcher at the national health institute of Transmutania, is a strong advocate for public investment in health programs, and particularly values the role that communities can play in supporting individuals and households to practice healthy behaviors around malaria, HIV, and diarrhea. Dr. Allen is concerned about maximizing the impact of such programs on the health and well-being of rural Transmutanians. She has been contacted by an SBC advocacy group to "make the case" for greater investment in SBC programming, including in community mobilization campaigns. She proposes a cost-effectiveness analysis to measure the incremental cost-effectiveness of expanding the SBC community mobilization component of the program.

As summarized in Table 6 , in this example analysts will include different costs, depending on their particular perspective.

In the cost analysis conducted from the perspective of the NGO provider, the relevant question for Mrs. Smith is what the community mobilization program will cost her organization, and thus what they will have to charge the government should they be contracted to run the program. As such, Smith is not interested in valuing the time of government clinical staff who help coordinate the program, the community volunteers who help to organize events, or the community members themselves who participate in the program.

From the government perspective, the national SBC program head for the Ministry of Health is interested in what it will cost the government, whether it pays for another organization or carries out the program itself. Thus, in addition to direct program operational costs such as design, printing, transportation, and field staff, Mr. Jones will want to include the cost of the government-paid staff working at nearby health centers and posts who liaise with and help coordinate community events. Mr. Jones, as a government employee, is also more sensitive 
TABLE 6 ILLUSTRATION OF HOW COSTS INCLUDED VARY ACCORDING TO A COSTING STUDY OF A COMMUNITY MOBILIZATION CAMPAIGN, CONDUCTED FROM THREE DIFFERENT PERSPECTIVES

\begin{tabular}{|c|c|c|c|}
\hline \multirow[b]{2}{*}{ COST } & \multicolumn{3}{|c|}{ PERSPECTIVE } \\
\hline & $\begin{array}{c}\text { NGO } \\
\text { PROVIDER }\end{array}$ & GOVERNMENT & SOCIETY \\
\hline Design & All costs & All costs & All costs \\
\hline $\begin{array}{l}\text { Printing of } \\
\text { pamphlets and } \\
\text { brochures }\end{array}$ & All costs & All costs & All costs \\
\hline $\begin{array}{l}\text { Program trans- } \\
\text { portation }\end{array}$ & All costs & All costs & All costs \\
\hline $\begin{array}{l}\text { Program field } \\
\text { staff }\end{array}$ & All costs & All costs & All costs \\
\hline $\begin{array}{l}\text { Government clini- } \\
\text { cal staff time }\end{array}$ & No costs & All costs & All costs \\
\hline Client time & No costs & No costs & All costs \\
\hline $\begin{array}{l}\text { Community vol- } \\
\text { unteer time }\end{array}$ & No costs & Some costs & All costs \\
\hline
\end{tabular}

than Mrs. Smith to the time taken up by community volunteers in helping to organize and manage events, and thus wants to include a portion of their time in his costs. Client time, however, is not something he is interested in valuing.

From the societal perspective, Dr. Allen is concerned with the costs of the community mobilization program to society as a whole. She and the advocacy group that has contracted her want to show that the program balances the interests of the government, providers, and the individuals that may benefit from the program. She also knows that an important audience for the study might be Ministry of Finance officials with ultimate say over the health ministry budget, and will want a full costing of the program to be able to compare investments across sectors. Since community volunteers make a significant time commitment to helping run the program, she feels it is important to value their time in any analysis. Similarly, the time that community members participate in the program draws on time that they otherwise might be engaged in productive activities. Thus, her analysis aims to capture the opportunity costs of volunteers, in addition to the service costs of running the program.

\section{ANALYSTS IN RWANDA ADOPTED A} GOVERNMENT PERSPECTIVE

Analysts looking at the cost-effectiveness of male circumcision in Rwanda (including the cost of SBC components counseling and promotion), adopted the perspective of the government as health care payer. As such, they included the costs of surgical materials, staff time, associated staff training, patient counseling, the treatment of adverse events, and related promotion campaigns, but excluded inputs such as client time and transport costs (Binagwaho et al. 2010).

\section{ANALYSTS IN MALAWI TOOK THE PERSPECTIVE OF THE HEALTH CARE PROVIDER}

Analysts examining cost and effectiveness of women's groups and volunteer peer counseling in rural Malawi took the perspective of the health care provider. They decided to value donated inputs but not volunteer time, reasoning that volunteers already received compensation in terms of financial allowances and goods, and volunteer work did not replace regular employment (Lewycka et al. 2013).

\section{ANALYSTS IN BURKINA FASO CHOSE A SOCIE- TAL PERSPECTIVE}

A cost-effectiveness analysis of a maternal and newborn health intervention emphasizing community mobilization in Burkina Faso chose a societal perspective to derive costs (Hounton and Newlands 2012).

\section{ANALYSTS IN INDIA CHOSE A PROVIDER PERSPECTIVE}

A cost-effectiveness analysis examining a program in India that educated mothers on childhood vaccination considered costs from a provider perspective only. Analysts collected costs through project accounting systems, categorized them as start-up or implementation costs, and excluded research costs (PowellJackson et al. 2018). 


\section{Principle 3 Defining the type of cost}

(2) https://ghcosting.org/pages/standards/ principles/study_design\#four

\section{The principle}

The type of cost being estimated should be defined in terms of whether it is financial vs. economic, real world vs. guideline, incremental vs. full cost, and net of future savings or not. The type of cost should be justified relevant to the purpose of the SBC cost estimation.

\section{Why important}

The purpose of the costing and the perspective chosen will determine the types of cost to analyze, thus driving key decisions about study design and measurement.

\section{Define if the cost is financial or economic.}

Cost analysts use the terms financial and economic cost to distinguish between what someone pays for a resource or input (the financial cost) and the opportunity cost of that resource (the economic cost). The opportunity cost is the value of the resource based on the alternative uses of that resource. Donated resources generally have zero financial cost but non-zero economic cost. For SBC interventions, the following types of inputs are often calculated differently for financial and economic costs:

- Donated labor, involving unpaid volunteers (thus, no financial cost) but whose time still has value in terms of the alternate uses of that time (economic cost).

- Many community mobilization activities involve community volunteers who are unpaid.

- Similarly, interpersonal communication and counseling activities often draw on community volunteers.

- Celebrities often donate their time to mass media and entertainment education interventions.

- Unpaid staff, where no payment is made (thus, no financial cost), but whose time still has an opportunity cost (economic cost).
- Staff drawn off other activities (including break time) to spend time on an intervention.

- Staff paid by organizations other than the one implementing the intervention.

- Donated goods or services, where no financial transaction occurs (financial cost), yet the goods or services have an opportunity or market cost (economic cost).

- Social marketing and other programs that work through mass media often rely on donated airtime for radio or television.

- Digital health interventions can rely on donated use of design activities, free corporate sponsorship of wireless time/usage, text message service, or use of servers.

- Donated physical space, indoor or outdoor.

- Implementing agencies often do not pay rent or mortgage for a building, tent, or outdoor space where SBC activities take place. Yet, these spaces have a value that, if not donated, the organization would have to pay.

- Inputs whose price may not reflect market prices.

- Although not donated, some inputs are subsidized heavily. For example, often airtime for television and radio spots produced by and for government mass media interventions is offered at a reduced rate. The subsidy price is a financial cost, while the true market price is the economic cost of the item.

- Client time, including time getting to and from an SBC activity and any time spent "consuming" the SBC intervention.

- What someone "pays" for client time is generally zero (the client does not pay for their own time); yet client time has an opportunity cost (generally considered as the money they could be earning during the time they are participating in the SBC intervention). This is the economic cost of their time.

The choice of using financial or economic costs in the costing estimation depends on the perspective (see "Defining perspective" pg 20), itself a function of study purpose and audience. For example, if you are costing for budgeting purposes only, you generally will not be interested in assigning an opportunity cost to free labor. 
- For budgeting and price setting, financial costs should suffice. Someone budgeting, like Mrs. Smith, head of the Transmutanian NGO in the example in "Defining perspective" (pg 20) is really only interested in what they will be paying for (the financial costs), and not the costs of donated labor or what other payers such as the government might have to pay for.

- For medium and long-term planning, the correct approach may vary. In the case of Mr. Jones, head of the government SBC office example in "Defining perspective" (pg 20), they may only be interested in financial costs if the assumption is that, moving forward, payment for the program will continue to be exactly the same. However, what if the expectation is that change in government policy will eventually require some sort of payment to reimburse community volunteers for the time spent organizing the program? Then, a costing to inform a five-year SBC strategy would warrant valuing community members' time using the appropriate opportunity cost.

- For an economic evaluation, there is a clear-cut reason to capture economic costs rather than only financial costs of the intervention. A costing that calculates economic costs will allow a fair comparison among a range of possible interventions, regardless of who might pay for a particular input. When Dr. Allen wants to compare the cost of the community mobilization intervention, she will definitely want to value volunteer time as well as client time participating in the program so that the resulting cost estimates are comparable to other studies that have similarly valued opportunity costs.

- For technical efficiency analysis, there are no clear-cut guidelines on whether to use economic or financial costs, and the answer will depend on the perspective chosen, although most technical efficiency analyses seem to take a "provider" perspective. For example, the Transmutanian government may want to undertake a study to compare the technical efficiency of counseling services across clinics and hospitals in the country. In such a scenario, with the government as the "provider," it is likely that they will be only interested in financial costs (those that the government bears.)
TABLE 7 QUICK GUIDE FOR WHEN TO USE FINANCIAL VS. ECONOMIC COSTS

\begin{tabular}{l}
\hline PURPOSE \\
$\begin{array}{l}\text { Budgeting and price } \\
\text { setting }\end{array}$ \\
$\begin{array}{l}\text { Medium to long- } \\
\text { term planning } \\
\text { Economic } \\
\text { evaluation }\end{array}$ \\
$\begin{array}{l}\text { Technical efficiency } \\
\text { analysis }\end{array}$
\end{tabular}

Table 7 provides a summary of when to use financial vs. economic costs.

\section{Describe whether you are estimating costs ac- cording to "normative best practice" or accord- ing to "real world" cost as implemented.}

For SBC interventions, as for any health intervention, there is usually a difference between how an intervention is supposed to operate (i.e., "normative best practice") and how it functions in practice ("real world"). Typically, "normative best practice" is associated with specific clinical guidelines or procedures that clinicians should follow. Such guidelines are less common in SBC interventions, but the analyst could discern these guidelines through review of program documents, interviews with program staff, or sampling of intervention sites. However, you could estimate costs of the SBC intervention based on one or the other of these approaches (or even a combination). It is important, however, to clearly state which approach you are using. That is because, particularly for costing as part of economic evaluation, the intervention may include activities to ensure guidelines compliance, and it is important to note the cost of those activities because of their potential contribution to effect size.

For example, the couples counseling intervention that forms part of the package of comprehensive Transmutanian SBC interventions has guidelines (norms) that state who provides the counseling, the amount of time they spend with the clients being counseled, and the number of total counseling sessions that should take place per couple. One approach would be to cost the counseling component according to these guidelines, 
based on a total number of counseling sessions that took place (or will take place). Another approach would be to actually go out and measure the actual number of sessions that took place, who counseled, and the average time per session. The two approaches could potentially give very different results if, for example, actual counseling session length were twice what the guidelines specify.

\section{Specify whether the cost is a full cost or incre- mental cost of adding SBC to existing programs or services.}

A costing can capture the "full" cost of the SBC intervention, or only measure the cost associated with that part of the intervention that is additional, or "incremental." Please see Principle 6-Scope of the costing, for more information on incremental cost.

\section{Report if the cost is net of future cost savings for health providers or households.}

For the type of economic evaluation known as benefit-cost analysis, it may be important to additionally calculate what future savings might result from the intervention, and to calculate an intervention cost that is net of these future savings. For example, the SBC intervention in Transmutania that aims to convince more people to sleep under insecticide treated bed nets reduces illness associated with malaria. Fewer malaria episodes means savings on hospitalization costs and reduction in lost earnings. The cost analyst could choose to reduce the intervention cost by the amount of these expected future monetary benefits associated with the intervention.

\section{ANALYSTS IN INDIA ESTIMATED FULL} ECONOMIC COSTS OF A CANCER AWARENESS AND EARLY DETECTION CAMPAIGN

A costing in India that estimated costs of cancer awareness and early detection campaign, estimating full economic costs of implementing the campaign from a societal perspective. Analysts calculated economic costs by valuing the opportunity cost of all the resources used for planning, implementing, and monitoring the campaign. This included the financial costs (explicit) and the opportunity cost of implicit resources such as personnel who spent time out of their regular schedules on the training (Thakur et al. 2016).

\section{A BENEFIT-COST ANALYSIS IN INDIA INCLUDED FUTURE COSTS SAVINGS ASSOCIATED WITH REDUCTION IN THE NEED FOR ANTIRETROVI- RAL THERAPY}

Analysts carried out a benefit-cost analysis of a community mobilization and empowerment initiative in India for addressing HIV/AIDS in female sex workers. Using sensitivity analysis, they reran their calculations to include the future cost savings associated with reduction in the need for antiretroviral therapy. Inclusion of future costs meant the intervention became cost saving (Vassall et al. 2014). 


\section{Principle 4 Clear definition of "units"}

https://ghcosting.org/pages/standards/

principles/study_design\#five

https://ghcosting.org/pages/stan-

dards/introduction/estimating_

the_cost_of_health_interventions_an_ introduction\#four

\section{The principle}

The "units" in the unit costs for SBC interventions should be defined, relevant for the costing purpose, and generalizable.

\section{Why important}

Clarity on what constitutes a "unit" for SBC interventions contributes to better comparison and use of unit cost estimates for a variety of purposes, including for informing estimates in other settings or for modeling.

\section{Analysts should report using standardized units that are clear, aligned with current national and international strategies, and respect the pur- pose of the study.}

As "What is a unit cost in the SBC context?" (pg 9) notes, the "unit" in an SBC intervention will vary depending on where the analyst focuses in the production process (input, activity, service, or intervention). Any one SBC intervention may be structured much differently from another, and thus the input, activity, and service units will vary greatly from one intervention to the next. That makes it difficult to generalize about what a standard unit should be at those levels. Thus, here we will focus on how the analyst can standardize the intervention unit, the expression of the product or output of the intervention.

Standardizing the intervention unit for SBC interventions is complicated, however, because SBC is not a single intervention but rather a group of interventions, potentially with different "products." All SBC interventions aim to influence the practice of healthy behaviors (such as handwashing, contraceptive use, and antenatal care) and can work via clients, community members, and health providers. The "product" any particular SBC intervention generates thus depends on which avenue the program takes. Table 8 suggests standard intervention units to use in $\mathrm{SBC}$ costing, according to the B-R operationalization of the four main categories of SBC interventions summarized in Table 2.

\section{TABLE 8 PROPOSED STANDARDIZED INTERVENTION UNIT ASSOCIATED WITH SPECIFIC SBC INTERVENTION CATEGORIES}

\begin{tabular}{|c|c|}
\hline $\begin{array}{l}\text { BROAD INTERVENTION } \\
\text { CATEGORY }\end{array}$ & INTERVENTION UNIT \\
\hline $\begin{array}{l}\text { Interpersonal } \\
\text { communication }\end{array}$ & Client reached \\
\hline $\begin{array}{l}\text { Mass, digital, and social } \\
\text { media }\end{array}$ & Client reached \\
\hline \multirow[t]{2}{*}{ Community mobilization } & Community member reached \\
\hline & Community reached \\
\hline $\begin{array}{l}\text { SBC service and program } \\
\text { strengthening activities }\end{array}$ & Provider reached \\
\hline
\end{tabular}

Interpersonal communication interventions work through individual clients, on the theory that better interpersonal communication results in more informed and motivated clients. The relevant output for any interpersonal communication intervention, therefore, is a client who is reached with the counseling or other approach. Similar to interpersonal communication interventions, mass, digital, and social media interventions typically aim to influence client behavior directly. Thus, again, it is client reached (where "client" means those the intervention aims to reach, for example, people in a target area and of a specific target group and with access to a radio) that is the appropriate unit of analysis at the intervention level. Community mobilization interventions, by contrast, are aimed not at clients directly but at the communities where those clients reside. The appropriate unit at the intervention level is the community member reached or community reached. SBC service and program strengthening activities encompass a range of provider behavior change interventions that have the health provider as the main channel or focus. Thus, the provider reached is the appropriate unit at the intervention level.

For mass, digital, and social media interventions in particular, determining the "dosage" or degree of exposure to 
the intervention can be key to evaluating effectiveness, but is also particularly challenging. Thus, it is important for the analyst to elaborate and report on the different degrees of exposure so that others may better interpret the meaning of "reached" in the specific context of the intervention.

\section{Analysts should consider the use of "quality adjusted units," especially where the study of efficiency is of primary importance.}

For many SBC interventions, the "quality" of the intervention output may vary from setting to setting. Since the resources you put into an intervention may influence quality, cost estimates of the same type of intervention may vary greatly from setting to setting, thus hindering comparisons. The GHCC Reference Case gives the example of measuring the cost per person per month of treatment versus the cost per person completing treatment (the latter being a better measure of the quality of the intervention). You may then want to choose an output unit that better reflects quality (versus quantity) of an intervention. Again, there is no one way to approach this, and it will vary by intervention type. For many SBC interventions, a "quality-adjusted" output unit is an output that is adjusted according to exposure or dosage of the intervention (discussed above). An example would be cost per person initiating modern family planning method and happy with care, pursuant to a provider behavior change intervention. For adherence, a quality-adjusted unit cost might be cost per person retained in care at six months.

\section{IN CAMEROON, ANALYSTS USED TWO} DIFFERENT MEASURES OF UNIT COST FOR A BED NET PROMOTION CAMPAIGN

Bowen et al. (2013) measured the costs and impact of a social marketing campaign in Cameroon to encourage people to use bed nets to prevent malaria. They measured the intervention unit using two measures: cost per individual reached with the campaign, and cost per additional individual sleeping under a mosquito net. 


\section{Principle 5}

\section{Determining the appropriate timeframe of cost data collection and disaggregated periods within the timeframe}

https://ghcosting.org/pages/standards/ principles/study_design\#five

\section{The principle}

The timeframe of SBC cost data collection (start and end dates) should be explicit and of sufficient length to capture costs relevant to the time horizon of the study purpose, and consideration should be given to disaggregating costs into separate time periods where they vary over the timeframe.

\section{Why important}

The time horizon is the length of time over which a costing study will consider the costs and benefits of an SBC intervention. Clearly specifying the time horizon is an important way to ensure that the cost estimate accurately captures costs and benefits of the intervention in a way that is relevant to the purpose of the costing. Disaggregation of costs into time periods may be critical to understanding how costs evolve over time.

\section{Choose a time horizon that appropriately re- flects the purpose of the costing estimation}

If your time horizon is too short, you may miss some key costs that contribute to producing the outcome you are measuring. If the time horizon is too long, you may be unnecessarily including costs and thus overstating the cost of an intervention relative to the outcome the program aims to achieve. The time horizon you choose should be a function of the purpose of the costing estimation.

- For an economic evaluation, choose the time horizon that adequately captures all relevant costs and impacts. For example, SBC interventions that aim at normative change may have a multi-year time horizon. You may have an intervention that lasts a year but continues to produce normative change beyond the one-year mark. You may only need to measure costs associated with the period of the intervention but continue to measure impact far beyond the intervention period. Some of the SBC interventions within the Transmutanian effort that look to improve provider behaviors may fall into this category. For example, a program that tries to improve provider attitudes towards women receiving maternity care may have a short duration, but result in changes in provider attitudes that persist for many years. Similarly, programs that work to change behaviors in young people, by working on social norms around desired family size, may only see an impact many years into the future on childbearing decisions.

- Like costing for economic evaluation, costing done for technical efficiency analysis may similarly have long time horizons, since full impacts may not be felt for several years beyond the actual intervention.

- Costing done for budgeting and financial planning is usually more straightforward, with the time horizon equivalent to the budgeting cycle (typically one year for short-term planning) or the financial planning cycle (typically two years and longer for long-term planning). An example of long-term planning is a strategic plan with a time horizon of five years or more.

\section{When relevant, take into consideration seasonal variation, and justify study timeframes of less than one year.}

Like for any intervention, seasonality may affect the timing and intensity of SBC interventions. In Transmutania, digital and mass media campaigns coincide with peak season for transmission of specific diseases, and around holidays. Spending on other types of SBC interventions in Transmutania also fluctuate with the weather, with more activity in the dry season and a slowdown in the rainy season, when transport becomes more difficult. Thus, the cost analyst in Transmutania tries to measure costs (and impacts) over an entire year, when possible, to smooth out any seasonal fluctuations.

\section{Disaggregate costs at a minimum into the program phases of "start-up" and "implementa- tion."}

Within the time horizon you choose for the costing, it may be important to distinguish between phases such as startup and implementation. Reporting on costs 
for disaggregated time periods will help other analysts compare and use the data from the study. Using a single unit cost for the intervention as a whole may give a misleading picture of intervention cost as a whole and lead to misuse of the unit cost information. For example, in Transmutania officials are planning a new mass media campaign that will unfold in three phases: design, startup, and implementation. Design costs may involve everything having to do with designing the spots (e.g., audience research, human centered design approaches); start-up costs could be all the work involved in producing and placing the spots before any airing. The actual implementation phase will involve the running of the spots on television and radio. The intervention may also comprise phases of treatment or behavior that the analyst will need to disaggregate. For example, an intervention to promote use of pre-exposure prophylaxis (PrEP) for prevention of HIV infection, encompasses activities at initiation, first follow-up, second month follow-up, and sixth month follow-up. Clients at each phase need different kinds of SBC support.
IN MALAWI, ANALYSTS USED A FIVE-

YEAR TIME HORIZON TO MEASURE

COST-EFFECTIVENESS OF BED NET DISTRIBUTION

In a study of the cost-effectiveness of bed net distribution to prevent malaria in Malawi, analysts used a five-year time horizon (1999-2003) (Stevens et al. 2005).

\section{A COSTING OF MEDIA CAMPAIGNS IN EGYPT BROKE DOWN COSTS BETWEEN PRODUCTION COST AND AIRTIME COSTS}

Cost analysis of four different family planning media campaigns in Egypt broke down costs between production cost and airtime costs (Robinson and Lewis 2003). 


\section{周 Resource Use Measurement}

Based on your study design decisions outlined in Principles 1-5, your next step is to measure input (resources) use. The SBC Costing Guidelines put forth the following principles related to resource use measurement:

6 - Scope of the costing

7 - Measuring and allocating resource use

8 - Sampling

9 - Measuring "units" of outputs

10 - Timing of data collection

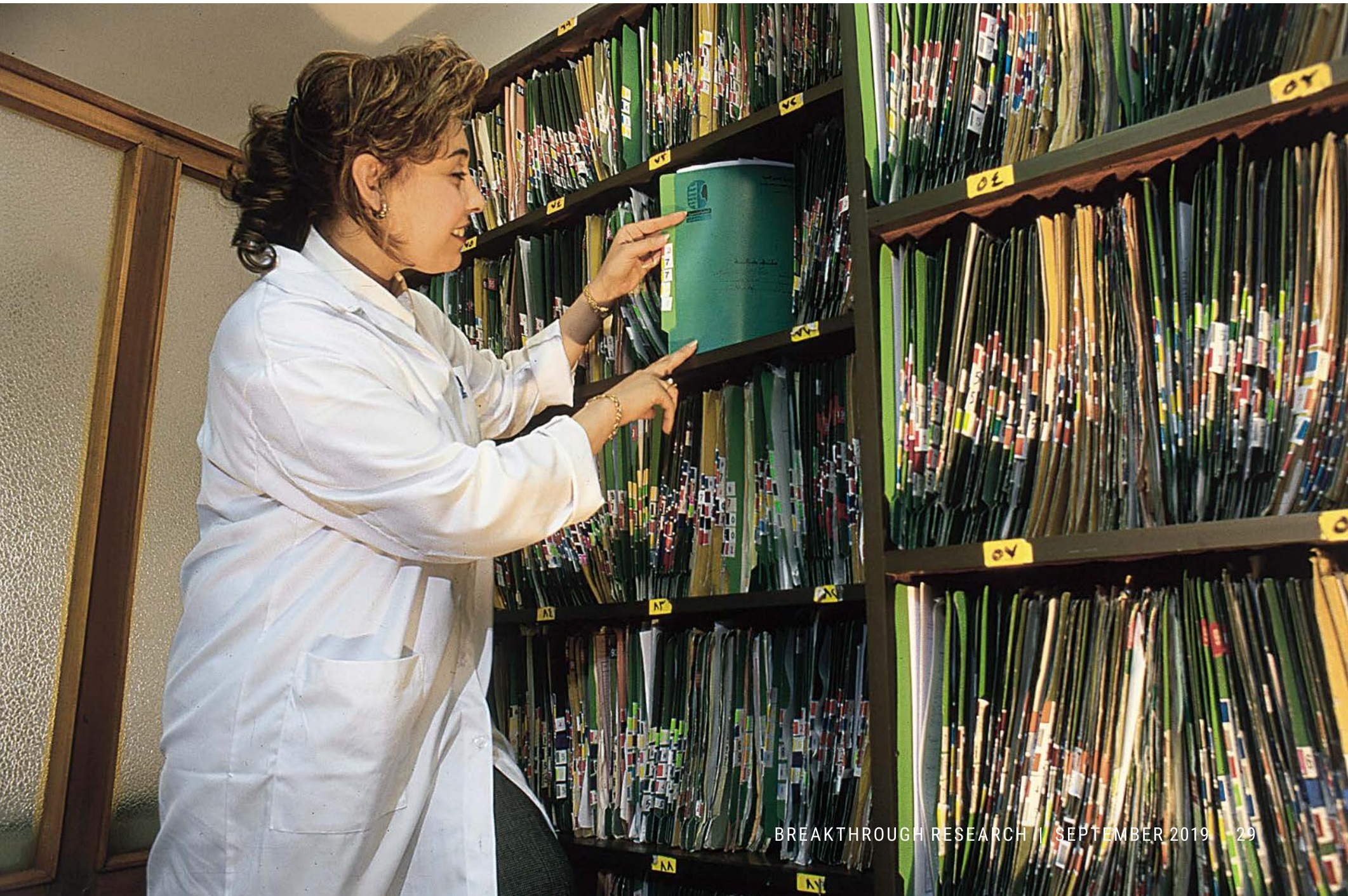




\section{Principle 6 Scope of the costing}

https://ghcosting.org/pages/standards/

principles/resource_use_measurement

https://ghcosting.org/pages/

standards/introduction/

estimating_the_cost_of_health_interven-

tions_an_introduction\#six

\section{The principle}

The scope of the inputs to include in the cost estimation should be defined and justified and relevant to purpose. Where inputs are excluded for pragmatic reasons these should be explicitly reported.

\section{Why important}

Clarity of the scope is necessary for knowing what costs to include or exclude, and for properly comparing costs across settings. SBC efforts have a complex relationship with health service delivery, making it even more important for clarity on the scope of the costing.

\section{Match the scope to the purpose, perspective, time frame, and type of cost being estimated.}

You should cost all inputs relevant to the purpose (Principle 1A, pg 15), perspective (Principle 2, pg 20), type of cost (Principle 3, pg 22), and time frame (Principle 5, pg 27). For example, when the Transmutanian Ministry of Health SBC office is budgeting for next year's activities, it is only interested in the costs that it pays for and thus will exclude cost of volunteer and client time. Similarly, those developing the budget for a mass media campaign will exclude the costs of the volunteer time of the celebrity whose image will appear in the television spots and on billboards promoting the program. However, an analyst carrying out a cost-effectiveness of the same media campaign would measure economic costs and thus value the input that is the celebrity's time.

\section{Report any deviation from the ideal scope, so that others can ascertain bias.}

Sometimes the analyst may need to exclude inputs when the cost in time or money of collecting information on inputs outweighs the benefit in terms of getting a more precise cost estimate. For example, a cost analyst in Transmutania tasked with costing the digital app that supports antiretroviral adherence may desire to cost client time spent using the app, but has no simple way of getting the information on time use by clients, other than through expensive telephone surveys, which are beyond the budget of the costing. You may also know that a program has certain inputs but know, based on previous experience or available information, such as from budgets, that their value is very low compared to others. The additional expense in getting that input may not be worthwhile. It is also okay to exclude entire categories of inputs when, for example, doing a technical efficiency analysis that may focus only on a subset of activities or inputs of an intervention. Those sorts of exclusions are perfectly allowable, but you must report them and reasons for not including, to allow others reading the results to judge the extent to which findings might translate to other settings.

\section{Map the full range of resources associated with production.}

A detailed mapping of the inputs associated with the SBC intervention is a key step that all analysts should undertake. Often, the best way to understand the production process (see "What is a unit cost in the SBC context?," pg 9) is to talk directly to those in charge of the program. As the Social Norms Costing Primer recommends, "Begin a cost analysis by interviewing the groups who are implementing the social norm intervention" (Homan 2016). Where appropriate, a visit by the cost analyst to the physical site where the SBC intervention takes place can provide further insight on the production processes and inputs associated with each phase and activity. The cost analyst tasked with costing the community mobilization program in Transmutania scheduled a visit to three of the districts where the program was taking place, spoke with field staff and community volunteers, toured the sites where community meetings were held, and talked to community members who participated in the meetings.

\section{Include "above-service delivery site" costs in the estimation.}

The GHCC Reference Case strongly urges cost analysts to include what it terms "above-service delivery site" inputs in any cost estimation, and gives examples of these as the inputs required for the "various support services provided by the central administration such as training, education and outreach, demand generation campaigns, and central laboratory services." Applying the concept of 
"site" costs and "above-service" costs to SBC interventions is somewhat challenging. Compared to a service delivery intervention, the concept of the "site" is more amorphous for many SBC interventions. For interventions such as provider behavior change, counseling, and community mobilization that take place in specific physical locations, the concept of "site" applies and is analogous to the physical place where people receive services. However, for other important SBC interventions such as mass media, mid-media, and digital and social media, the "site" analogy does not hold. To better fit the SBC context, these SBC Costing Guidelines define "above-service" costs as those that support the client-facing intervention (which may or may not be a "service" or take place at a "site" per se).

Using the community mobilization program in Transmutania as an example, the "site" for the community mobilization element of the program is the location (communities) where the program takes place. The analyst can then identify inputs associated with site activities, versus those "above-site" support activities at the district, regional, and central level supporting (Figure 4).

A somewhat different conception of site and above-site applies to the digital media campaign that Transmutania is undertaking (Figure 5). The "site" is the digital device

\section{FIGURE 4 SITE-LEVEL AND ABOVE-SITE LEVEL ACTIVITIES OF THE ILLUSTRATIVE COMMUNITY MOBILIZATION INTER- VENTION IN TRANSMUTANIA}

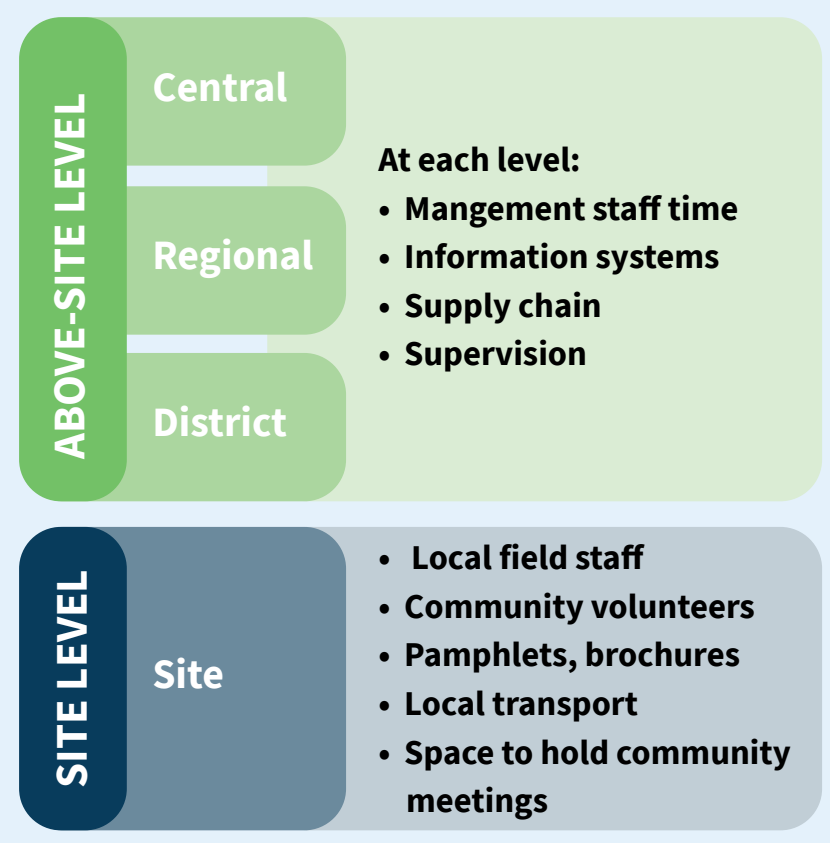

\section{FIGURE 5 SITE-LEVEL AND ABOVE-SITE LEVEL ACTIVITIES OF THE ILLUSTRATIVE DIGITAL MEDIA INTERVENTION IN TRANSMUTANIA}

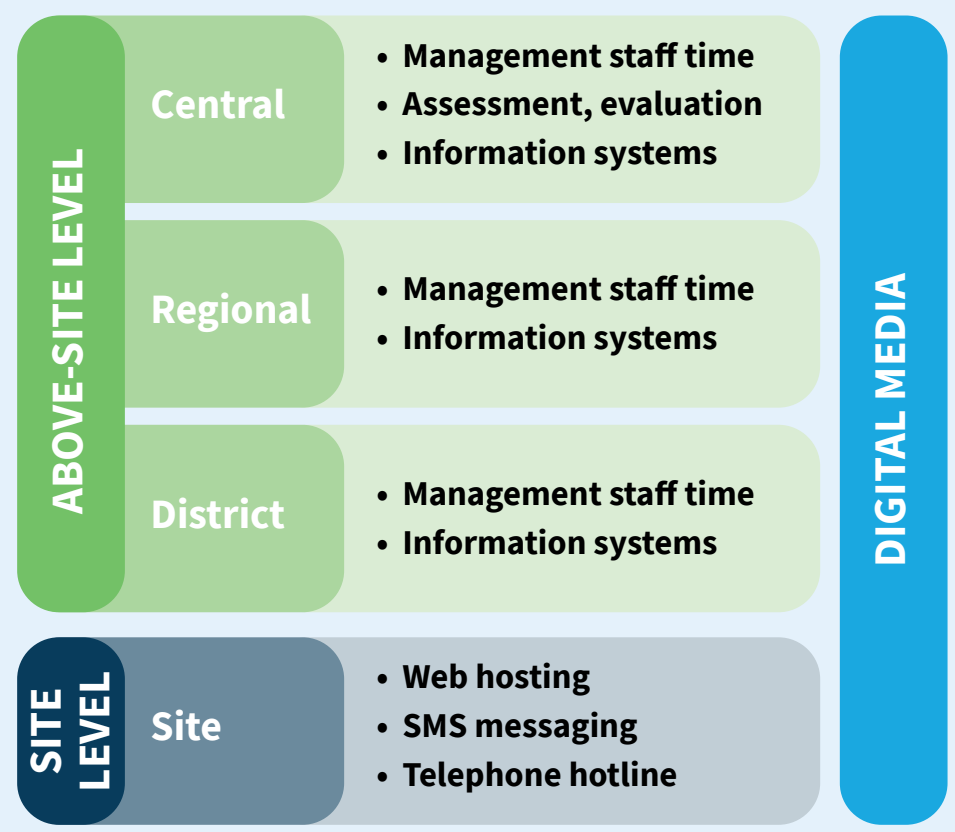

where the client receives the information. What they see immediately is made possible by web hosting, text messaging, and a telephone hotline. "Above-site" costs in this case are the management staff time for program monitoring at district, regional, and central levels;

assessing and evaluating the digital media approach; and the information system put in place to track usage of the digital media campaign.

\section{Clarify the extent to which the cost estimate is incremental.}

If the cost estimate is for economic evaluation, then the correct cost to use is the incremental cost, defined by the GHCC Reference Case as the "difference in cost between two or more interventions or programs, or to compare a change of scale or approach to an intervention to the current provision." Although primarily for economic evaluation, analysts can also use incremental cost for a straight-up estimate of cost differences, without explicitly comparing one intervention with another. It is important then for the cost analyst to state clearly the incremental comparison when they present their analysis. Table 9 provides some simple examples of the types of comparisons the analyst might do. In the first, the analyst might be comparing the cost of adding a community 
TABLE 9 SIMPLE EXAMPLES OF CALCULATING INCREMENTAL COST FOR SBC INTERVENTIONS

\begin{tabular}{|c|c|c|c|c|}
\hline & & COMPARISON & $\operatorname{cost}$ & INCREMENTAL COST \\
\hline \multirow[t]{2}{*}{1} & Intervention & Existing package of SBC interventions + community mobilization component & 1,100 & \multirow{2}{*}{100} \\
\hline & Comparator & Existing package of $\mathrm{SBC}$ interventions & 1,000 & \\
\hline \multirow[t]{2}{*}{2} & Intervention & Existing package of SBC interventions & 1,000 & \multirow{2}{*}{1,000} \\
\hline & Comparator & "Doing nothing" & 0 & \\
\hline \multirow[t]{2}{*}{3} & Intervention & Community mobilization programs with weekly meetings & 120 & \multirow{2}{*}{20} \\
\hline & Comparator & Community mobilization program with monthly meetings & 100 & \\
\hline \multirow[t]{2}{*}{4} & Intervention & Service delivery program + package of SBC interventions & 6,000 & \multirow{2}{*}{1,000} \\
\hline & Comparator & Service delivery program & 5,000 & \\
\hline
\end{tabular}

mobilization component to an existing package of SBC interventions. The new package costs 1,100 compared to 1,000 for the existing package, giving an incremental cost of 100. Another study could be measuring the cost of an SBC package (without the community mobilization component) versus doing nothing, in which case it would yield an incremental cost of 1,000. In the third example, the analyst is looking only at community mobilization efforts, comparing the cost of weekly versus monthly meetings, yielding an incremental cost of 20. The fourth example shows how the analyst might be looking at the incremental cost of adding an SBC package to an existing service delivery intervention, resulting in an incremental cost of 1,000 . 


\section{ANALYSTS MEASURED THE COST OF SEPARATE PROGRAM COMPONENTS IN HONDURAS}

Costs analysts compared contraceptive social marketing and community-based distribution programs in Honduras, analyzing the cost of separate program components, including the publicity/information, education, communication/promotion components of the overall program (Janowitz et al. 1992).

\section{ANALYSTS OF A REPRODUCTIVE HEALTH TRAINING PROGRAM IN KENYA EXPLAINED WHICH COSTS THEY} INCLUDED AND EXCLUDED

A costing of supervisor training to improve reproductive health service quality in Kenya included personnel costs, transportation, venue, mailings, materials, and supplies. The analysts excluded cost of participant time, although they acknowledged that valuing participant time might become important in a scenario in which the Ministry of Health takes over training for scale up. The costing also excluded costs associated with development of the training package, on the grounds that the package had already been developed and was being replicated in its existing form. The analysis also excluded research costs (Reynolds et al. 2008).

\section{ANALYSTS OF AN INTRAUTERINE DEVICE (IUD) PROMOTION EFFORT IN KENYA EXCLUDED RESEARCH, START-UP, AND MOH SALARY COSTS FROM THEIR CALCULATION}

In a study of a program to promote IUD use in Kenya, the analysts excluded research and startup-related costs since they were only interested in knowing what the costs would be for replication of the intervention. They also excluded salary cost for Ministry of Health staff on the assumption that such staff would carry out the intervention as part of their normal supervisory duties (Wesson et al. 2008).

\section{ANALYSTS OF A BED NET PROMOTION CAMPAIGN IN CAMEROON INCLUDED ABOVE-SITE COSTS IN THEIR CALCULATIONS}

To capture the cost of the social marketing campaign to encourage bed net use in Cameroon, analysts included a number of "above-site" costs, including support staff in-country and in the U.S., in-country and international travel, country office overhead, and monitoring and evaluation (Bowen et al. 2013).

\section{ANALYSTS OF A VASECTOMY CAMPAIGN IN BRAZIL CALCULATED INCREMENTAL COSTS}

Cost analysts looking at the costs and effectiveness of vasectomy demand creation campaign in Brazil only looked at the additional cost of the campaign (not the service delivery cost) and calculated an incremental cost-effectiveness ratio of $\$ 53$ per visit to a clinic and $\$ 93$ per vasectomy (Kincaid 1996). 


\section{Principle 7}

\section{Measuring and allocating resource}

\section{use}

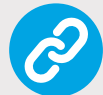

\section{https://ghcosting.org/}

pages/standards/principles/

resource_use_measurement\#three

\section{The principle}

The methods for estimating the quantities of inputs (resources) should be described, including data sources, criteria for allocating shared costs, and exclusion of research costs.

\section{Why important}

The better and more appropriate your methods are for measuring the use of inputs you identified as within the scope of your costing, the more accurate your cost estimate will be. The GHCC Reference Case is agnostic on the "best" input measurement techniques. That is partly because "best" depends on many factors, not least of which is what you are trying to achieve with the costing, how much time and money you have available to cost, and the relative weight of the various inputs in the total cost of the intervention. Since each costing and each intervention is unique, there will not be a single answer to the question of what measurement technique is best.

\section{Use a combination of methods that include both gross and micro-costing approaches.}

The two broad approaches to costing are gross costing and micro-costing. The GHCC Reference Case defines gross costing as a process by which input use is estimated in total, whereas micro-costing is when the analyst aims to estimate the usage of each input separately. Micro-costing of SBC interventions is generally more comprehensive and less likely to result in an underestimate of costs, but gross costing may be appropriate in situations where micro-costing is not feasible.

\section{Be explicit about the method you use to allocate "joint" or shared inputs.}

Some of the more important decisions you may have to make as a cost analyst of an SBC intervention are how to allocate "joint" or "shared" inputs. A joint cost is a production cost incurred in creating two (or more) products. Many "above-site" costs are from joint inputs. For example, the regional health managers in Transmutania spend their day managing the overall functioning of health activities in the region. They may not do anything specific to the SBC intervention, but their overall management helps the SBC intervention to operate successfully. The regional manager's time is a joint cost that the analyst needs to determine how to allocate to the SBC intervention. Typically, one allocates such costs using an estimate of the weight of the SBC intervention in the overall activities of the region. For example, if the direct costs of the SBC intervention account for 10 percent of direct costs of all activities in the region, one would allocate 10 percent of the regional health manager's time to the SBC intervention. Another approach would be to interview the regional manager and ask them what proportion of their time they spend managing the SBC intervention. That may be difficult for them to answer if their activities have more to do with overall regional management versus management of a specific program. Another example is when a health worker spends their time on multiple activities. To measure the amount of time they spend on the SBC intervention, one could ask them to keep a log of their work, ask them to recall what they spent their time on, or use a similar allocation process based on some measure of the weight of the SBC intervention in the overall activities they carry out. The different approaches represent examples of "bottom-up" versus "top-down" methods of allocating joint costs. There is no "best" approach.

\section{Pay careful attention to methods used to mea- sure human resources costs.}

People are usually the biggest cost of any SBC intervention, so think hard about the way you plan to measure their cost. The costing literature is replete with methods for measuring human resource use including interviews, surveys, direct observation, and time logs. ${ }^{9}$

${ }^{9}$ For more information on tradeoffs in terms of data quality and other considerations, see for example, Appendix 7 in DeCormier Plosky, Kripke, Bollinger, and Forsythe (2018) PrEP Costing Guidelines, (https://www. prepwatch.org/wp-content/uploads/2019/01/)OPTIONS_PrEP_Cost_ Guidelines_Dec2018.pdf. Also, table on pg 5 in Homan, R. (2016) “Costing 


\section{Focus measurement efforts on those inputs likely to have the greatest impact on total cost.}

Before deciding on a measurement strategy, it is a good idea to consider which inputs are likely to have the greatest impact on total cost. SBC interventions vary a lot, so it is hard to generalize about which components make up most of costs. For most health interventions, personnel is the biggest cost, but personnel has less weight in mass media programs that spend relatively more on air time, for example. You can use your knowledge about similar interventions or review intervention budgets to focus your data collection and analysis efforts on those major cost drivers.

\section{Clearly identify any inputs associated with in- tervention research.}

Often cost analysts will undertake a cost estimate in a research context. With respect to the research activities associated with the intervention, analysts of SBC interventions should follow guidelines similar to those for other types of interventions. If you collect information on research inputs and their costs, be sure to describe such inputs clearly and present them separately from the intervention cost estimate. Use input prices for inputs that will be used in real life rather than input prices in the research trial. Be very clear about delineating what is "research" and what is "implementation," using your judgement about how organizations will implement the intervention in the real world. Be sure to identify costs of any adjustments made to the intervention design for research purposes. Take into account, if relevant, differences in efficiency between research sites and sites where the implementation will eventually take place.

\section{ANALYSTS IN THE PHILIPPINES TOOK A} GROSS COSTING APPROACH

To measure cost-effectiveness of a mass media family planning campaign in the Philippines, analysts took a gross costing approach, and used the cost of the campaign subcontracted to a local advertising agency as the numerator in the cost-effectiveness calculation (Kincaid et al. 2006).

\section{ANALYSTS IN BANGLADESH APPORTIONED JOINT COSTS BASED ON SERVICE TIME AND VOLUME OF PRODUCTION}

An analysis of the "doorstep" family planning and maternal child health program in Bangladesh, which includes an SBC component of information, motivation, and counseling to couples during home visits, apportioned joint costs such as salary of administrative and support staff based on how service providers allocated their time to the different family planning and maternal child health services and the volume of production of each of those services (Routh et al. 2000).

\section{A STUDY IN BANGLADESH USED LOGBOOK INFORMATION TO ESTIMATE WORKER TIME}

In a study of family planning fieldworkers and clinic staff in Bangladesh, cost analysts used prospective data from workers' logbooks to construct a monthly work pattern and calculate the number of days spent on different activities, including home visits. They complemented this information on time use with surveillance of workers and observational studies at clinics (Janowitz et al. 1997).

\footnotetext{
of social norm interventions: a primer from the passages project." Washington, D.C.: Institute for Reproductive Health, Georgetown University for the U.S. Agency for International Development (USAID). Available at: http://irh.org/wp-content/uploads/2016/10/Costing_ Social_Norm_Interventions_Passages.pdf
} 


\section{Principle 8 \\ Sampling}

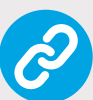

https://ghcosting.org/

pages/standards/principles/

resource_use_measurement\#four

\section{The principle}

The sampling frame, method, and size should be determined by the precision demanded by the costing purpose and be designed to minimize bias.

\section{Why important}

For some SBC interventions, the cost analyst may be able to collect available cost data on all inputs without resorting to sampling. Mass, digital, and social media campaigns that have costs concentrated at the central level lend themselves to complete cost collection. However, for other types of SBC interventions such as community engagement and interpersonal communication, sampling may be the only practical way to collect costs. There is no "best" way to sample for costs. The nature and scope of the intervention will largely determine whether you need to sample costs and what type of sampling strategy you will need to undertake. Three important considerations are the sampling frame, the sample method, and the sample size.

\section{Begin sampling with a recent, accurate, and complete sampling frame.}

The sampling frame is simply the list of sites or population from which to take the sample. If the costing were examining the counseling intervention, you would start with the list of all facilities or sites where counseling takes place. The sampling frame for a costing of a community mobilization effort similarly would list all communities hosting the intervention. Program records or official facility lists from health ministries are often the best source to construct the frame.

\section{Choose an appropriate sampling method.}

The GHCC Reference Case cautions against using a convenience sample, advocating for a random approach or stratification (e.g., by facility type, or by urban/rural). Nonetheless, political considerations or resource constraints may limit the analyst to a convenience sample. See the GHCC Reference Case and resources such as Appendix 8 in the PrEP Costing Guidelines for more on sampling methods.

\section{The more sites you include in the costing, the better.}

The GHCC Reference Case does not recommend specific sample sizes for costing, in part because statistical techniques for interpreting sampled cost data remain underdeveloped. It does, however, counsel using larger samples when feasible, acknowledging the observed wide variation in costs from one site or one program (such as mass media, that does not take place at a site) to another. The cost can vary by sites due to many factors (such as type of facility, the volume served, the services offered, type of staff, and type of population servedsome are much harder to reach). The number and type of sites sampled also relates to the purpose of the study. If you are simply surveying more facilities of the same type, that may not answer the question about how cost varies by platform (facility vs. mobile platform versus community outreach) or by type of client served.

ANALYSTS USED RANDOM SAMPLING
TO SELECT FACILITIES FOR INCLUSION
IN A COST-EFFECTIVENESS ANALYSIS IN
RWANDA
A cost-effectiveness analysis of the integrated
family planning and immunization services in
Rwanda randomly selected 14 public health
facilities from a national sampling frame, and
then randomly allocated seven facilities to the
intervention group and seven to the control
group (Dulli et al. 2016).




\section{Principle 9}

\section{Measuring "units" of outputs}

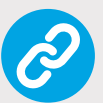

https://ghcosting.org/

pages/standards/principles/

resource_use_measurement\#five

\section{The principle}

The selection of the data source(s) and methods for estimating the "units" for unit costs should be described and potential biases reported in the study limitations.

\section{Why important}

Units constitute the denominator in the unit cost calculation. Good measurement is important to provide accurate estimates of units and thus of unit costs. Although it is beyond the scope of this guide to discuss in-depth measurement of units, we can articulate some general principles that will apply. Appendix 1 contains references to additional resources on general evaluation of SBC interventions that discuss measurement of units.

\section{Use the method of data collection that best gets the information you need on units.}

As the principle itself implies, there is no single "best" way to measure units for SBC interventions (or for any other interventions); it depends on the type of unit you want to measure, available information systems, and trade-offs between accuracy and cost of data collection. The first thing to remember from the discussion in the introductory section on what constitutes "units" for SBC interventions is that units are disaggregated by activity, service, and intervention. As we saw in our example from Transmutania (see Principle 4, pg 25), each of the interventions had different units associated with each type of disaggregation. Table 10 summarizes the suggested method of data collection, by level or type of unit. You can often find information on activity units through program records and reports. You can often find information on service units via logbooks, service statistics systems, supervisory reports, and program reports. For intervention units, you may have to rely on national, regional, or local sample surveys with members (preferably a representative sample) of the intended audience, service statistics, supervisory reports, and web statistics. 
TABLE 10 METHODS TO COLLECT DATA ON "UNITS"

\begin{tabular}{|c|c|c|c|}
\hline $\begin{array}{l}\text { INTERVENTION } \\
\text { TYPE }\end{array}$ & UNITS LEVEL & ILLUSTRATIVE UNITS & $\begin{array}{l}\text { METHOD OF DATA } \\
\text { COLLECTION }\end{array}$ \\
\hline \multirow{3}{*}{$\begin{array}{l}\text { IPC and } \\
\text { counseling }\end{array}$} & Activities & & Program records \\
\hline & Services & \# counseling sessions & $\begin{array}{l}\text { Logbooks } \\
\text { Service statistics } \\
\text { Report review }\end{array}$ \\
\hline & Intervention & \# people reached with counseling & $\begin{array}{l}\text { Service statistics } \\
\text { Supervisory reports }\end{array}$ \\
\hline \multirow{3}{*}{$\begin{array}{l}\text { Community } \\
\text { mobilization }\end{array}$} & Activities & & Program records \\
\hline & Services & \# community meetings & $\begin{array}{l}\text { Service statistics } \\
\text { Program reports }\end{array}$ \\
\hline & Intervention & $\begin{array}{l}\text { \# communities mobilized via community mobilization efforts } \\
\text { \# of community members reached through community mobilization }\end{array}$ & $\begin{array}{l}\text { Service statistics } \\
\text { Program reports } \\
\text { Surveys }\end{array}$ \\
\hline \multirow[t]{3}{*}{ Mass media } & Activities & \# media campaigns designed & Program records \\
\hline & Services & \# of media spots aired & Program logbooks \\
\hline & Intervention & \# persons reached via mass media campaign & $\begin{array}{l}\text { Population survey of } \\
\text { intended audience }\end{array}$ \\
\hline \multirow[t]{3}{*}{ Digital media } & Activities & \# of social media campaigns & Program reports \\
\hline & Services & \# of downloads of material & Server records \\
\hline & Interventions & \# of persons reached via social media & $\begin{array}{l}\text { Population survey } \\
\text { Web statistics }\end{array}$ \\
\hline
\end{tabular}

\section{ANALYSTS OF FAMILY PLANNING MASS}

MEDIA IN EGYPT REPORTED THREE

DIFFERENT UNIT COSTS

Cost analysts reported unit costs for four different family planning media campaigns in terms of cost per airing of the television program or longer 15-20 dramatized presentations (the service unit cost), cost per person reached (the intervention unit cost), and cost per single-client exposure (the quality-adjusted intervention unit cost) (Robinson and Lewis 2003). 


\section{Principle 10}

\section{Timing of data collection}

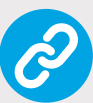

https://ghcosting.org/

pages/standards/principles/

resource_use_measurement\#timing

\section{The principle}

Consideration should be given to the timing of data collection to minimize recall bias and, where relevant, the impact of seasonality and other differences over time.

\section{Why important}

Princple 5 (pg 27) discussed the importance of choosing an appropriate time horizon for the costing study. This section discusses principles around the timing of cost data collection within the time period selected. Timing of data collection may significantly affect the accuracy of the estimate, so you need to take into account several factors when considering when and how to capture SBC intervention costs.

\section{Consider whether retrospective or prospective data collection is most appropriate}

Cost analysts often face the choice of collecting data prospectively, from the beginning of the intervention, or retrospectively, looking backward. The GHCC Reference Case does not recommend one side over the other, conceding that this often is a judgement call. Similarly, Homan (2016) points out that each approach has its advantages and disadvantages. In Transmutania, the SBC cost analyst asked the paid field staff of the community mobilization project and other paid project personnel to maintain, from the beginning of the intervention, a daily log of the time they spend on the different aspects of the program. This request was justified given the importance of personnel costs in the overall cost of the community mobilization program. On the other hand, the cost analyst decided it would be intrusive and overly time-consuming to ask that community volunteers undertake a similar prospective collection of data on time use. Thus, the cost analyst decided to interview the community volunteers at the 6 - and 12-month marks of the community mobilization program, retrospectively asking them to recall how much time they spent organizing and attending community meetings over the previous six months. Retrospective cost data collection may also be more practical when the intervention maintains good records that allow tracking of resource use and expenditures.

\section{Consider whether costs will evolve over time}

As noted in the discussion in Principle 5 (pg 27) on the timeframe of cost data collection, collecting and reporting on cost at different phases of an intervention can be critical. This is especially true when an intervention changes substantially over time. For example, the digital media campaign in Transmutania was designed using human-centered design principles, and the government implemented it using an "adaptive management" approach in which it used frequent feedback from users to tweak the way the application interacted with digital users, resulting in substantial changes in costs over the first year of the intervention.

\section{Consider recall period from interviews}

The GHCC Reference Case cautions against using recall periods that are too long, such as not waiting too long before asking health workers and other intervention personnel to recall how much time they may have spent on an activity, or what inputs the intervention consumed for a particular activity or process. Although the GHCC Reference Case states that the analyst should justify any recall period longer than three months, this is again often a judgement call of the analyst, who must weigh the cost of data collection against the potential harm to the accuracy of the data collected as the recall period lengthens.

\section{Consider seasonality of the intervention when developing a cost data collection plan}

Timing of data collection should consider seasonality. Because the digital and mass media campaigns in Transmutania coincide with peak season for transmission of diarrheal disease and malaria ("When relevant, take into consideration seasonal variation, and justify study timeframes of less than one year," pg 27), the planned data collection needs to be adjusted accordingly.

\section{Consider the frequency of data collection}

The GHCC Reference Case does not make a definitive statement about what an appropriate frequency of data collection is. The time horizon and intervention structure (whether it is a new intervention or one that has been operating for a while) will dictate frequency of data collection, another judgement call the analyst must make. 
Analysts costing HIV prevention for high-risk groups in India collected costs prospectively over a five-year period (Chandrashekar et al. 2014).

ANALYSTS OF A PROGRAM IN RWANDA

EXCLUDED START-UP COSTS FROM THEIR UNIT COST CALCULATION

The cost analysts looking at the introduction in Rwanda of an integrated Health Belief Model to encourage family planning use during immunization visits reported the cost per woman fully exposed to the intervention excluding start-up costs like training and materials development (Dulli et al. 2016). 
Once you have identified and measured inputs, your next steps are to put a value on them, as outlined in Principles 11-14.

11 - Sources of price data

12 - Valuing capital inputs

13 - Discount, inflation, and currency conversion rates

14 - Using shadow prices

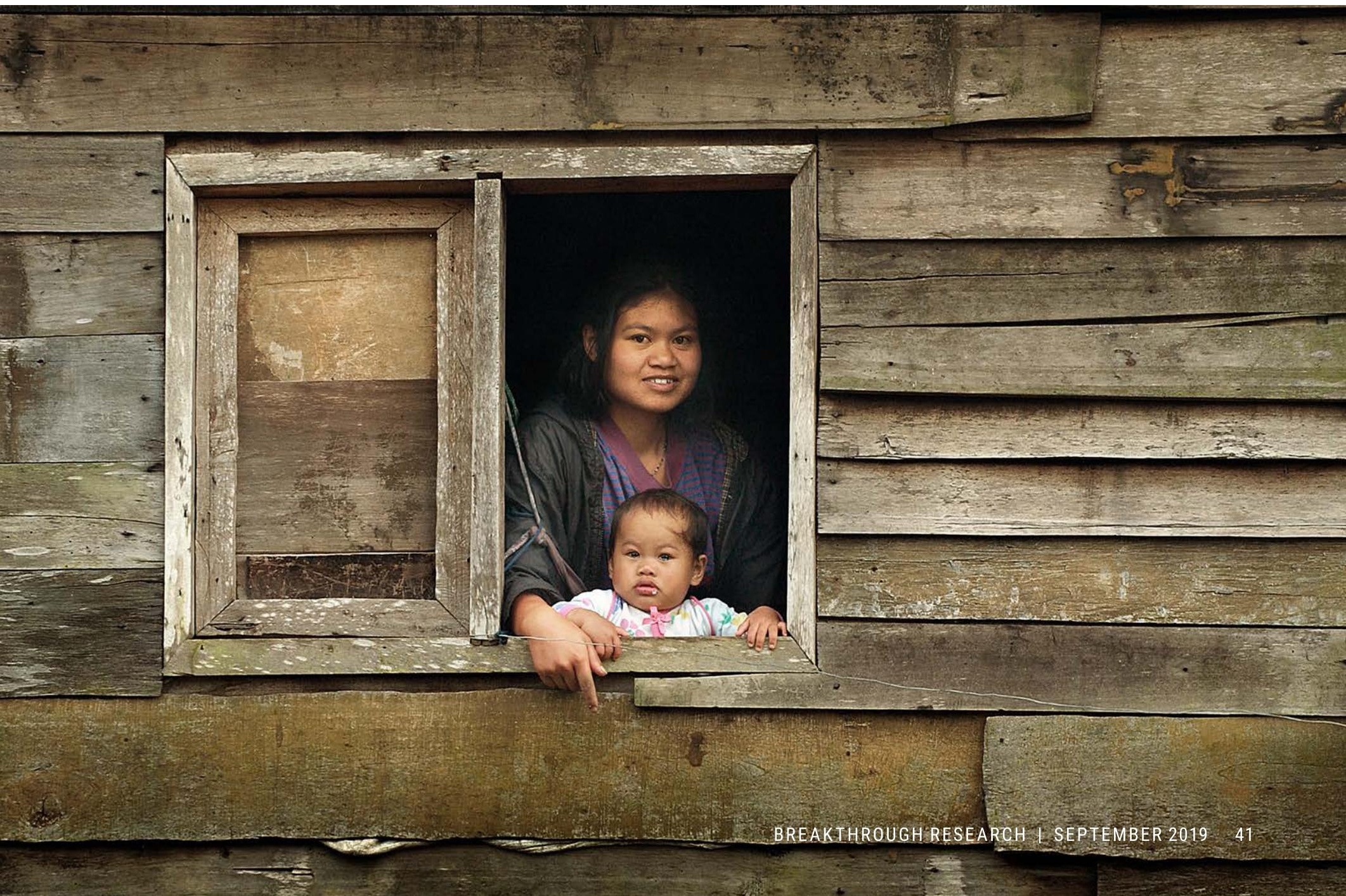




\section{Principle 11 Sources of price data}

https://ghcosting.org/pages/standards/ principles/pricing_and_valuation

\section{The principle}

Sources of price data should reflect the price relevant to the purpose of the SBC costing and be described in a way that allows for adjustment across settings.

\section{Why important}

As "What is a unit cost in the SBC context?" (pg 9) notes, cost analysts consider the price of something as the "input unit cost" or the cost of one specific input. Prices thus are things like the cost of a minute of a health worker's time, or the cost of one poster used for community mobilization, or the cost of a bus ride for a community volunteer to attend a community meeting, or the cost of a one-minute television spot. Knowing the source for prices, as well as which prices a cost estimation uses, is critical in allowing the users of the cost estimate to interpret the results appropriately and to apply the cost estimate to other settings, as necessary and appropriate.

\section{Align price data with the purpose of the costing}

The purpose of the study largely determines pricing strategies.

Budgeting and price-setting. With a time horizon for budgeting of generally one year, the cost analyst is typically safe in using current prices of the various inputs in their calculations. Analysts typically look to budgets, program records, and accounting systems for prices. As much as possible, analysts should draw on local sources of information for prices. However, it may be desirable (and less costly) to draw on prices from other countries, particularly when budgeting for a new intervention.

Financial planning. Financial planning can extend anywhere from 2 to 10 years or more, meaning the cost analyst may have to consider potential future changes in input prices. For example, many programs operate initially using subsidized commodities. For planning purposes, a commodity that may be free or very low cost initially may eventually become a large proportion of a budget once the program removes the subsidy. Typically, service delivery programs, not SBC interventions, find themselves in this situation. The analogy for SBC interventions is when an intervention is currently getting free volunteer time that may in the future cost them something. The Transmutania program, for example, may use volunteers for now but eventually have to start paying those community volunteers as pressure increases to adequately compensate community members for their time operating the program.

Economic evaluation. As discussed under Principle 3 in "Define if the cost is financial or economic" (pg 22) an economic evaluation requires the cost analyst to calculate the economic costs of inputs. The price should reflect opportunity cost. Principle 14 ("Using shadow prices," pg 48) addresses this in more detail.

Technical efficiency analysis. The efficiency analysis will typically use financial cost, meaning drawing on expenditure records.

See Appendix 3 for more information on sources for prices of SBC inputs.

\section{Distinguish local from international price sourc- es, and tradable from non-tradable inputs.}

It is important for the analyst, when reporting prices, to distinguish between prices for non-tradable and tradable inputs. Non-tradable inputs are those that cannot readily move from one setting to another, like staff. Non-tradable inputs will have only local prices, leading to price estimates that can vary widely between countries for the same input. Tradable inputs are those that can readily cross country borders, such as drugs, equipment, vehicles, and supplies. Tradable inputs will have an international and a local price. Reporting on which price the analyst used will allow better transfer of cost estimates across countries (see Principle 13, pg 46). Table 11 shows how SBC intervention inputs are typically classified. 
TABLE 11 TYPICAL CLASSIFICATION OF SBC INTERVENTION INPUTS AS TRADABLE OR NON-TRADABLE

\begin{tabular}{|lll|}
\hline INPUT TYPE & $\begin{array}{l}\text { NON-TRADABLE } \\
\text { INPUTS }\end{array}$ & TRADABLE INPUTS \\
\hline Personnel & $\begin{array}{l}\text { Management and } \\
\text { field staff, community } \\
\text { volunteers }\end{array}$ & $\begin{array}{l}\text { International, } \\
\text { specialized design } \\
\text { personnel, such as } \\
\text { those who work on } \\
\text { developing media } \\
\text { campaigns, digital } \\
\text { media, etc. }\end{array}$ \\
Other & $\begin{array}{l}\text { Utilities; fuel and } \\
\text { maintenance for }\end{array}$ & \\
& $\begin{array}{l}\text { vehicles; local trans- } \\
\text { portation cost; hotel } \\
\text { accommodations; }\end{array}$ & \\
& $\begin{array}{l}\text { food and restaurant } \\
\text { costs }\end{array}$ & \\
Capital & Buildings & \\
\hline
\end{tabular}

For Transmutania, what are examples of tradable goods for which the cost analyst might seek an international price? The Transmutania community mobilization program uses many four-wheel drive vehicles to transport staff from headquarters to communities for supervision and to run events. One could apply a local cost to the vehicle, including taxes, shipping, and other fees. The government might charge a tariff of 100 percent on the cost of importation, essentially raising the local cost from $\$ 25,000$ to $\$ 50,000$. You report the price as $\$ 50,000$. An analyst carrying out a costing in another country may mistakenly use that price of $\$ 50,000$, even though their country's government charges only a 10 percent tariff on vehicles imports, meaning its price is only $\$ 27,500$ $(\$ 25,000+\$ 2,500)$. Either way, the analyst should identify whether it is a local or international price.
ANALYSTS OF A BED NET DISTRIBUTION

PROGRAM IN MALAWI PRESENTED COST IN BOTH LOCAL CURRENCY AND US DOLLARS

In a study of the cost-effectiveness of bed net distribution to prevent malaria in Malawi, analysts measured costs in a combination of local currency (Malawi kwacha) and in US dollars, depending on whether the program purchased the resources locally or overseas. The analyst then translated all costs to US dollars on the kwacha-dollar exchange rate for the midpoint of the year of the study (Stevens et al. 2005). 


\section{Principle 12 Valuing capital inputs}

(2) https://ghcosting.org/pages/standards/ principles/pricing_and_valuation\#three

\section{The principle}

Capital input prices should be appropriately annuitized or depreciated to reflect the opportunity cost of capital inputs over the relevant timeframe.

\section{Why important}

Capital inputs are those with a useful life of greater than one year. Most people think of capital in terms of large, solid items like buildings, vehicles, and computers. However, capital can also encompass non-equipment inputs like training, start-up costs, and intervention design. What the cost analyst identifies as capital costs, how the analyst assigns a useful life, and how the cost analyst spreads the cost of capital inputs over its useful life can make a big difference on the overall total cost and intervention unit cost of an SBC intervention.

\section{Identify which of the inputs are capital costs and assign them a useful life}

As a first step, the cost analyst should identify those inputs that qualify as capital costs. The word "capital" brings to mind obvious items like buildings and large pieces of equipment like vehicles, medical equipment, billboards, etc. In fact, the most important capital inputs for SBC interventions are not likely to be such visible items but rather other things (intangibles) like licenses, software, design, training, and other startup costs that are really agglomerations of other inputs. SBC interventions vary greatly, and thus the types of capital inputs typically included also vary. Rules of thumb exist for assignment of useful life to things like buildings (20-30 years); furniture (10 years); vehicles (5 years); and computers (3 years). However, countries typically have their own cost accounting guidelines that specify useful life for different classes of capital inputs. By contrast, little guidance exists for setting useful life for non-equipment, intangible capital goods.
Intervention design potentially plays a big role in SBC intervention cost. This may be even more the case as agencies use techniques such as human-centered design and adaptive management techniques in the design and implementation of interventions. ${ }^{10}$ New types of interventions within digital and social media tend to have low implementation costs relative to design. This is certainly the case in Transmutania, where the cost analyst would be remiss to not include such design costs in their estimate. Much of the cost of a digital behavior change intervention may be in the design of the app that people use rather than in the use of the app itself. Little guidance exists on assignment of useful life to design inputs, so the cost analyst must use their judgement to determine how long the program/intervention will operate before the design is outdated.

Training can also be a major capital input. The cost analyst will typically need to distinguish between training that is part of the start-up phase (and thus considered a capital cost) and training that may be part of the implementation of the intervention itself. Regardless, training can only be considered a capital cost if the training has a useful life (that is, is useful to the production process, or what the intervention is trying to produce) beyond a year. If the effect of the training only lasts a year or less, then the analyst should classify it as recurrent. Assigning useful life will depend on the "expiration date" of the training-when it will be outdated-and when refresher training may have to take place, or if there is high staff turnover requiring training of new staff.

Television and radio spots are capital costs if they have a useful life of greater than a year. Similar to intervention design, there is little guidance on how to assign useful life to television, radio, and other mass media designs. Again, the analyst will have to use judgement about how many years the spots might be expected to run before they become outdated. In Transmutania, the mass media program produced spots that ran for a year, and then continued to rerun the spots for another two years, before they became outdated. The spots then become a capital cost with a useful life of three years. Similarly, materials like posters or billboards that have a useful life of over a year are capital costs, and the analyst will

${ }^{10}$ See USAID (2018) Discussion note: adaptive management. https:// usaidlearninglab.org/sites/default/files/resource/files/dn_-_adaptive_ management.pdf 
have to apply similar considerations to useful life to their design and deployment in the program before they need replacement.

\section{Use depreciation or annualization depending on whether the SBC cost estimate requires a finan- cial or economic estimation}

To decide on the appropriate way to spread the capital cost across its useful life, the analyst will first need to decide whether it is a financial or economic cost (see "Define if the cost is financial or economic," pg 22). Guidance from the GHCC Reference Case is to use straightline depreciation for financial costs (divide the input price by the years of useful life) and to use amortization (or annualization) for economic costs. Amortization uses a default 3 percent discount rate (see "Use the appropriate discount rate" [pg 46] for more on how to set an appropriate discount rate) to account for the opportunity cost of using the capital input in the program. Many guides include tables for calculating amortization. ${ }^{11}$

\footnotetext{
${ }^{11}$ See Appendix 9 in DeCormier Plosky, Kripke, Bollinger, and Forsythe. (2018) PrEP Costing Guidelines. Durham, NC: Avenir Health, for the Optimizing Prevention Technology Introduction on Schedule (OPTIONS) Consortium. Available at: https://www.prepwatch.org/wp-content/ uploads/2019/01/OPTIONS_PrEP_Cost_Guidelines_Dec2018.pdf
} 
Principle 13

\section{Discount, inflation and currency conversion rates}

\section{(2) https://ghcosting.org/pages/standards/ principles/pricing_and_valuation\#four}

\section{The principle}

Where relevant, appropriate discount, inflation, and currency conversion rates should be used to adjust prices to estimate the cost for other settings and time periods.

\section{Why important}

Prices are specific to a setting and time, and subject to assumptions about the present versus the future value of costs and benefits of an intervention. Thus, being clear about the assumptions the cost analyst uses for discounting, inflation, and currency conversion will make it much easier for those using the results to compare prices and ultimately costs across countries and between one year and another.

\section{Use the appropriate discount rate}

As cost analyst, you may have two opportunities to "discount" prices or costs. The first we mentioned above-a discount rate to properly annualize capital costs when calculating the economic cost of a capital input (Principle 12 , pg 44). The GHCC Reference Case recommends applying a 3 percent annual discount rate for international comparison as well as a local discount rate. In addition, you should choose a local discount rate equal to the rate at which the national government can borrow funds on the international market. The 3 percent rate is applicable when making comparisons of the results in your country with results in other countries. Use the local discount rate when you want to make comparison to relevant interventions within the country. Dr. Allen, the cost analyst carrying out the cost-effectiveness analysis in Transmutania, sets the discount rate at 6 percent, equal to the rate that the Transmutanian Treasury borrows on the international market (12 percent) less the 6 percent annual inflation rate.

\section{Use appropriate price indices to adjust prices across time}

The price of any input can only be properly interpreted by placing it in a specific point in time. The analyst must be consistent in using input prices that apply to the same period. However, price data may come from different periods. The way to address this is to adjust prices using price indices (Table 12). The price index to use depends on whether the input is a non-tradeable local input or a tradable international input (for more on these inputs, see "Distinguish local from international price sources, and tradable from non-tradable inputs," pg 42). For non-tradeable local inputs (like local staff time), use the country's gross domestic product (GDP) deflator or consumer price index (CPI). For tradeable inputs, the best approach is to use, when feasible, price indices for the specific input (international labor; medicines, etc.). Where such information is not available, you can use the U.S. GDP deflator as a proxy for international price index.

\section{Use appropriate currency conversion rate to express results in both local currency and US dollars}

The GHCC Reference Case recommends that the analyst present cost estimates in both local currency and US dollars, as a way to reach local and international audiences with the study results. You may want to present estimates in other currencies (for example, the currency

\begin{tabular}{|c|c|c|}
\hline INPUT TYPE & $\begin{array}{c}\text { PRICE } \\
\text { ADJUSTMENT } \\
\text { METHOD }\end{array}$ & SOURCE \\
\hline \multirow[t]{2}{*}{$\begin{array}{l}\text { Non-tradeable } \\
\text { (e.g., local } \\
\text { staff, land) }\end{array}$} & $\begin{array}{l}\text { Local gross } \\
\text { domestic product } \\
\text { deflator }\end{array}$ & $\begin{array}{l}\text { Central bank } \\
\text { websites }\end{array}$ \\
\hline & $\begin{array}{l}\text { Local consumer } \\
\text { price index }\end{array}$ & \\
\hline \multirow[t]{2}{*}{ Tradeable } & $\begin{array}{l}\text { Input-specific price } \\
\text { index or price } \\
\text { databases }\end{array}$ & $\begin{array}{l}\text { Varies depending on the } \\
\text { input }\end{array}$ \\
\hline & US GDP deflator & $\begin{array}{l}\text { US Bureau of } \\
\text { Economic Analysis } \\
\text { https://www.bea.gov/ } \\
\text { data/prices-inflation/ } \\
\text { gdp-price-deflator }\end{array}$ \\
\hline
\end{tabular}


of the country that may be donating funds to the SBC intervention or that has commissioned the cost estimate). The analyst should specify the "currency year," that is the year to which the prices correspond. When converting from local to US dollars, the analyst should specify which exchange rate they used and the source for the exchange rate. Using the published exchanges rates is adequate for cost estimates that have budgeting or financial planning as their purpose. For economic evaluation, especially when comparing to results from other countries, it may be preferable to report results in international dollars, that is, dollars adjusted to take into account differences in purchasing power between countries. To do so, the analyst would use the purchasing power parity (PPP) conversion factor. To convert local currency units to international dollars, divide the local currency unit by the PPP conversion factor. ${ }^{12}$ Dr Allen, in reporting her results of the cost-effectiveness analysis of the community mobilization program in Transmutania, reports total costs and costs per person reached in local currency (swapps) at 2018 prices, in 2018 US dollars, and in 2018 international dollars (Table 13).

\section{TABLE 13 COST RESULTS REPORTED IN LOCAL CURRENCY, US, AND INTERNATIONAL DOLLARS}

\begin{tabular}{|lcrc|}
\hline & $\begin{array}{c}\text { LOCAL } \\
\text { CURRENCY } \\
\text { (SWAPPS) }\end{array}$ & $\begin{array}{c}\text { US } \\
\text { DOLLAR }\end{array}$ & $\begin{array}{c}\text { INTERNATIONAL } \\
\text { DOLLAR }\end{array}$ \\
\hline Total cost & $1,000,000$ & 100,000 & 83,333 \\
$\begin{array}{l}\text { Cost per } \\
\text { person } \\
\text { reached }\end{array}$ & 200 & 20 & 17 \\
\hline
\end{tabular}

aExchange rate of 10 Transmutanian swapps per 1 US dollar bPPP conversion factor of 12 in 2018

cThe program reached 5,000 clients

\section{ANALYSTS IN MALAWI USED A 3\%}

DISCOUNT RATE TO ANNUALIZE CAPITAL

ITEMS

In a study of the cost-effectiveness of bed net distribution to prevent malaria in Malawi, analysts annualized capital items using a 3 percent discount rate (Stevens et al. 2005).

\footnotetext{
${ }^{12}$ Available at: https://data.worldbank.org/indicator/PA.NUS.PPP
} 


\section{Principle 14 Using shadow prices}

https://ghcosting.org/pages/standards/ principles/pricing_and_valuation\#five

\section{The principle}

The use and source of shadow prices to value inputs without a market price and the opportunity cost of time should be reported.

\section{Why important}

When calculating an economic versus a financial cost, the analyst should use the opportunity cost of the input (see discussion in "Define if the cost is financial or economic," pg 22). The unit cost for an input for which the market price is unknown or does not exist is a shadow price. It is important for the analyst to use a shadow price to more accurately reflect the market price of an input. SBC interventions can employ a range of inputs for which shadow pricing is necessary (for more, see "Define if the cost is financial or economic," pg 22).

\section{Apply shadow pricing to donated labor}

Community volunteers. Many SBC interventions use community volunteers. To assign a market value to volunteer time, the analyst typically uses the local wage rate as a proxy for the value of volunteer time. For example, the minimum wage in Transmutania is set at 100 swapps a day. Assuming an 8-hour day, this translates into 12.5 swapps per hour. The analyst would use this hourly rate in valuing the time of community volunteers. As an alternative to the minimum wage, the analyst could use the local cost of unskilled labor (typically less than the minimum wage) to value volunteer time.

Donated professional time. SBC interventions also may benefit from pro bono services provided by professionals, for example those who donate their services to the design of a media or marketing campaign. The analyst would assign a shadow price to their time in accordance with their salary. For example, a media specialist in Transmutania makes on average $\$ 20,000$ per year. At 260 days per year, this works out to a daily rate of $\$ 76.92$.
Celebrity volunteers. Celebrities often donate their time to mass media and entertainment education interventions. Cost analysts should employ a similar strategy to value their time, and ask what that celebrity would earn for their performance, attendance at an event, or willingness to have their image used for a commercial marketing campaign. For example, Transmutania's mass media campaign to promote handwashing has used the face of one of the country's famous pop music stars.

\section{Apply shadow pricing to donated or subsidized goods or services}

Many SBC activities rely in part on donated or subsidized goods or services, where no financial transaction occurs (financial cost), yet the goods or services have an opportunity or market cost (economic cost). It behooves the cost analyst to place a shadow price on these goods and services. Usually the analyst can find the equivalent market price for whatever donated good or service. For example, for a mass media campaign that relied in part on donated radio and television airtime, the analyst would investigate the market price for the same airtime (over the same channels and at the same time), and then apply that market price to the value of the donated airtime.

\section{Apply shadow pricing to donated physical space}

Many SBC interventions may take advantage of donated physical space to run their intervention. For example, the counseling sessions for Transmutania's IPC program take place at community locations such as schools and churches that are free to the program. However, the cost analyst is interested in knowing what it would cost the program if it were to pay for such space. The cost analyst in Transmutania asks around and finds out that it typically costs $\$ 10$ per hour to rent a similar size space for events in the communities where the program takes place. She then uses that $\$ 10$ as the shadow price for an hour's use of a counseling room.

\section{Apply shadow pricing to client time}

Some cost estimates may require valuing client time, including time getting to and from an SBC activity and any time spent "consuming" the SBC intervention. Client time may be an important component of the analysis where one of the main aims of the intervention is to save the client time relative to a comparable intervention. In part, the aim of the digital health reminder app program in Transmutania is to reduce the time clients would need 
to spend receiving similar information relative to the time they might spend visiting a health worker at a nearby clinic or spending time with a community volunteer. The cost analyst should set a shadow price to reflect the opportunity cost of client time, similar to the recommendation for valuing of community volunteer time. This would be done using the local wage rate or official minimum salary, as shown in the example above.

\section{ANALYSTS IN ETHIOPIA VALUED COM-}

MUNITY HEALTH WORKER TIME USING OPPORTUNITY COST

In their analysis of the costs and impact of adding a social marketing approach to community-based distribution of contraceptives in Ethiopia, analysts valued community health worker time using opportunity cost, which they defined as "the cost of their time that could have been spent on other activities if they were not involved in this program" (Prata et al. 2016).

\section{ANALYSTS OF A MASS MEDIA PROGRAM IN EGYPT REPORTED THAT THE CAMPAIGN \\ RECEIVED AIRTIME AT REDUCED COSTS}

Robinson and Lewis (2003) reports that airtime for mass media campaigns for family planning is offered to the SBC intervention at reduced costs. 


\section{Analyzing and Presenting Results}

Principles 15-17 offer further guidance on analyzing and presenting results of an SBC costing.

15 - Exploring cost functions and heterogeneity

16 - Dealing with uncertainty

17 - Transparency

Photo Credit: @ 2015 Haydee Lemus/PASMO PSI Guatemala, Courtesy of Photoshare

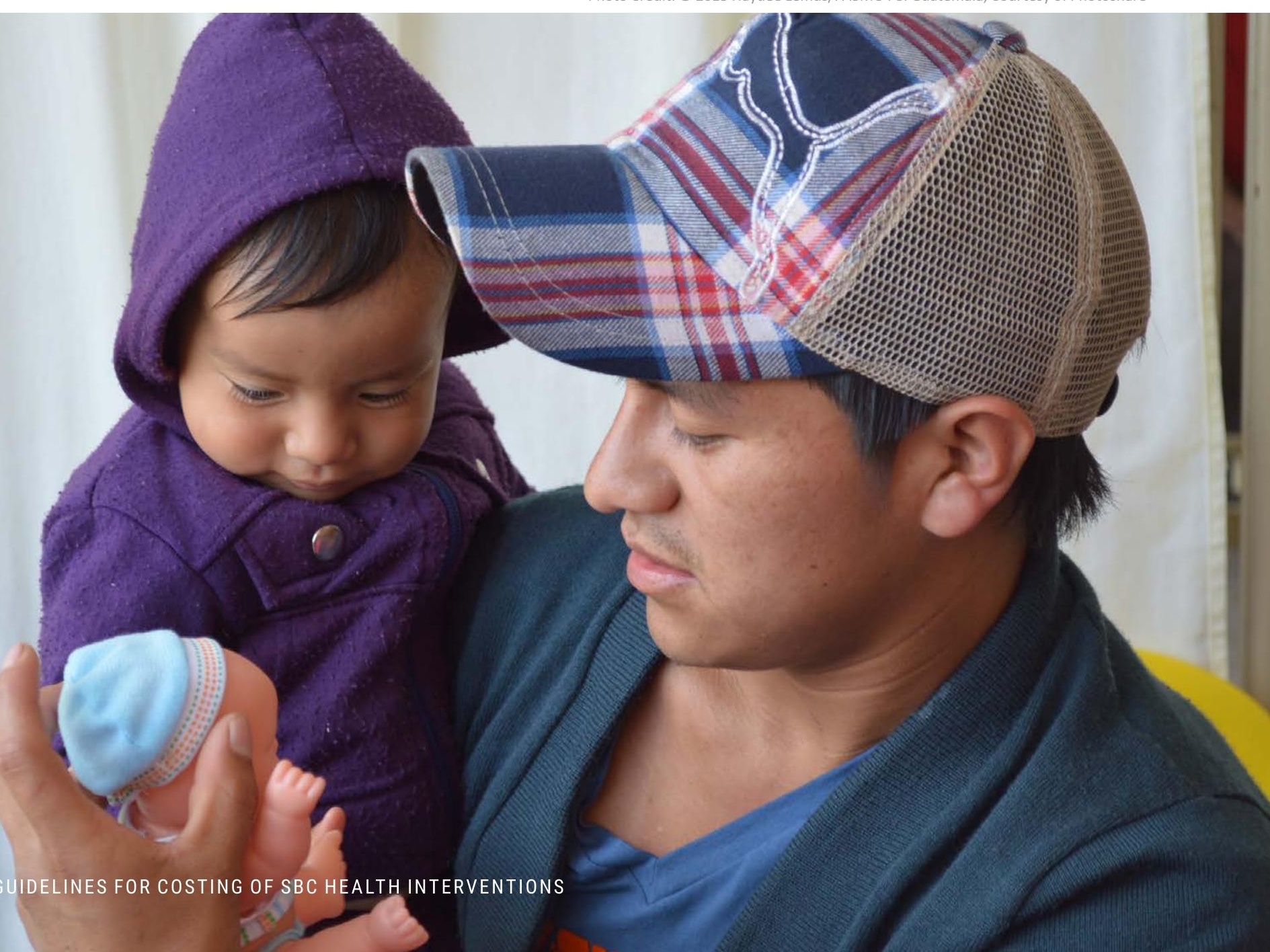




\section{Principle 15 \\ Exploring cost functions and heterogeneity}

(2) principles/analysing_and_presenting_

\section{The principle}

Variation in the cost of the intervention by site size/ organization, sub-populations, or other drivers of heterogeneity should be explored and reported.

\section{Why important}

Unit costs can change with scale, across sites, and for different populations. Reporting on these differences is important to draw appropriate conclusions from results.

Please note, this Principle is complex and beyond the scope of these SBC Costing Guidelines. For those wishing more detail on Principle 15 as stated by the GHCC Reference Case, please visit the link above. 


\section{Principle 16 \\ Dealing with uncertainty}

(-)

https://ghcosting.org/

pages/standards/principles/

analysing_and_presenting_results\#three

\section{The principle}

The uncertainty associated with cost estimates should be appropriately characterized.

\section{Why important}

Any SBC cost estimate has uncertainty about how far the estimate is from reality. It is important for the cost analyst to characterize the sources of that uncertainty so that the results are easier to compare across settings.

\section{Characterize the sources of uncertainty of any cost estimate}

The GHCC Reference Case refers to the quality of a cost estimate in terms of accuracy and precision. Omitting inputs or using the wrong input price can affect accuracy. Using a small or non-representative sample to generate the cost estimate can affect precision. The cost analyst should carefully characterize these sources of uncertainty.

Uncertainty from lack of precision. As Principle 8 (pg 36)discusses, sampling for costing is a very underdeveloped art. Resource constraints mean that analysts can visit relatively few sites (or whatever the unit of observation is). Even those studies that sample a larger range of sites will have difficulty applying statistical techniques that assess precision of the estimate. Nonetheless, the cost analyst should do their utmost to explain any uncertainty from lack of precision, including the distribution of results and a confidence interval if feasible.

Uncertainty from lack of accuracy. It is likely that the cost analyst will get something wrong, as the analyst lacks the time or money to capture data accurately, leaves out an element of the production process (on purpose or inadvertently), or has to make an educated guess about the price or quantity of an input). Examples of typical sources of lack of accuracy in SBC intervention cost estimates include:

- Completeness. The cost analyst looking at the program in Transmutania had an incomplete picture of the production process for the community mobilization program, and inadvertently left out one or two inputs. They were also unable to get information on the design phase of the intervention because of poor record keeping. The unit in Transmutania that developed the app for digital health behavior change did not keep good records on the effort that went into app design and development, so the analyst chose not to include that design element in the cost estimate.

- Possible under-or over-reporting of quantities of inputs. The cost analyst in Transmutania found it difficult to document time spent by community volunteers in the community mobilization program. Time and resource limitations meant that the analyst was only able to rely on estimates from program field staff rather than from interviews of the volunteers themselves. That generated considerable uncertainty around the estimate of the true amount of time the volunteers spent on the program.

- Distortions or incompleteness in the prices of inputs. For the community mobilization program, the cost analyst was unclear on which estimate to use to price volunteer time. Similarly, there was uncertainty about the assumptions used to value the space used for the program, having based the estimate on a quick phone call rather than an in-depth survey of analogous rental costs.

The analyst needs to assess the possible sources of uncertainty, select the most important, and test them through analysis. For uncertainty stemming from either lack of precision or lack of accuracy, one standard approach is to use sensitivity analysis. Sensitivity analysis allows the analyst to gauge the extent to which a change in the parameters of the costing might change the estimate. It can thus make the results more comparable and generalizable. It is beyond the scope of these guidelines, however, to discuss these techniques. ${ }^{13}$

\footnotetext{
${ }^{13}$ For more on sensitivity analysis, see for example Appendix 11 in DeCormier Plosky, Kripke, Bollinger, and Forsythe. 2018. PrEP Costing Guidelines. Durham, NC: Avenir Health, for the Optimizing Prevention Technology Introduction on Schedule (OPTIONS) Consortium. Available at: https://www.prepwatch.org/wp-content/uploads/2019/01/OPTIONS_ PrEP_Cost_Guidelines_Dec2018.pdf
} 


\section{Make recommendations about the generalizabil- ity of the estimate}

The GHCC Reference Case defines generalizability as "the extent to which the cost estimate can be directly applied to other programmatic settings." The cost analyst should, in reporting the findings of the study, discuss the generalizability of the findings, taking into account characteristics such as scale, the nature of study population, and the fidelity of program implementation.

\section{ANALYSTS CONDUCTED SENSITIVITY}

ANALYSIS OF AN HPV SCREENING CAMPAIGN IN KENYA

For an analysis of the cost of human papilloma virus (HPV) screening at community health campaigns and health clinics in rural Kenya, analysts conducted a series of sensitivity analyses to assess the extent to which cost per HPV screening were sensitive to changes in the way the program was implemented. Analysts varied assumptions around transport inputs, reducing the number of personnel (Shen et al. 2018).

\section{ANALYSTS OF A BREASTFEEDING PROMOTION}

EFFORT IN UGANDA CONDUCTED SENSITIVITY

\section{ANALYSIS AROUND KEY ASSUMPTIONS}

In their analysis of peer counseling for a breastfeeding promotion in Uganda, cost analysts used sensitivity analysis to understand how varying cost assumption might influence the study outcome. They varied the discount rate by replacing the local bond rate $(20 \%)$ with internationally standard $3 \%$ and $6 \%$; varied personnel costs up and down by $20 \%$; varied the number of visits per mother (+/-20\%) and varied the allocation of staff time between project implementation and evaluation $(+/-20 \%)$, for the project coordinator and driver, who were involved in both activities (Chola et al. 2011). 


\section{Principle 17 \\ Transparency}

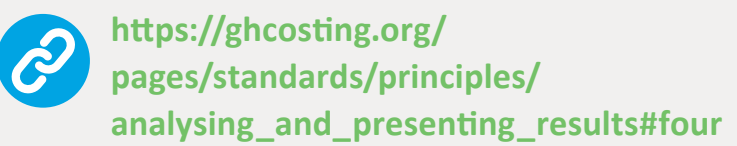

\section{The principle}

SBC cost estimates, including the methods used, should be communicated clearly and transparently to enable decision-maker(s) to interpret and use the results.

\section{Why important}

The more the users of a cost estimate know about why and how the study was conducted, the better they will be able to interpret and use the results. Therefore, for each of the principles elucidated in these guidelines, the GHCC Reference Case recommends a clear statement embodied in "Minimum Reporting Standards" described in Appendix 4. 


\section{References}

Beck E, and C. Avila. 2011. Manual for Costing HIV Facilities and Services. UNAIDS: Geneva, Switzerland.

Benson, A. et al. 2018. "Longitudinal evaluation of the Tupange Urban Family Planning Program in Kenya," International Perspectives on Sexual and Reproductive Health 43(2): 75-87. doi:10.1363/43e4117

Binagwaho, A. et al. 2010. "Male circumcision at different ages in Rwanda: a cost-effectiveness study," PLoS Medicine 7(1): e1000211. doi:10.1371/journal. pmed.1000211

Breakthrough RESEARCH. 2018a. A Framework for a Business Case for Social and Behavior Change.

Breakthrough RESEARCH. 2018b. Developing a Research \& Learning Agenda for Social and Behavior Change. A Summary of Desk Review Findings and Outcomes from a Series of Technical Expert Consultations.

Breakthrough RESEARCH. 2018c. Meeting Report: A Framework for a Business Case for Social and Behavior Change Programming in Health. An Expert Consultation Meeting hosted by Breakthrough RESEARCH

Chandrashekar, S. , et al. 2014. "The costs of scaling up HIV prevention for high risk groups: lessons learned from the Avahan Programme in India," PLOS ONE 9(9): e106582. doi:10.1371/journal.pone.0106582

Chola, L. et al. 2011. "Cost of individual peer counselling for the promotion of exclusive breastfeeding in Uganda," Cost Effectiveness and Resource Allocation 9: 11. doi: 10.1186/1478-7547-9-11

Drummond, M. et al. 2015. Methods for the Economic Evaluation of Health Care Programmes, Fourth Edition. New York: Oxford University Press.

Dulli, L.S. et al. 2016. “Meeting postpartum women's family planning needs through integrated family planning and immunization services: results of a cluster-randomized controlled trial in Rwanda," Global Health: Science and Practice 4(1): 73-86. http://dx.doi.org/10.9745/ GHSP-D-15-00291.
Fisek, N. and K. Sumbuloglu. 1978. "The effects of husband and wife education on family planning in rural Turkey," Studies in Family Planning 9(10/11): 280-285.

Health Communication Capacity Collaborative (HC3). 2017. "The Circle of Care Model." Baltimore, MD: HC3. https://healthcommcapacity.org/hc3resources/ circle-care-model/

Hernandez, A. and M. San Sebastian. 2014. "Assessing the technical efficiency of health posts in rural Guatemala: a data envelopment analysis," Global Health Action 7: 23190. doi: 10.3402/gha.v7.23190

High-Impact Practices in Family Planning (HIPs). 2018. "Social and behavior change: a critical part of effective family planning programs." Washington, DC: USAID. https://www.fphighimpactpractices.org/wp-content/ uploads/2018/04/SBC_Overview.pdf

Homan, R. 2016. "Costing of social norm interventions: a primer from the passages project." Washington, D.C.: Institute for Reproductive Health, Georgetown University for the U.S. Agency for International Development (USAID). Available at: http://irh.org/wp-content/ uploads/2016/10/Costing_Social_Norm_Interventions_ Passages.pdf

Hounton, S. and D. Newlands. 2012. "Applying the net-benefit framework for analyzing and presenting cost-effectiveness analysis of a maternal and newborn health intervention," PLOS ONE 7(7): e40995. doi:10.1371/journal.pone.0040995

Janowitz, B. et al. 1992. "Impact of social marketing on contraceptive prevalence and cost in Honduras," Studies in Family Planning 23(2): 110-117.

Janowitz, B. et al. 1997. "Can Bangladeshi family planning program meet rising needs without raising costs?," International Family Planning Perspectives 23: 116-121 \& 145. 
Jehu-Appiah, C. et al. 2014. "Ownership and technical efficiency of hospitals: evidence from Ghana using data envelopment analysis," Cost Effectiveness and Resource Allocation 12: 9. doi: 10.1186/1478-7547-12-9

Kincaid, L. et al. 1996. "Impact of a mass media vasectomy promotion campaign in Brazil," International Family Planning Perspectives 22: 169-175.

Kincaid, L and M. Phuong Do. 2006. "Multivariate causal attribution and cost-effectiveness of a national mass media campaign in the Philippines," Journal of Health Communication 11(Suppl 2): 69-90. doi: 10.1080/10810730600974522.

Lewycka, S. et al. 2013. "Effect of women's groups and volunteer peer counselling on rates of mortality, morbidity, and health behaviours in mothers and children in rural Malawi (MaiMwana): a factorial, cluster-randomised controlled trial," The Lancet 381(9879): 1721-1735. doi: 10.1016/S0140-6736(12)61959-X

Naik, S., T. Suchi, and R. Lundgren. 2010. "Options for maintaining quality family planning counseling: strategies for refresher training," International Journal for Quality in Health Care 22(2): 145-150. doi: 10.1093/intqhc/mzp062

Orobaton, N. et al. 2016. "Scaling-up the use of sulfadoxine-pyrimethamine for the preventive treatment of malaria in pregnancy: results and lessons on scalability, costs and programme impact from three local government areas in Sokoto State, Nigeria," Malaria Journal 15: 533. doi: 10.1186/s12936-016-1578-x

Portela, A. et al. 2017. "Social, behavioural and community engagement interventions for reproductive, maternal, newborn and child health: an evidence gap map," 3ie Evidence Gap Map Report 11. London: International Initiative for Impact Evaluation (3ie).

Powell-Jackson, T. et al. 2018. "Effect and cost-effectiveness of educating mothers about childhood DPT vaccination on immunisation uptake, knowledge, and perceptions in Uttar Pradesh, India: a randomised controlled trial," PLOS Medicine 15(3): e1002519. doi: 10.1371/journal.pmed.1002519

Prata, N. et al. 2016. "Cost of providing injectable contraceptives through a community-based social marketing program in Tigray, Ethiopia," Contraception 93(6): 485-491. doi: 10.1016/j.contraception.2016.01.017
Reynolds, H.W. et al. 2008. "Effectiveness of training supervisors to improve reproductive health quality of care: a cluster-randomized trial in Kenya," Health Policy and Planning 23: 56-66. doi: 10.1093/heapol/czm037

Robinson, W. and G. L. Lewis. 2003. "Cost-effectiveness analysis of behaviour change interventions: a proposed new approach and an application to Egypt," Journal of Biosocial Science 35(4): 499-512.

Rosen, J et al. 2018 (unpublished). "Roadmap for an SBC business case." Breakthrough RESEARCH.

Routh, S. Barkat-E-Khuda. 2000. "An economic appraisal of alternative strategies for the delivery of $\mathrm{MCH}-\mathrm{FP}$ services in urban Dhaka, Bangladesh," The International Journal of Health Planning and Management 15(2): 115-132. doi: 10.1002/1099-1751(200004/06)15:2<115::AIDHPM586>3.0.CO;2-6

Ruiz-Rodriguez, M., L.A. Rodriguez-Villamizar, and I. Heredia. 2016. "Technical efficiency of women's health prevention programs in Bucaramanga, Colombia: a fourstage analysis," BMC Health Services Research 16: 576. 10.1186/s12913-016-1837-0

Shen, J. et al. 2018. "Cost of HPV screening at community health campaigns (CHCs) and health clinics in rural Kenya," BMC Health Services Research 18: 378. doi: 10.1186/s12913-018-3195-6

Stevens, W. et al. 2005. "The costs and effects of a nationwide insecticide-treated net programme: the case of Malawi," Malaria Journal 4: 22. doi:10.1186/1475-2875-4-22

Thakur, J.S., S. Prinja, G. Jeet, and N. Bhatnagar. 2016. "Costing of a state-wide population based cancer awareness and early detection campaign in a 2.67 million population of Punjab State in northern India," Asian Pacific Journal of Cancer Prevention 17(2): 791-797. doi: 10.7314/APJCP.2016.17.2.791

USAID. 2018a. "Discussion note: adaptive management." Washington, DC: USAID. https://usaidlearninglab.org/ sites/default/files/resource/files/dn___adaptive_management.pdf 
USAID. 2018b. Social and behavior change. https:// www.usaid.gov/what-we-do/global-health/

cross-cutting-areas/social-and-behavior-change.

USAID. 2016. "USAID Evaluation Policy: evaluation-learning from experience." Washington, DC: USAID. https:// www.usaid.gov/sites/default/files/documents/1870/ USAIDEvaluationPolicy.pdf

Vassall, A. et al. 2014. "Community mobilisation and empowerment interventions as part of HIV prevention for female sex workers in Southern India: a cost-effectiveness analysis," PLOS ONE 9(10): e110562. doi:10.1371/ journal.pone.0110562

Vassall, A. et al. 2017. "Reference case for estimating the costs of global health services and interventions." Global Health Cost Consortium. https://ghcosting.org/pages/ standards/reference_case

Vernon, R., G. Ojeda, and M.C. Townsend. 1988.

"Contraceptive social marketing and community-based distribution systems in Colombia," Studies in Family Planning 19(6): 354-360.

Wesson, J. et al. 2008. "Reaching providers is not enough to increase IUD use: a factorial experiment of 'academic detailing' in Kenya," Journal of Biosocial Science 40(1): 69-82. doi: 10.1017/S0021932007002027

World Bank. 2015. HIV Allocation Efficiency Analysis: Guidelines: Methods for improving the Efficiency of HIV Resource Allocation, Volume 1. Washigton, DC: World Bank. http://optimamodel.com/docs/AE-GuidelinesVol-1.pdf 


\section{Appendices}

tery of Photoshare

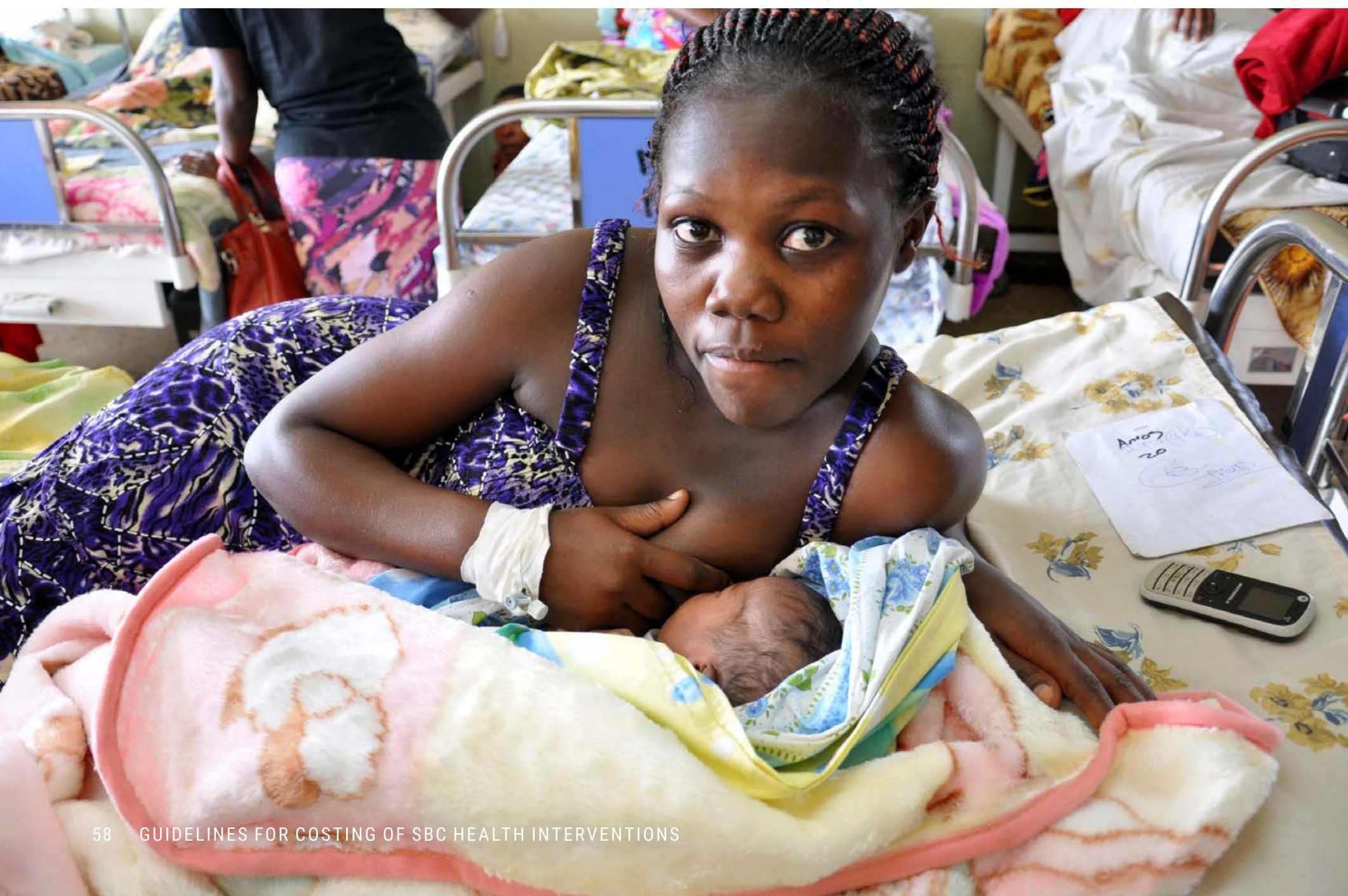




\section{Appendix 1}

\section{Additional resources on costing}

\section{SBC costing}

Homan, R. 2016. "Costing of social norm interventions: a primer from the Passages Project." Washington, D.C.: Institute for Reproductive Health, Georgetown University for the U.S. Agency for International Development (USAID). Available at: http://irh.org/wp-content/ uploads/2016/10/Costing_Social_Norm_Interventions_ Passages.pdf

\section{General health costing}

Vassall, A. et al. 2017. "Reference case for estimating the costs of global health services and interventions." Global Health Cost Consortium. Available at: https://ghcosting. org/pages/standards/reference_case

International Decision Support Initiative (iDSI). 2017.

GHCC reference case for economic evaluation. Available at: http://www.idsihealth.org/resource-items/ idsi-reference-case-for-economic-evaluation/

DeCormier Plosky, W., K. Kripke, L. Bollinger, and S. Forsythe. 2018. PrEP Costing Guidelines. Durham, NC: Avenir Health, for the Optimizing Prevention Technology Introduction on Schedule (OPTIONS) Consortium. Available at: https://www.prepwatch.org/wp-content/ uploads/2019/01/OPTIONS_PrEP_Cost_Guidelines_ Dec2018.pdf

Drummond, M. et al. 2015. Methods for the Economic Evaluation of Health Care Programmes, Fourth Edition. Oxford University Press: New York, NY.

Lloyd-Williams H, Edwards R. 2013. Sample size calculation in trials of public health interventions: a discussion of implications for health economists. Lancet 382 (S64). Available at: http://www.thelancet.com/journals/lancet/ article/PIIS0140-6736(13)62489-7/abstract

Muennig, P. 2008. Cost-effectiveness Analysis in Health. A Practical Approach, Second Edition. Jossey-Bass: San Francisco.

Neumann, P. et al. 2017. Cost-effectiveness in Health and Medicine, Second edition. Oxford University Press: New York, NY.
Sanders, GD et al. 2016. "Recommendations for conduct, methodological practices, and reporting of cost-effectiveness analyses: second panel on cost-effectiveness in health and medicine," Journal of American Medical Association 316(10): 1093-103. doi:10.1001/ jama.2016.12195

Turner, A. et al. 2001. Sampling Manual for Facility Survey: for population, maternal health, child health, and STD programs in developing countries. Measure Evaluation Project. Chapel Hill, NC: Carolina Population Center, University of North Carolina at Chapel Hill. Available at: https://www.measureevaluation.org/ resources/publications/ms-01-03

Wilkinson, T. et al. 2016. "The International Decision Support Initiative GHCC Reference Case for Economic Evaluation: an aid to thought," Value Health 19(8): 921-928. doi: 10.1016/j.jval.2016.04.015

WHO. 2014. "Cost effectiveness and strategic planning (WHO-CHOICE)." Geneva: WHO. Available at: http:// www.who.int/choice/cost-effectiveness/en/

Tan-Torres Edejer, T. et al. 2003. Making Choices in Health: WHO guide to cost-effectiveness analysis. Geneva: WHO. Available at: https://www.who.int/choice/publications/p_2003_generalised_cea.pdf

\section{General SBC program evaluation}

MEASURE Evaluation. Family Planning and Reproductive Health Indicators Database. Social and Behavior Change Indicators. Available at: https://www.measureevaluation. org/prh/rh_indicators/service-delivery/sbcc

C-Change. 2012. CModules: a learning package for social and behavior change communication (SBCC). Washington, DC: C-Change/FHI 360. Available at: https:// www.fhi360.org/resource/c-modules-learning-package-social-and-behavior-change-communication

Hutchinson, Paul and Jennifer Wheeler. 2006. "The cost-effectiveness of health communication programs: what do we know?" Journal of Health Communication 11 (Suppl 2): 7-45. 


\section{Family Planning and Reproductive Health}

Adesina,B., and E. Rottach. 2015. Estimating the Costs of Delivering Services for Post-Gender-Based Violence Care at a Health Facility: guidance manual. Washington, DC: Futures Group, Health Policy Project. Available at: https://www. healthpolicyproject.com/index. $\mathrm{cfm}$ ?id=publications\&get=pubID\&publd=686

Terris-Prestholt, F., A. Santos, S. Sweeney, and L. Kumaranayake. 2011. "Implementation 1: guidelines for cost effectiveness analysis of syphilis screening strategies," in The Rapid Syphilis Test Toolkit: a guide to planning, management and implementation. London: London School of Hygiene and Tropical Medicine. Available at http://idc-dx.org/resources/ the-rapid-syphilis-test-toolkit

FP2020. 2018. Family Planning Costed Implementation Plan Toolkit. Washington, DC: United Nations Foundation. Available at: http://www.familyplanning2020.org/ microsite/cip

Godbole, R., and E. Smith. 2012 (Updated 2014). Crosswalk of Family Planning Tools: A Guide to Costing, Planning, and Impact Analysis Tools. Washington, DC: Futures Group, Health Policy Project. Available at: https://www.healthpolicyproject.com/pubs/117_ CrosswalkofFamilyPlanningToolsGuideFINAL.pdf

Janowitz, B and J. Bratt. 1994. Methods for Costing Family Planning Services. UNFPA and Family Health International. Available at: https://pdfs.semanticscholar. org/09b8/1c26855c4a7735bd252633725738ae1754e4. pdf?_ga=2.111979844.1162190355.15689026692048613554.1567798572

Moreland, S., S. Foley, and S. Gobin. 2018. Reproductive Health Cost Reporting System: a user guide. Measure Evaluation. Available at: https://www.measureevaluation.org/resources/publications/ms-18-126

\section{HIV}

Beck, E., and C. Avila. 2011. Manual for Costing HIV Facilities and Services. UNAIDS: Geneva, Switzerland. Available at: http://files.unaids.org/en/media/unaids/ contentassets/documents/document/2011/20110523_ manual_costing_HIV_facilities_en.pdf

Family Health International. 2004. "Monitoring and evaluating behavior change communication programs." In Monitoring HIV/AIDS Programs: a facilitator's training guide. A USAID resource for prevention, care, and treatment. Washington, DC: FHI 360. Available at: https://www.fhi360.org/sites/default/files/media/ documents/Monitoring\%20HIV-AIDS\%20Programs\%20 (Facilitator)\%20-\%20Module\%206.pdf

DeCormier Plosky, W., K. Kripke, L. Bollinger, and S. Forsythe S. 2018. PrEP Costing Guidelines. Durham, NC: Avenir Health, for the Optimizing Prevention Technology Introduction on Schedule (OPTIONS) Consortium. Available at: https://www.prepwatch.org/wp-content/ uploads/2019/01/OPTIONS_PrEP_Cost_Guidelines_ Dec2018.pdf

UNAIDS and Asian Development Bank. 2004. Costing Guidelines for HIV Intervention Strategies: INPUT software, Goals Model, and Resource Needs Model included. Geneva: UNAIDS and Asian Development Bank. Available at: http://data.unaids.org/publications/irc-pub06/ jc997-costing-guidelines_en.pdf

World Bank. 2015. HIV Allocation Efficiency Analysis Guidelines: methods for improving the efficiency of HIV resource allocation, Volume 1. Washington, DC: World Bank. Available at: http://optimamodel.com/docs/ AE-Guidelines-Vol-1.pdf

\section{Immunization}

Brenzel, L. 2013. "Common approach for the costing and financing analyses of routine immunization and new vaccine introduction costs (NUVI)," Working Paper. Seattle: Bill and Melinda Gates Foundation. https://static1.squarespace.com/static/556deb8ee4b08a534b8360e7/t/55970258e4b03cf942da51ac/1435959896232/ WEBSITE_Common+Approach.pdf

\section{Malaria}

Philips, M., A. Mills, and C. Dye. 1993. Guidelines for Cost-effectiveness Analysis of Vector Control, PEEM guidelines Series 3. Geneva: WHO. Available at: https:// apps.who.int/iris/bitstream/handle/10665/61098/ WHO_CWS_93.4_eng.pdf?sequence=1\&isAllowed=y

\section{TB}

WHO. 2002. Guidelines for Cost and Cost-effectiveness Analysis of Tuberculosis Control. WHO. Geneva: Switzerland. Available at http://apps.who.int/iris/ handle/10665/67728 


\section{Appendix 2 Glossary}

https://ghcosting.org/pages/standards/ glossary

Unless otherwise noted through italics, the definitions are adapted from the GHCC Reference Case or from the PrEP Costing Guidelines.

Above-site/Above-service costs: costs incurred above the point-of-care/service delivery site, such as central management or administrative services, centralized training or education, centralized laboratory services, procurement/collection/distribution/storage of supplies, record-keeping, and surveillance. Note that above-site implies more centralized processes. There can be management, procurement, etc. at the site-level as well that are conducted by the site/program.

Amortization/Annualization: the method to smooth out the one-time cost of a capital input by putting a "piece" of the cost across each of the years of use of that input (useful life years). Economic cost estimation uses the method of annualization, which estimates the annual opportunity cost of not investing the same purchase (or resale) price, plus interest (or the expected [discount] rate of return on the alternate investment).

\section{Benefit-cost analysis (BCA) (formerly referred to as cost-benefit analysis): a form of economic evaluation where both the measures in the numerator (difference in cost) and in the denominator (difference in effect) are expressed as monetary values, so that the resulting benefit-cost ratio (BCR) expresses value for investment in exclusively monetary terms (i.e., " $x$ " dollars in for " $x$ " dollars back).}

Capital costs: one-time costs for inputs that have a useful life of over one year (such as buildings, vehicles, medical equipment, training, intervention design, and television and radio spots and programs).

Client perspective: the costs by the client to access/complete the activity, service, or intervention at the point of care. This can include co-pays, fees, purchase of medical supplies or drugs, travel expense, and childcare. It can also include opportunity costs such as lost wages due to the time spent traveling to/from a visit, waiting for a visit, and during a visit. It can also extend to the costs borne by the household and even community to allow the client to access/complete the activity, service, or intervention. This can include paying for drugs, medical supplies, and food, and lost wages/productivity for the time spent caring for/accompanying the client.

Cost-effectiveness analysis (CEA): a form of economic evaluation that essentially divides the difference in cost between the alternatives [numerator] (e.g., less/more comprehensive interventions, different ways of delivering an intervention, or different technologies such as drugs or tests) by the difference in a unidimensional measure of effect [denominator] (e.g., HIV infections averted, years of life gained) to calculate an incremental-cost-effectiveness ratio (ICER).

Cost functions: mathematical functions that show the relationship between costs and components of cost (e.g., personnel, capital) or cost and the determinants/drivers of costs (e.g., scale, coverage, type of provider, time etc.). Cost functions describe how cost is determined by input cost, the amount of resources used, and other factors that may modify these such as the scale of production, or other characteristics such as quality.

Cost minimization analysis (CMA): a form of economic evaluation that assumes that the effectiveness [denominator] between the alternatives is equal and therefore only the costs [numerator] are compared. It is often used in the case of pharmaceuticals, where there is reliable evidence that a generic drug has equal therapeutic effect to a brand-name drug in the same dose.

Cost-utility analysis (CUA): a form of economic evaluation that translates the denominator of the incremental cost-effectiveness ratio (ICER) into a bi-dimensional measure of effect relative to: a) an individual's years of life gained AND adjusted by the quality of health (quality-adjusted life year, or QALY), or b) an individual's years of life "diminished" and adjusted by quality of "capacity" (i.e., disease burden or disability) (disability-adjusted life year, or DALY). Technically, this result is an incremental cost-utility ratio (ICUR).

Current price: the price of input stated in terms of the price level during the time period of the study. 
Discount rate: the rate at which the analyst discounts future costs to account for time preference. It is also the expected rate of return on an investment alternative to a particular purchase.

Economic costs: costs that reflect the full value of all resources utilized in producing a good or service, inclusive of "opportunity costs" that represent the value of the forgone opportunity to devote "unpaid" resources (such as volunteer time and donated goods) to another purpose.

Economic evaluation: the process of systematic identification, measurement, and valuation of the inputs and outcomes of two alternative activities, and the subsequent comparative analysis of these (Wikipedia at: https://en.wikipedia.org/wiki/Economic_evaluation from Drummond 2005).

Economies of scale: when long-run average cost decreases as output increases.

Expenditures: the financial outlay that an agent (e.g., government, donor, or individual) spends during a period for goods and services. Expenditures can refer to the entire sum required by specified health services, or they may pertain only to those outlays incurred by a subset of the organizations involved in delivering the service. Note that expenditure data are usually reported using the cash basis method of accounting, that is, no amortization to capital goods is applied; all capital goods expenditures are recorded in full as they are incurred.

Financial costs: reflect financial outlays for goods and services needed to carry out a public health or medical intervention (in the context of global health), and as such are similar to expenditures. However, in contrast to expenditure data, financial costs depreciate capital expenditures over time.

Fixed costs: those costs that do not vary with scale (changes in the level of output). These costs would be incurred even if the output was zero. Common examples include items such as buildings and equipment, but note that "fixity" depends on context and there are fixity "tipping" points where existing numbers of resources such as personnel or buildings are no longer sufficient at a certain scale.

Full cost: means that the cost estimate is covering all resources used within the standard of care for that intervention at a specific level of coverage, in comparison to incremental cost where one is looking at the difference in cost between two interventions and there may only be one difference in the care provided.

Gross costing: a costing approach where input use is estimated from total cost.

Incremental cost: This is technically the positive difference in cost between comparison interventions or different amounts of an intervention. Note that the comparator intervention may be "doing nothing."

Incremental cost-effectiveness ratio (ICER): a measure of the cost-effectiveness of an intervention that uses a unidimensional measure of effect in the denominator (see cost-effectiveness analysis description above for the calculation).

Incremental cost-utility ratio (ICUR): a measure of the cost-effectiveness of an intervention that uses multidimensional measure of effect (disease burden or quality of life) in the denominator (see cost-effectiveness analysis description above for the calculation).

Inputs: the basic granular resources needed to produce some output necessary for improved health.

Joint cost: a production cost incurred in creating two (or more) products.

Marginal costs: the cost of producing one or more unit(s) of a service/output.

Micro-costing approach: a costing approach where the analyst estimates the cost and quantity of every input consumed in an intervention.

Net of future cost savings: an accounting of how costs (expressed in present values) change if there is consideration for including the expected future cost of providing the intervention +/- the costs/benefits from either the illness in question (related cost/benefits) or other future life happenings (unrelated costs/benefits).

Non-traded inputs: services and commodities that cannot be traded on the international market.

Normative best practice: an activity, service, or intervention provided according to guidelines. Note there may be additional cost to adhere to those guidelines. 
Production process: the process of combining different inputs (such as labor, commodities, and equipment) to generate outputs (such as health services).

Provider perspective: the costs by the service provider to produce the activity, service, or intervention at the point of care.

Recurrent costs: the value of resources/inputs with useful lives of less than one year (such as supplies and personnel).

Real world practice: an activity, service, or intervention provided where some elements may not be included or implemented as guidelines suggest (due to local context, practice, or resource constraints).

Societal perspective: includes all costs incurred by an activity, service, or intervention regardless of who pays for it.

Straight-line depreciation: a way to "smooth out" the one-time cost of a capital input by putting a "piece" of the cost across each of the years of use of that input (useful life years). Straight-line depreciation simply divides the one-time cost by the years of useful life to obtain an annual cost.

Shadow price: the estimated price of a good or service for which no market price exists.

Start-up costs: the one-time commitment of resources required to establish a program to the point where service delivery can begin. Some of these resources may be donated or subsidized; thus, the financial costs may be less than the full economic costs. Start-up costs typically include some capital costs, but also include activities related to planning, staff training, materials development, infrastructure expansion, legal fees, or personnel recruitment. The analyst should amortize some start-up costs; for example, if staff training needs to repeat every five years, training costs would spread over five years.

Technical efficiency: the ability of a decision-making unit to produce maximum output that is feasible from a given level of inputs (Jehu-Appiah 2016).

Total costs: the summation of all cost inputs needed to produce all units of an activity, service, or program over a specified period.
Unit costs: the average cost of the inputs needed to produce one unit of activity, service, or intervention during a specified period.

Useful life: the period of time over which the organization expects an asset to provide economic value to the production process.

Variable costs: costs that vary with scale (changes in the level of output). 


\section{Appendix 3 \\ Typical sources for input prices, SBC interventions}

\begin{tabular}{|c|c|c|}
\hline COST CATEGORY & ILLUSTRATIVE INPUTS IN COST CATEGORY & SOURCES FOR INPUT PRICE INFORMATION \\
\hline \multicolumn{3}{|l|}{ Recurrent } \\
\hline $\begin{array}{l}\text { Service delivery } \\
\text { personnel }\end{array}$ & $\begin{array}{l}\text { Outreach workers, peer supporters; com- } \\
\text { munity volunteers or home visitors; doctors, } \\
\text { nurses, midwives, counselors; pharmacy and } \\
\text { drug shop workers; social media coordinators }\end{array}$ & $\begin{array}{l}\text { Program/facility payroll records; interviews with } \\
\text { health staff and administrative officials; government } \\
\text { salary scales; labor ministry for minimum wage for } \\
\text { shadow pricing }\end{array}$ \\
\hline Support personnel & $\begin{array}{l}\text { Administrators, supervisors; procurement } \\
\text { officers, supply clerks, accountants; legal staff; } \\
\text { receptionists; community strategy/mobili- } \\
\text { zation supervisors; data and IT staff; drivers; } \\
\text { gardeners; security guards; kitchen staff; } \\
\text { custodians or cleaning staff. }\end{array}$ & \\
\hline $\begin{array}{l}\text { Office supplies and } \\
\text { materials }\end{array}$ & $\begin{array}{l}\text { Pens, pencils, dry-erase markers, highlight- } \\
\text { ers; printer paper, post-it notes, notebooks, } \\
\text { calendars; paper clips, binder clips; file folders; } \\
\text { envelopes, stamps; tape, glue; scissors, } \\
\text { staplers, hole-punchers; calculators; memory } \\
\text { sticks; batteries; lanyards. }\end{array}$ & $\begin{array}{l}\text { Program/facility purchasing and shipping order } \\
\text { forms, invoices, and expenditure records; market } \\
\text { prices (catalogues, price lists); Central Medical Stores }\end{array}$ \\
\hline Promotional materials & Posters, brochures, pamphlets & $\begin{array}{l}\text { Program/facility purchasing and shipping order } \\
\text { forms, invoices, and expenditure records }\end{array}$ \\
\hline $\begin{array}{l}\text { Space or equipment } \\
\text { rental and } \\
\text { maintenance }\end{array}$ & $\begin{array}{l}\text { Rent for capital inputs (buildings, equipment, } \\
\text { vehicles); maintenance: painting, roof, heat- } \\
\text { ing/plumbing, windows; tires, spare parts, oil/ } \\
\text { lubricants, tune-ups; computer repair. }\end{array}$ & $\begin{array}{l}\text { Program/facility purchasing and shipping order } \\
\text { forms, invoices, and expenditure records; Ministry } \\
\text { of Health and Ministry of Public Works (equipment } \\
\text { costs and estimates of the cost per square foot/me- } \\
\text { ter for buildings and/or the cost to replace a specific } \\
\text { facility type; Central Motor Pool staff interviews and } \\
\text { vehicle logbooks; building and vehicle service/utility } \\
\text { records); market prices (catalogues, price lists, or by } \\
\text { visiting local vendors such as auto dealerships/repair } \\
\text { services, electronic equipment retailers, farm supply } \\
\text { retailers, and furniture or office supply stores); local } \\
\text { real estate agents or assessors for land value and } \\
\text { building rental prices }\end{array}$ \\
\hline
\end{tabular}




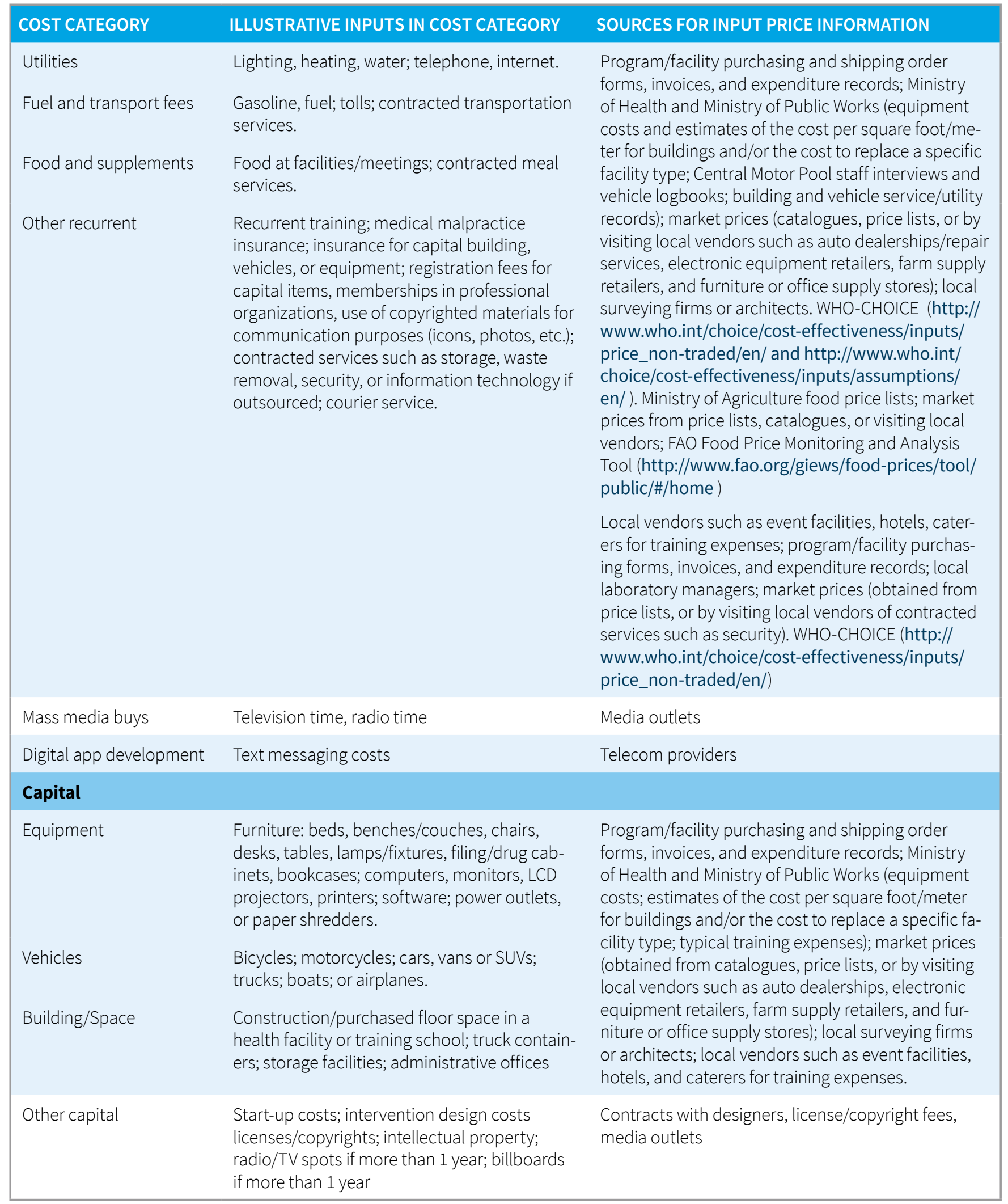

Source: Modified from the PrEP Costing Guidelines (DeCormier Plosky, Kripke, Bollinger, and Forsythe 2018) 


\section{Appendix 4 \\ Principles and methods reporting checklist}

Below is an SBC-adapted version of a table the GHCC Reference Case recommends for reporting of costing methods. For a specific costing study, the "options" column should be completed according to how the study was conducted.

\begin{tabular}{|c|c|}
\hline CHECKLIST ITEMS & OPTIONS \\
\hline \multicolumn{2}{|l|}{ STUDY DESIGN } \\
\hline \multicolumn{2}{|c|}{$\begin{array}{l}\text { Principle 1a-The purpose of the SBC cost estimation should be defined. } \\
\text { Principle } 1 \mathrm{~b}-\text { The analyst should clearly define the intervention being costed. }\end{array}$} \\
\hline \multicolumn{2}{|l|}{ Purpose } \\
\hline Purpose type: & $\begin{array}{l}\text { Economic evaluation, financial planning, budget impact } \\
\text { analysis, efficiency analysis, other }\end{array}$ \\
\hline Relevance for health practice and/or policy decisions: & Free text \\
\hline Aim of the cost analysis: & Free text \\
\hline Intended user(s) of the cost estimate: & Free text \\
\hline \multicolumn{2}{|l|}{ Intervention } \\
\hline Main activities/technologies involved: & Free text \\
\hline Target population: & $\begin{array}{l}\text { As relevant: age, gender, geographical location, clinical } \\
\text { indication }\end{array}$ \\
\hline Coverage level or project phase: & Percentage of target population or sites; pilot, scaled-up \\
\hline $\begin{array}{l}\text { Delivery mechanism (e.g., health system level, facility type, owner- } \\
\text { ship, etc.): }\end{array}$ & As relevant: level of health service, facility type \\
\hline Epidemiological context (i.e., incidence/prevalence of disease) & As relevant: incidence and/or prevalence \\
\hline \multirow[t]{5}{*}{ Ecological level } & Individual (e.g., client) \\
\hline & Household \\
\hline & Community \\
\hline & Organizational (e.g., provider) \\
\hline & Policy (e.g., advocacy) \\
\hline Ownership & Public, private, NGO. \\
\hline Main SBC intervention activities & $\begin{array}{l}\text { Describe production process (e.g., list main activities and } \\
\text { key technologies involved in delivering the intervention) }\end{array}$ \\
\hline \multicolumn{2}{|c|}{ Principle 2-The perspective of the SBC cost estimation should be defined. } \\
\hline Study perspective (e.g., provider, health system, societal, household): & $\begin{array}{l}\text { (Named) provider or societal, and list specific payers. State } \\
\text { any stopping rules. }\end{array}$ \\
\hline
\end{tabular}


Principle 3-The type of cost being estimated should be defined, in terms of financial vs. economic, real world vs. guideline, incremental vs. full cost, and whether the cost is net of future savings or not. The type of cost should be justified relevant to the purpose of the SBC cost estimation.

\section{Defining the cost}

Economic vs financial cost

Real world vs guideline cost

Full vs incremental cost

Net of future cost
Economic vs financial cost

Real world vs guideline cost

Full vs incremental cost

Yes or No

Principle 4-The "units" in the unit costs for SBC interventions should be defined, relevant for the costing purpose, and generalizable.

List the unit costs used

Describe any adjustments made to reflect the quality of service output
Choose from list of standardized unit costs

Choose from list of standardized adjustments

Principle 5 -The timeframe of SBC cost data collection (start and end dates) should be explicit and of sufficient length to capture costs relevant to the time horizon of the study purpose, and consideration should be given to disaggregating costs into separate time periods where they vary over the timeframe.

\section{Time period}

Period type (start-up vs implementation):

Start-up, implementation, or both

Time period:

Years and months

\section{RESOURCE USE MEASUREMENT}

Principle 6-The scope of the inputs to include in the cost estimation should be defined and justified and relevant to purpose. Where inputs are excluded for pragmatic reasons these should be explicitly reported.

\section{Defining the scope}

Above service delivery costs included

Costs of supporting change included

Research costs included

Unrelated costs included

If incremental costs, assumptions made for existing capacity

Any other exclusions to scope
Yes or No

Yes or No

Yes or No

Yes or No

Free text

Free text

Principle 7-The methods for estimating the quantities of inputs (resources) should be described, including data sources, criteria for allocating shared costs, and exclusion of research costs.

Describe the measurement of each input as

either top-down or bottom-up

Describe method to allocate human resources inputs

Describe methods to allocate above site/overhead inputs

Describe the methods for excluding research costs

Describe the methods for measuring other resources
Top down or bottom-up

Observation, time sheets, work-sampling, interviews, other

Method, criteria, and data source for criteria

Method, criteria, and data source for criteria

Method and data source 
Principle 8-The sampling strategy used should be determined by the precision demanded by the costing purpose and designed to minimize bias.

Site/client selection process/criteria

Describe geographic sampling (if applicable)

Frame and method

Describe site sampling (if applicable)

Frame and method

Describe patient sampling (if applicable)

Frame and method

Describe methods to calculate sample size

Calculation

Principle 9-The selection of the data source(s) and methods for estimating service use should be described, and potential biases reported in the study limitations.

Identify the data source used to measure the units

Case note extraction, patient interviews, provider interviews, routine information systems, claims data, other

Where relevant, describe the sampling frame, method, and size: Free text

Describe any method used to fill missing data

Free text

Principle 10-Consideration should be given to the timing of data collection to minimize recall bias and, where relevant, the impact of seasonality and other differences over time.

The timing of data collection should be specified in the following ways:

Timing of data collection (resource and service use)

Date of data collection

Prospective or retrospective

Prospective or retrospective

Longitudinal vs cross-sectional data

Longitudinal vs cross-sectional data

Recall period, where relevant

Months or weeks

\section{PRICING AND VALUATION}

Principle 11- Sources of price data should reflect the price relevant to the purpose of the SBC costing and be described in a way that allows for adjustment across settings.

Report the sources of price data by input

Ministry of Health, local market, etc.

Report inputs where local and international prices were used

Local or international

Principle 12-Capital input prices should be appropriately annuitized or depreciated to reflect the opportunity cost of capital inputs over the relevant timeframe.

Describe the depreciation approach

Straight line depreciation, amortization

Describe any discount rate used for capital goods

Percentage

Report the expected life years of capital goods, and data sources

Years and free text

Principle 13-Where relevant, appropriate discount, inflation, and currency conversion rates should be used to adjust prices to estimate the cost for other settings and time periods.

Describe any discount rate used for future costs

Percentage

Describe the reported currency year

Currency and Year

Describe any conversions made

Exchange rate, source, and year

Report the inflation type and rate used

Percentage, GDP deflator/CPI, source 
Principle 14-The use and source of shadow prices to value inputs without a market price and the opportunity cost of time should be reported.

Methods for valuing the following should be reported:

Report methods for valuing volunteer time

Free text

Report adjustments for input prices (donated or subsidized goods)

Free text

ANALYZING AND PRESENTING RESULTS

Principle 15-Variation in the cost of the intervention by site size/organization, sub-populations, or other drivers of heterogeneity should be explored and reported.

Describe any sub-groups or populations analyzed

Free text

Describe any statistical methods used to establish

differences in unit costs by sub-group

Free text

Describe any determinants of cost (model specification)

Free text

Describe any multivariate statistical methods used to

Free text

analyze cost functions

\section{Principle 16-The uncertainty associated with cost estimates should be appropriately characterized.}

Describe sensitivity analyses conducted

List possible sources of bias
Free text

Free text

Principle 17-SBC cost estimates, including the methods used, should be communicated clearly and transparently to enable decision-maker(s) to interpret and use the results.

\section{Limitations}

Limitations in the design, analysis, and results

Free text

Aspects of the cost estimates that would limit generalizability of

Free text

results to other constituencies

\section{Conflicts of interest}

All pecuniary and non-pecuniary interests of the study contributors

Free text

All sources of funding that supported conduct of the costing

Free text

Non-monetary sources of support for conduct of the costing

Free text

\section{Open access}






\section{Population Council}

4301 Connecticut Ave., NW | Suite 280

Washington, DC 20008

+12022379400

breakthroughactionandresearch.org 